"Ich habe schon mehrmals im Leben mein Gepäck binter mich gewarfen. Stoßt an; weil wir sterben mïssen, sollen wir tapfer sein."

(Freiherr vom Stein)

\title{
6. Exil - Vorbereitung für ein neues Deutschland
}

„Exil heißt, seinen Platz in der Welt verlieren.“ Dieser Satz von Sartre stimmt und stimmt auch nicht. Er stimmt bezogen auf das private Schicksal des Emigranten; er stimmt nicht, wenn dieser Mensch sich nicht nur als Privatperson, sondern als homo politicus versteht. Dann nämlich müßte der Satz umgedreht werden: Exil heißt, seinen Platz in der Welt gewinnen! Auch wenn man davon ausgehen muß, daß jeder Fall anders liegt, unterschiedliche Lebenssituationen und unterschiedliche Verluste eine Rolle spielen, läßt sich für Klepper und Menschen, die dachten wie er, nachweisen, daß sie ihren Platz in der Welt nicht nur verloren, sondern auch gewonnen haben. Dies gilt allerdings nur für den kleineren Teil der Exilierten'1.

Die Privatperson Klepper, ein Beispiel für viele, hat ihren privilegierten Platz in der Welt verloren. Was hat er aufgegeben, als er sich entschloß, Deutschland zu verlassen? Er hatte eine steile Karriere gemacht, war schon mit 43 Jahren preußischer Finanzminister geworden; er hatte eine Familie mit drei Kindern ${ }^{2}$ und lebte in einer schönen Villa mit großem Garten in Zehlendorf; er besaß zwei Autos, hatte einen Chauffeur, Dienstboten, war unabhängig und gesellschaftlich anerkannt. Was tauschte er dagegen ein? Ungewißheit, Verfolgung, Armut, Trennung von der Familie, Trennung von der Heimat, an der er hing. Einem engen Mitarbeiter hat er nach dem Kriege einmal anvertraut, daß er in der Zeit seines französischen Exils manchmal, wenn er es gar nicht mehr aushalten konnte, an die französisch-deutsche Grenze gefahren sei und rübergeschaut habe, mit Tränen in den Augen. Insofern verlor er wie viele andere seinen Platz in der Welt. Nie wieder hat er in so gesicherten, so befriedeten und so glücklichen Umständen leben können ${ }^{3}$. Nie wieder konnte er solchen Einfluß in der Politik gewinnen, denn als die Chance sich noch einmal ergab, war er zu alt, um seine grundsätzlichen Überzeugungen von der Art, wie Politik zu machen sei, so zu verändern, daß sie noch in die andersartige politische Praxis der Nachkriegszeit gepaßt hätten.

Dennoch gilt für Klepper und andere Menschen seiner Art auch die Umkehr des Satzes. Er gewann einen Platz in der Welt. Dazu bedurfte es bestimmter Voraussetzungen, die er erfüllte. Voraussetzungen, die mit der anfangs skizzierten Traditionslinie, seiner geistigen Heimat und seiner Herkunft eng zusammenhingen; ein wesentlicher Punkt da-

\footnotetext{
1 Ein Beispiel für viele: Noth: „Das Exil erscheint dem Verbannten oft wie ein Weg ohne Rückkehr“ (S. 426).

2 Viele blieben aus Rücksicht auf ihre Kinder. Vgl. die Antwort des RFMs Schwerin v. Krosigk an Hans Staudinger, „er habe sieben Kinder" (Staudinger, S. 134).

${ }^{3}$ Lübke, Ansprachen, S. 7.
} 
bei war die Einstellung zu Deutschland einerseits und zu Europa und der Welt andererseits. Das Schlüsselwort dafür war Patriotismus, ein Begriff, der aus der Zeit der Französischen Revolution stammt und nichts mit der verengten Vorstellung eines „deutschen Patrioten" zu tun hat, den Heine so trefflich beschrieb, indem er sagte: „[...] daß sein Herz enger wird, daß es sich zusammenzieht wie Leder in der Kälte, daß er das Fremdländische haßt, daß er nicht mehr Weltbürger, nicht mehr Europäer, sondern nur ein enger Deutscher sein will“" . Im Gegensatz dazu war Klepper in einer Tradition aufgewachsen, die Frankreich nicht nur als Herkunftsland, sondern auch als geistige Heimat betrachtete und Deutschland als Teil eines freiheitlichen Europa verstanden wissen wollte. Diese Auffassung von Patriotismus brauchte die Liebe zum Geburtsland, die sich auf die Vielfalt der deutschen Landschaft, der deutschen Kultur und Geschichte bezog ${ }^{5}$, nicht zu verleugnen, war diese doch ohne den engen Zusammenhang mit der europäischen Kultur und Geschichte gar nicht zu denken. Sie war Grundlage für den Glauben vieler Emigranten an ein „besseres“, das „andere Deutschland "6, sie gab ihnen Mut und Kraft zum Durchhalten und war zugleich Ansporn und Auftrag, die zerstörte europäische Ordnung wiederherzustellen. Dies galt auch für Klepper ${ }^{7}$. Bewahrten sich so viele Emigranten trotz des Fernseins oder wegen des Fernseins von der Heimat eine Vorstellung von Patriotismus, so wurde dieser Begriff für die Masse der Deutschen durch den Nationalsozialismus derart pervertiert, daß er nach dem Zweiten Weltkrieg zum Tabu wurde. Gleichzeitig aber hatten die meisten derjenigen, die zu Hause geblieben waren, ihren Platz in der Welt verloren, weil sie zwölfeinhalb Jahre in einer fast völligen Isolation von der Außenwelt gelebt hatten. Hier liegt mit ein Grund für die Verständigungsschwierigkeiten zwischen den Emigranten und den Daheimgebliebenen in der Nachkriegszeit.

Die Zahl der politisch engagierten bürgerlichen Demokraten, die von Anfang an scharfe Gegner des Nationalsozialismus waren und gleich emigrierten, war verhältnismäßig klein, meist waren es Journalisten, wenige waren Politiker. Sie wurden mit besonderer Vehemenz von den Nationalsozialisten verfolgt, weil sie das Bild nach außen störten $^{8}$. Klepper wurde unter der Rubrik „führende Männer des Systems, konfessionelle Parteien, Zentrum“ geführt". "Was ihm [Klepper] passiert, wenn Himmler seiner habhaft wird“, schrieb Karl Brandt im November 1940 an Arnold Brecht in New York, „bedarf keiner Ausmalung. “10

„Sein Entschluß, in die Emigration zu gehen, war eine politische Entscheidung für die Sache der Freiheit." "11 Hatte er überhaupt eine Wahl? Welche Alternativen hätte es gege-

\footnotetext{
${ }^{4}$ Heine, Romantische Schule, 1. Buch, S. 379.

$5 \mathrm{Vgl}$. u. a. Jasper, Heinrich Mann, S. $47 \mathrm{f}$.

- Begriffe aus der Exilpublizistik und -literatur.

7 Vgl. Kleppers Brief aus dem Exil in Frankreich vom 27. 11. 1940 aus Quillan/Aude an den Schatzmeister der von Hubertus Prinz zu Löwenstein gegründeten Hilfsorganisation „American Guild for German Cultural Freedom", Oswald Garrison Villard, in: Dt.Bibl., Akte Klepper. Zur American Guild vgl. Zühlsdorff.

${ }^{8}$ Jaeger nennt nur Höpker-Aschoff, Klepper und August Weber, allerdings sei „die Zahl der demokratischen Journalisten“" "groß" gewesen (IfZ, ED 210, Bd. 32, B1. 407).

9 BAK, R 58/236, Nr. 90 und 245.

10 BAK, NL-Brecht, Nr. 33: Brandt an Brecht, 5. 11. 1940 und Brecht an New England Committee for Refugees, Cambridge, 3. 11. 1940. Er wird auch von vielen anderen als im höchsten Grade gefährdet eingestuft. Vgl. Briefwechsel American Guild.

1 Pufendorf, Zwischen den Zeiten, S. 5.
} 
ben? Die von den Nationalsozialisten angebotene Zusammenarbeit war keine echte Alternative, obwohl sie einem Mann wie Klepper, der aktiv gestalten wollte, ungeheure Möglichkeiten zu bieten schien, Möglichkeiten, die manch einen verführt haben, mitzumachen. Hans Staudinger berichtet von seinem Abschiedsbesuch bei Popitz, der Klepper als Reichskommissar für preußische Finanzen am 20. Juli 1932 abgelöst hatte und nun, im Frühsommer 1933, Staudinger mit den Worten empfing: „Da kommt doch ein strammes und intellektuelles Musterexemplar von einem Nazi. Sie sind gemacht für einen Naziführer.“ Staudinger „solle doch der Partei beitreten. Göring habe eingehend mit ihm darüber gesprochen. "Staudinger lehnte auch nach weiteren Überredungsversuchen entschieden mit den Worten ab: „Kein preußischer Beamter dürfe sich an Mordtaten, Verfassungsbrüchen, offensichtlich krankhaften Willkürmaßnahmen seiner Vorgesetzten mitschuldig machen." 12 Viele, ja die meisten, glaubten Ende 1932 noch, die Nationalsozialisten seien eine vorübergehende Erscheinung, so die Stimme Schwerin v. Krosigks: „Aber im Herbst ist doch alles schon vorbei!“ Der „Widerstand in der eigenen Partei wachse. Strasser habe die Führung der Opposition. Die bürgerlichen Politiker organisierten einen fundamentalen Widerstand, der ein Echo unter den von den Nazis Enttäuschten finde, die sich mit fortschreitender Besserung der Wirtschaftslage ständig vermehrten. Der Terror der Nazis kehre sich mehr und mehr gegen diese selbst. "13 Staudinger glaubte ebensowenig daran wie Klepper: „Wäre ich, wie ich wohl gekonnt hätte, Nazi geworden, so hätte ich mir selbst günstigstenfalls das moralische Genick gebrochen." 14

Es war auch deshalb keine Alternative, weil Klepper die Nationalsozialisten schon früh durchschaut hatte und wußte, daß sie, wenn sie die ganze Macht hätten, die Demokratie zerstören würden ${ }^{15}$. Er gab sich keinen Illusionen hin, wie viele andere es taten und sich dabei womöglich noch auf ihr Pflichtbewußtsein beriefen. So antwortete Schwerin v. Krosigk auf Staudingers Frage, "warum er unter diesem mörderischen System diene“, er sei „Beamter, der dem Staat zu dienen habe, selbst wenn er mit dessen Aktionen nicht übereinstimme"16.

Eine andere Alternative wäre gewesen, sich ins Privatleben zurückzuziehen und als Anwalt in der Provinz sein Brot zu verdienen, mehr oder weniger belästigt von der NSDAP, aber ohne ernste Bedrohung. Viele von denen, die später die Nachkriegspolitik bestimmen sollten, haben diesen Weg gewählt, auch solche, die während der Weimarer Zeit schon gegen den Nationalsozialismus gekämpft haben wie zum Beispiel Adenauer. Auch diese Alternative kam für Klepper nicht in Frage, weil sie seinem Naturell widersprach, er konnte nicht mehr oder weniger ruhig abwarten, bis alles vorüber sein würde, er mußte sich voll einsetzen, nicht nur gegen den Nationalsozialismus, sondern auch für

\footnotetext{
12 Staudinger, S. $134 \mathrm{f}$.

${ }^{13}$ Ebenda, Zitat aus einem Gespräch, das Staudinger mit Schwerin v. Krosigk führte, als er sich von ihm verabschiedete.

14 Engelmann, S. 47.

${ }^{15}$ Klepper an Carlos G. Liebmann (Quito/Ecuador), Aug.1950: „Meinerseits habe ich mich vom Nationalsozialismus nicht nur deshalb distanziert, weil ich die politische Richtung für falsch hielt. Einer der wesentlichen Gründe, warum ich das tat, war vielmehr, daß ich von der Unmenschlichkeit des Regimes, ganz besonders von dem Antisemitismus abgestoßen war" (KNL) und Engelmann, S. 37.

16 Staudinger, S. 134.
} 
das Ansehen eines besseren Deutschlands im Ausland ${ }^{17}$. Vor allem konnte er nicht in Unfreiheit leben, Freiheit war neben der Zivilcourage einer der Schlüsselbegriffe seines Denkens und Handelns.

Die dritte Möglichkeit wäre gewesen, sich von politischen Einwirkungsmöglichkeiten fernzuhalten und sich mit der Familie an einen ruhigen Platz im Ausland zurückzuziehen, wie zum Beispiel Otto Braun nach Ascona, oder nach Südfrankreich, wo Klepper Freunde hatte und wo es viele Angebote vom französischen Staat gab, sich in der Landwirtschaft zu betätigen ${ }^{18}$, oder auch nach Südamerika, wohin er 1936 ein Auswanderungsangebot erhalten hatte ${ }^{19}$. Auch diese Alternative kam aus den oben genannten Gründen für ihn nicht in Frage. Wahrscheinlich empfand er seine Lage so, wie er sie in seiner Artikelserie „Der Umschwung in Deutschland“ für den „nicht gefügigen Volksgenossen“ beschreibt: Eine „Alternative zwischen Emigration oder Konzentrationslager"20. Er wählte die Emigration.

Was Klepper in der Emigration von vielen anderen unterschied, war sein Einzelkämpferdasein ${ }^{21}$, ihm fehlte der, wärmende 'Zusammenhalt der Gruppe oder Partei, allerdings war er auch nicht eingeengt durch eine solche. Was ihn gewiß nicht von anderen unterschied, war die Tatsache, daß sein Vermögen beschlagnahmt, sein Einkommen gestrichen, seine berufliche Existenz zerstört ${ }^{22}$, seine Familie auseinandergerissen, seine Kinder gefährdet ${ }^{23}$ und die Zukunft ungewiß war. Robert Neumann beschreibt das Emigrantsein auf sarkastische Weise: „Die Emigration, emigratio communis primaria, unterscheidet sich von anderen chronischen Krankheitsvorgängen erstens dadurch, daß der Patient sich des Befallenseins erst nach einer gewissen, individuell variierenden Inkubationsfrist bewußt wird. Zweitens kennt sie Zwischenperioden eines trügerischen Sichwohlbefindens, klinisch bezeichnet als Euphorie. Die, drittens, abwechseln mit für dieses Übel typischen Zuständen der Großen Verzweiflung, [...] in denen der Patient entweder die Einsamkeit sucht [...] oder gleichartig Erkrankte aufspürend Amok läuft und die Einsamkeit meidet." 24 Klepper scheint diese Stadien auch durchlaufen zu haben.

${ }^{17}$ Klepper an Hedwig v. Kalinowski, 19. 4. 1933, „daß man politisch gesehen für Deutschland lebt, ist naturgegeben, soweit [...] Impulse notwendig sind, aber selbstverständlich".

${ }^{18}$ Rawitscher, ein Freund und Mitarbeiter Kleppers aus der Zeit der Preußenkasse, hatte in der Nähe von Grasse eine kleine Obstplantage auf einem Gelände aufgebaut, das ursprünglich Pflanzungen für die Parfüm-Herstellung gedient hatte. Er wurde als Franzose naturalisiert (Gespräche mit Degon und mit Landy-Degon sowie ihr Bericht). In der PTZ erschienen immer wieder, besonders kurz vor und zu Beginn des Krieges, Werbungskampagnen zur Ansiedlung deutscher Bauern in Süd- und Süd-West-Frankreich.

19 BAP, NL-Spiecker, Bl. 77, Klepper an Spiecker, Mallorca, 24. 1. 1936 (alle künftig zitierten Briefe stammen aus dem NL).

${ }^{20}$ Klepper, Umschwung, S. 173.

${ }^{21}$ Klepper an Spiecker über die Schwierigkeiten, den Kampf gegen Hitler „auf eigenes Risiko“ zu führen (24. 1. 1936).

22 Klepper hatte inzwischen sein Amt als Finanzminister niedergelegt und bestätigte damit die von Hirtsiefer, Schmidt, Schreiber, Steiger und Grimme gez. Amtsniederlegung im Schreiben des PrStM an den Reichskommissar vom 25. 3. 1933 (GSTAM, Rep. 151 HB, Nr. 43, Bl. 49 und BAP, 62DAF3, 17632, Bl. 107/8). Daraufhin wurden alle Wartegelder und Bezüge für ihn, Severing, Grzesinski, Hirsch, Schreiber und Grimme bis auf weiteres gesperrt ( $\mathrm{Nr} .43$, Bl. 50 ff.).

${ }^{23}$ Die Kinder waren damals 12, 11 und 9.

${ }^{24}$ R. Neumann, S. $509 \mathrm{ff}$. 


\section{Finnland: erste Station - der Blick zurück}

Immerhin, und da hatte er es gewiß besser als viele, er war gerettet, hatte Freunde und fand mit seiner Frau sogar zunächst ein sehr angenehmes und komfortables Exil in Finnland vor, was nach außen fast wie Ferien aussah: Kleppers waren Gäste auf dem Landgut Wuoliyokis ${ }^{25}$. Auch die Briefe von Hedwig v. Kalinowski, seiner Sekretärin, die nun in Berlin die Kinder und das Haus versorgte, klangen zunächst ganz harmlos ${ }^{26}$, doch hielt diese scheinbare Idylle nicht lange an.

Am Abend des 22. März war in seinem Hause in der Sophie-Charlottenstraße „eine Bande in SS-Uniform eingedrungen“, hatte alle Hausbewohner „im Eßzimmer bewacht und die ganze Wohnung durchkämmt und alle Wertgegenstände [...] mitgenommen“. Die danach von Hedwig v. Kalinowski herbeigerufene Kriminalpolizei nahm alle Schäden auf, „hat alles durchgesehen, nichts mitgenommen [und sei] sehr freundlich" gewesen. Hier zeigt sich die typische Taktik Regimegegnern gegenüber: erst Bedrohung, dann der Schein einer vollkommenen Rechtsstaatlichkeit. Natürlich wurde v. Kalinowski ausgefragt sowie Post und Telefon überwacht, weshalb sie Klepper dringend bat, nicht mehr anzurufen und alles über die Finnische Gesandtschaft zu erfragen ${ }^{27}$.

Wie recht sie mit ihrer Vorsicht hatte, geht aus den Berichten der Deutschen Gesandtschaft in Helsingfors hervor, die regelmäßig über Klepper und den Eindruck, den er in der Öffentlichkeit machte, nach Berlin berichtete ${ }^{28}$. Er sei von Wuoliyoki in „Kreise der Gesellschaft, der Industrie und des Bankwesens" eingeführt worden und habe diese „,insbesondere in Helsingfors in einem gegen die Deutsche Regierung gerichteten Sinne beeinflußt". Wuoliyoki, der sich ständig auf Klepper berufe, habe gesagt, "daß die augenblickliche nationale Regierung nur von kurzer Dauer sei und unter allen Umständen zum Bolschewismus führen müsse“. Auch auf den Direktor der Kansallis-Bank, Senator Julio Paasikivi, ein „Beschützer Kleppers“"29, habe Klepper einen großen Einfluß, was um so gravierender sei, als Paasikivi nicht nur seinerseits großen Einfluß, sondern auch eine Tochter habe, die „als finnische Delegierte am 20. April nach Genf“ und im Sommer zum „International Women Council nach Chicago“ reise. Klepper habe den „Reichs-

${ }^{25}$ Ankunft mit dem Dampfer Nordland am 8. 3. 1933 (PA-AA, Geheimakten, Bericht, 8. 4. 1933, B1. 4 f.). Klepper hatte ein Durchreisevisum für Polen (Paß, KNL).

26 9. 3. 1933: „Und es ist wirklich, was Ihre persönlichen Sachen betrifft, nichts los [...] Wie er [Lauffer] mir heute früh sagte, habe er nur Günstiges über Sie gehört, und es würde sehr vernünftig aufgenommen, daß Sie die Reise unternommen hätten."

${ }_{27} 23.3 .1933$, die Schrift unterscheidet sich stark von der anderer Briefe, woran sich die Aufregung ablesen läßt. Sie fügte hinzu: „Ich habe ja die ganze Zeit darauf gewartet, nun haben wir es Gott sei Dank hinter uns." Die Einbrecher waren gestört worden und hatten fluchtartig das Haus verlassen. Kalinowski beruhigte Kleppers, sie sollten sich keine Sorgen machen, es sei "alles geschehen, was geschehen mußte, und nichts geschehen, was hätte unterbleiben sollen".

${ }^{28}$ PA-AA, R 30663K, Bericht vom 8. 4. 1933 (Bl. 2). Klepper und seine Frau wohnten, seit Wuoliyokis wieder in Berlin waren, im Karelia Hotel in Helsingfors. Er gab am 8. April seine Karte in der Deutschen Gesandtschaft ab.

29 Paasikivi verhalf Klepper offensichtlich auch zur Flucht, Frl. Paasikivi begleitete die Familie Klepper zum Schiff (Kopie von Fotos in KNL). Gesandter Büsing erwähnt in seinem Bericht vom 18. 4. 1933 als „ein eigenartiges Spiel des Zufalls, daß Senator Paasikivi zugleich ein alter Freund des Generals Rüdiger Graf v. d. Goltz ist, so daß dieser während der jetzt bevorstehenden Feiern des 15. Jahrestages der Befreiung Finnlands durch die Deutschen bei Herrn Paasikivi wohnen wird" (Bl. 22). 
kanzler als ,blutigen Demagogen' hingestellt [...] und erzählt, Mitglieder der NSDAP seien in seine Wohnung in Zehlendorf eingedrungen, hätten dort Pelze und Uhren gestohlen und alle Spiegel in der Wohnung zerschlagen“. Selbst der „frühere Ministerpräsident Prokopé soll bereits dem Einfluß Kleppers unterlegen sein "30. Diesem sehr aufgeregten Bericht folgten acht Tage später etwas abmildernde Ausführungen des Gesandten Hans Karl Büsing, der meinte, daß Klepper zwar mit seiner Kritik an „unserem Vorgehen gegen das Judentum" Beifall finden werde, "denn in dieser Frage sind die hiesigen Sympathien leider nicht ganz auf unserer Seite", aber „im großen und ganzen" könne Klepper keinen „allzu ernstlichen Schaden anrichten“, zumal bekannt geworden sei, "daß ein Verfahren gegen ihn eröffnet worden" $\operatorname{se}^{31}$.

Tatsächlich war am 13. April 1933 das Untersuchungsverfahren gegen Klepper und Hans Walter Schmidt von der Domänenbank wiederaufgenommen worden ${ }^{32}$, was eine Kette von Maßnahmen gegen Klepper auslöste. Am 25. April wurde „durch Beschluß des Landgerichts I, Berlin [...] gemäß $\$ 284$ Strafprozeßordnung“ das gesamte Vermögen des "Abwesenden“ beschlagnahmt, inklusive seiner Akten. Gleichzeitig wurde "Anklage wegen Untreue und Aktenbeseitigung“ und „der Antrag der Auslieferung und Inhaftnahme" vom Untersuchungsrichter, Landgerichtsrat Jenne, vorbereitet ${ }^{33}$. Klepper nahm in zwei Interviews mit den Zeitungen Helsingin Sanomat und Sosiaalidemokaratti Stellung zu dem Untersuchungsverfahren und erläuterte, daß es sich um eine Wiederaufnahme des alten preußischen Verfahrens handele ${ }^{34}$. Am 3. Mai wurde der Haftbefehl erlassen mit der fadenscheinigen Begründung, ,wegen des dringenden Verdachts, in den Jahren 1931 und 1932 als Beamter ihm amtlich anvertraute und zugängliche Urkunden beiseite geschafft zu haben, und zwar in der Absicht, sich oder einem anderen einen Vermögensvorteil zu verschaffen oder einem anderen Schaden zuzufügen, Verbrechen gegen $\$ \$ 348$ Abs. 2, 349 des Reichsstrafgesetzbuches“" 35 .

Nun, da der Haftbefehl veröffentlicht und ein Auslieferungsantrag an die Finnische Regierung gestellt worden war, begann von deutscher Seite eine zweigleisige Politik, die

${ }^{30}$ Ebenda, Bericht „streng geheim, eilt sehr!" vom 10.4. 1933 (Bl.6-8). Hjalmar Johan Prokopé war nicht Ministerpräsident, sondern von 1927-1931 Außenminister.

${ }^{31}$ Ebenda, 18. 4. 1933 (Bl. 21/22).

32 BAP, 62 DAF3, 17632, Frankfurter Zeitung vom 13.4. 1933 (Bl. 110), ebenda, Berliner Börsenzeitung, Nr. 50, 2. 2. 1935 (Bl. 109).

${ }^{33}$ Abschrift des Abschlußberichts vom 18. 3. 1936 von RA Stange, der als Abwesenheitspfleger eingesetzt worden war. Er ließ das Vermögen in Anwesenheit von Kalinowski schätzen, wobei Besitzstücke der Ehefrau ausgenommen wurden, und sorgte dafür, daß es eingelagert wurde, mit dem Erfolg, daß sein Gehalt und die Lagerkosten sich schließlich mit dem Besitz ausglichen (Stange-Bericht). Die Liste der im Hause beschlagnahmen Dokumente in: GSTAM, Rep. 151 HB, Nr. 41. Vgl. Aufzeichnungen des Gesandtschaftsrats Siegfried Hey vom 26. 4. 1933 (PA-AA, Ref. D/Pol., Nr. 40/5, Material zur Ausbürgerung, Teil II). Vermutlich sind die noch unregistrierten Akten in Merseburg (VNL-K) Teil des von den Nationalsozialisten für den Prozeß zusammengestellten Bestandes.

${ }^{34}$ Kopien übersandt von der Deutschen Botschaft in Helsinki mit Brief vom 16. 12. 1992 (GSTAM, Rep. $151 \mathrm{HB}, \mathrm{Nr} .42, \mathrm{Bl} .6-8$ ). Karl Brandt, mit dem Klepper in regelmäßigem Briefkontakt stand, warnte vor weiteren Interviews: „Sie hetzen bloß die ganze Meute hier wieder hoch“ (22. 5. 1933, KNL).

35 Haftbefehl in: PA-AA, Nr. 40/5, Teil II. Die Liste der beschlagnahmten Akten enthält keinen Titel, der für eine derartige Begründung hätte herhalten können. Mitte Mai gab Klepper eine offizielle Gegenerklärung gegen die erhobenen Anschuldigungen ab (Bericht der Deutschen Gesandtschaft in Helsingfors, ebenda, 19.5. 1933). 
zwischen Schikanen gegen Klepper und dem Versuch, im Ausland nicht unangenehm aufzufallen, hin und her lavierte. Besonders deutlich wird dies an der Überlegung, die unmündigen Kinder Kleppers als Geiseln zu behalten, und der Verwerfung dieser Idee, weil dies „eine für den Auslieferungsantrag sehr ungünstige Atmosphäre in Finnland und im weiteren Ausland schaffen würde" ${ }^{36}$. Erst Mitte Mai gelang es, mit Hilfe von Karl Brandt und anderer Freunde die Kinder nach Finnland zu holen ${ }^{37}$. Hedwig v. Kalinowski, die immer stärker unter Druck geraten war, löste unter schwierigsten Umständen den Haushalt in Berlin auf und konnte sich gerade noch durch Flucht einer drohenden Verhaftung entziehen.

Die Gesandtschaft, die den offiziellen Auftrag bekommen hatte, Klepper zu beobachten, verlegte sich eher aufs Beschwichtigen, was sicherlich einmal damit zusammenhing, daß die Gesandtschaften damals zum großen Teil noch nicht in dem Maße dem nationalsozialistischen Einfluß ausgesetzt waren wie die Behörden in Berlin, und zum anderen die Aufgabe hatten, die ausländischen Regierungen realistisch einzuschätzen und deren Absichten richtig zu interpretieren. Entsprechend telegraphierte der Gesandte Büsing am 3. Juni nach einem Gespräch mit dem finnischen Außenminister nach Berlin, daß „eine Auslieferung nicht erfolgen" werde, „weil Stimmung allgemein dagegen, zumal

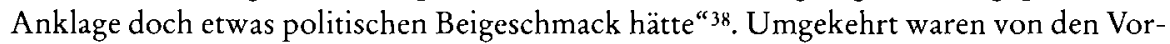
gängen um Klepper Auswirkungen auf die Innenpolitik des Landes zu beobachten. So hieß es im Gesandtschaftsbericht, als „Ergebnis der Klepperschen Greuelpropaganda soll das Verbot der Uniform des finnischen Schützen Corps (Anhänger der Lappo-Bewegung) ${ }^{39}$ bevorstehen ${ }^{40}$. Andererseits forderten der Lappo-Bewegung nahestehende Kreise, die einen sowohl von der russischen wie von der deutschen Politik unabhängigen Kurs zu steuern versuchten und sich mit der neuen deutschen Regierung nicht anlegen wollten, die Abberufung Wuoliyokis, der in der Ajan Suunta als internationaler Marxist bezeichnet worden war. Er solle durch Talas, einen alten Freund Deutschlands, der flieBend Deutsch spreche, ersetzt werden ${ }^{41}$.

Kleppers Einstellung zu Finnland war sehr positiv. Seine vielen Kontakte, seine Erfahrungen und Forschungen zum Genossenschaftswesen haben ihn einen fundierten Eindruck gewinnen lassen. Er hat sich seinen Respekt für dieses kleine Land immer bewahrt und es häufig in Artikeln als Beispiel für demokratische Strukturen erwähnt. Am besten hat er sein Urteil in einem Artikel für Die Zukunft zusammengefaßt, der zu einer Zeit

36 Ebenda, Aufzeichnung Hey. Auch gegen die Tatsache, daß Kleppers Post über die finnische Botschaft lief, was eine Verletzung der Postgesetze bedeutete, ließ sich so recht nichts machen aufgrund des exterritorialen Status der Gesandtschaft.

${ }^{37} \mathrm{Zu}$ den Schwierigkeiten vgl. die Briefe Brandts und Kalinowskis an Frau Klepper, 27. 4. 1933 (KNL). Paß von Renate Klepper, Ausreisestempel Stettin 13. 5. 1933, Einreise Helsinki 15. 5. 1933. Das AA schloß aus der Reise der Kinder nach Finnland, daß Klepper länger dort zu bleiben gedachte (Rep. $151 \mathrm{HB}, \mathrm{Nr} .43, \mathrm{Bl} .5$ ).

38 PA-AA, R 30663K, Bl. 02, Telegramm, 3. 6. 1933 und Zitat aus dem eher rechten Blatt der Lappobewegung, Ajan Suunta, 8. 4. 1933: Klepper, dem "geflohenen deutschen Minister, sollte aber das Asylrecht in Finnland nicht verweigert werden".

${ }^{39}$ Lappobewegung (nach einem Kirchspiel „Lappo“ genannt) war eine antikommunistische Baucrnbewegung, dic um 1930 Einfluß auf die Innenpolitik gewann.

${ }^{40} \mathrm{R} 30663 \mathrm{~K}$, Bericht „streng geheim, eilt sehr!" vom 10.4. 1933 (Bl. 6-8).

${ }^{41}$ Ebenda, Bl. $23 \mathrm{f}$. Die Ajan Suunta hielt Wuoliyoki für ungeeignet, Finnland in Deutschland zu vertreten. Wuoliyoki war scit 1927 Gesandter in Berlin (ebenda, 8. 4. 1933, Bl. 2). Zur Biographie vgl. Horkenbach (Hrsg.), S. 546. 
veröffentlicht wurde, als Finnlands Existenz durch den Winterkrieg aufs äußerste bedroht war. „Finnland besitzt, was Deutschland fehlt, einen intelligenten Konservativismus.“ Es hat „die aus der russischen Zeit überkommenen feudalistischen Überreste durch eine bäuerliche Agrarreform liquidiert. Gleichzeitig erwuchs eine Arbeiterbewegung, deren kennzeichnendes Merkmal evolutionäre Beharrlichkeit ist. Bauern und Arbeiter schufen sich ein vorbildliches Genossenschaftswesen. [...] Auf so gutem Boden gedieh eine Demokratie, die allen Versuchen, ins Totalitäre abzugleiten - auch an ihnen fehlte es nicht - widerstand. “42

Am Beispiel Klepper zeigt sich, wie leicht Emigranten zwischen die Fronten außenpolitischer Interessen geraten konnten. Die Reaktionen der einzelnen Länder auf die Auslieferungsbegehren der nationalsozialistischen Regierung waren sehr unterschiedlich, je nach Größe, nationaler Interessenlage, politischer Richtung und traditioneller Einstellung zu Deutschland; doch immer geriet der Emigrant, zumal der politisch profilierte, in die Mühlen dieser widerstrebenden Zielsetzungen. Dies gilt in besonderem Maße für Klepper, da er sich bereits in diesem frühen Stadium, im Frühsommer 1933, in einer Artikelserie für das angesehene schwedische Wirtschaftsblatt Göteborgs Handelsoch Sjöfarts-Tidning (GHST) ${ }^{43}$ zu den Gründen, die zum Scheitern der Weimarer Republik geführt und die Machtergreifung Hitlers ermöglicht haben, äußerte und mit Kritik am nationalsozialistischen Regime nicht sparte.

„Um dem Faschismus entgegentreten zu können“, so erklärte er, müsse zunächst nach den „sachlichen Gründen“, die zum „Niedergang der Demokratie“ geführt hätten, geforscht werden, erst dann könne man mit einer „Kritik der nationalsozialistischen Regierungsweise“ beginnen. Da auf Kleppers Kritik an der Weimarer Republik bereits im Zusammenhang mit seiner Ernennung zum Finanzminister und mit seiner Rolle beim Staatsstreich vom 20. Juli 1932 eingegangen wurde, soll hier nur kurz seine Kritik am soeben sich unter dem Trommelfeuer der Propaganda etablierenden nationalsozialistischen Regime wiedergegeben werden. Für Klepper hatte mit der Machtergreifung der Nationalsozialisten zugleich die Idee der Französischen Revolution und damit die abendländische Kultur eine Niederlage erlitten, das heißt, der Sieg des Nationalsozialismus war in seinen Auswirkungen für ihn ein gesamteuropäisches Phänomen, und deshalb waren für ihn „die Schwingungen der Ereignisse in der gesamten politischen Atmosphäre Europas“ wahrzunehmen und würden in naher Zeit „Europa vor Entscheidungen stellen “44.

Klepper fand, daß der von den Nationalsozialisten selbst verwandte Ausdruck ,Gleichschaltung;, der einer „technischen Vorstellungswelt entlehn““ sei, das erste halbe Jahr nationalsozialistischer Herrschaft „,in hervorragender Weise“ charakterisiere: „Man hat die politische Maschinerie gleichförmig eingestellt, man läßt sie mit voller Kraft laufen, und sie steigt auf eine übernormale Tourenzahl, weil sie im Leer-

42 Klepper, in: Die Zukunft, 23. 2. 1940.

${ }^{43}$ Schumacher gibt in seiner Einführung ( $($. 146-160) genauere Informationen zum GHST und zur kritischen Einstellung der schwedischen Öffentlichkeit gegenüber Deutschland, S. $153 \mathrm{ff}$. Er bezeichnet die Artikel als die „möglicherweise erste grundsätzliche, öfentliche Stellungnahme eines bürgerlichen Vertreters der Weimarer Koalition zum Scheitern der Republik und zum Sieg des Nationalsozialismus in Deutschland“, S. 152.

${ }^{44}$ Klepper, Umschwung, S. 161. 
lauf geht." An alle wichtigen Schaltstellen habe man Parteileute gesetzt und zwar „dank der uns Deutschen eigenen Systematik $[$ bis] in die abstrakt geistige Sphäre hinein“. Im übrigen sei „diese Umstellung gegen künftige Störungen lückenlos abgesichert", einmal durch die Abschaffung der Grundrechte und die Entlassung von Beamten „ohne förmliches Verfahren“, zum anderen durch die Schaffung von „Terrorinstrumenten“ wie der Geheimen Staatspolizei, der SS und der Konzentrationslager. Trotz aller Vereinheitlichung seien alle Chancen für eine echte, Deutschland einende Verwaltungsreform verspielt worden, da „die staatsrechtliche Struktur von Reich und Ländern unberührt geblieben“ und damit ein „Reservoir für den zur Zeit verdrängten Partikularismus angelegt“ worden sei. Trotz des "Anschein[s] einer Verminderung der Ausgaben" zeige sich, „daß die öffentlichen Ausgaben erheblich gestiegen" seien. Kein Problem sei gelöst worden, weder der schon länger „vorliegende Bankrott einer Reihe von kleineren Ländern" noch die Finanzkrise der Kommunen und öffentlichen Versicherungsträger. „Formal hat man den Etat durch optimistische Einnahmeschätzungen ausgeglichen." Der Beschäftigungsgrad sei nur in den Industrien gestiegen, die etwas mit Rüstung zu tun hätten, der Außenhandel liege dagegen nur noch bei $40 \%$ des gleichen Monats im Jahr zuvor. Klepper nennt das „wirtschaftspolitische Ergebnis der halbjährigen nationalsozialistischen Regierungstätigkeit [...] trostlos“. Außenpolitisch mache Hitler Zugeständnisse, „die keine der früheren deutschen Regierungen erwogen hätte“, um "damit die Aufrechterhaltung der Parteiherrschaft im Inlande zu erkaufen“. Der „Aufbruch der Nation“ sei „soziologisch beflügelt“ worden durch die „Beförderung des deutschen Proletariers zum Herrenmenschen" und die Propagierung von „Gemeinnutz“ statt „Eigennutz“45.

Kleppers Kritik an dem halben Jahr nationalsozialistischer Herrschaft war detailliert, bezog neueste Ereignisse ein und zeigte eine verblüffende Klarsicht ${ }^{46}$. Sie war auf allen Gebieten vernichtend. Der Artikel schließt mit dem Satz: „Man kann weder dem russischen noch dem italienischen System gedankliche und sachliche Gestaltungsfähigkeit absprechen. Daß die gesamte Macht einer politischen Bewegung zufallen konnte, die gedanklich und materiell so vollkommen steril ist wie der Nationalsozialismus, ist das Rätsel, das Deutschland der Welt aufgegeben hat." 47

Sicherlich haben die Artikel, so meint Schumacher, „im Sommer 1933 das negative Bild Deutschlands in der schwedischen Öffentlichkeit gefestigt, wenn auch diese Wirkung nicht meßbar ist“48. Andererseits hatte die von Klepper scharf kritisierte Außenpolitik Hitlers auch in vielen Ländern die Wirkung, daß die Kritik der Emigranten an Deutschland auf Ablehnung stieß, gar als Kriegshetzerei verurteilt wurde, weil man Ruhe haben wollte ${ }^{49}$. So gerieten die Emigranten in die unangenehme Lage, daß

\footnotetext{
${ }^{45}$ Ebenda, S. $173 \mathrm{ff}$.

${ }^{46}$ Schumacher belegt Kleppers Angaben mit Zahlen und Daten, was zeigt, wie genau Klepper über die Vorgänge in Deutschland informiert war, u. a. dank Karl Brandt.

47 Ebenda, S. 177.

${ }^{48}$ Schumacher, S. 156. Deutsche Gesandtschaft Stockholm, Abt. A, Bd. 17. Die schwedische Zeitung, GHST, wurde im August 1934 im Reichsgebiet zunächst für 6 Monate verboten, 1935 wurde das Verbot stillschweigend verlängert (Bd. 12). Der „reichsschädigende Charakter der Artikelserie“" mußte 1936 noch einmal zur Begründung der endgültigen Ausbürgerung Kleppers herhalten.

49 Vgl. den Gesandtschaftsbericht vom 18. 4. 1933 (PA-AA, R 30663K).
} 
sie einerseits die härtesten Kritiker ihres eigenen Vaterlandes waren, sich andrerseits aber in ihren Gastländern unbeliebt machten, weil man ihre Warnungen nicht hören wollte ${ }^{50}$.

Derweil „dreht sich in Deutschland“, wie Brandt nach Helsingfors berichtete, „das Rad der Geschichte [...] so rasend, die Menschen purzeln so massenweise von ihren Posten, werden so massenweise verhaftet, gestern in Braunschweig 1350 auf einmal, alle negativen Eigenschaften der Bestie Mensch vollführen einen solchen Spuk, daß alles frühere schon als historische Literatur dagegen verblaßt" ${ }^{*}$. Was sollte nun mit Klepper und seiner Familie geschehen? Wo konnte er sie alle ernähren, vor Verfolgung sicher sein und, was für Klepper wohl das Wichtigste war, wo konnte er am effektivsten gegen den Nationalsozialismus wirken?52 Karl Brandt gab auf diese Frage eine klare Antwort: „Sie haben eine große Aufgabe und große Chancen, alle Köpfe draußen $z u$ organisieren, zusammenzuschweißen und $[z u]$ arbeiten. Es liegen 1000 Möglichkeiten da. Die Zeit muß genutzt werden. Sie läuft hier schneller als man glaubt. Und wenn es reif ist, muß man draußen so weit sein. Wer kann das besser als Sie??! Und wer hat mehr Verantwortung als Sie?! Das alles können Sie nur in Paris oder London." 53

Am 31. Mai 1933 wurde von der französischen Botschaft in Helsingfors ein einjähriges Einreisevisum für Familie Klepper nach Frankreich bewilligt, am 13. Juni schiffte sie sich auf dem Dampfer "Arcturus“ ein. Die Tatsache, daß die Familie Klepper unter finnischem Namen, Hakanson, reiste, zeigt, daß die Ausreise nicht ungefährlich war, und in der Tat verfolgten die deutschen Behörden jede Etappe dieser mühseligen Reise mit dem Schiff zunächst nach Kopenhagen, dann nach Antwerpen und schließlich mit dem Zug nach Paris, wo Kleppers am 19. Juni eintrafen. Die Telefone waren abgehört worden, um das Reiseziel herauszubekommen, das finnische Außenministerium wurde mit Verbalnoten und Protestschreiben traktiert, und die tatsächlich oder nur vermutlich angesteuerten Länder Dänemark und Norwegen wurden mit Auslieferungsbegehren belästigt ${ }^{54}$. Alles ohne Erfolg, im Gegenteil: Das finnische Außenministerium führte die Botschaft offensichtlich irre, und alle skandinavischen Länder verweigerten die Auslieferung, weil sie zurecht politische Gründe dahinter vermuteten ${ }^{55}$.

\footnotetext{
so Vgl. Walter, Internierung (mit vielen zeitgenössischen Zeugnissen).

${ }^{51}$ Brandt an Klepper, undatiert (KNL).

$52 \mathrm{Vgl}$. auch Langkau-Alex, S. 36.

${ }^{53}$ Brandt an Klepper, 22. 3. 1933. Brandt war selbst auf dem Absprung nach USA, vgl. zur Biographie: Kürschner, S. $249 \mathrm{f}$.

54 Bericht, Reisepaß und Fotos von der Abreise in Helsinki. Vgl. PA-AA, Ref. D. Pol. 5 IV Nd und P.A., Extraakte K.: Telegramm Büsing an AA vom 13.6. 1933: „Erfahre soeben aus privater Quelle, daß Familie K. mit finnischen Reisepässen unter Namen Hakanson 13. Juni Dampfer Arcturus nach Kopenhagen abgefahren. Reiseziel angeblich Oslo. Amtl. Nachprüfung nicht vor Montag erreichbar." Vgl. auch: Bericht Büsing vom 26.6. 1933 und Akten zur Auslieferung Kleppers.

55 Ebenda, PrJM an AA, 13.11. 1933.
} 


\section{China: Klepper als Agrar- und Finanzberater}

Familie Klepper kam zwar heil am Gare du Nord in Paris an, aber die Situation war nach wie vor schwierig, etwa so, wie Walter Mehring sie in seinem Gedicht „Die kleinen Hotels“ beschreibt: „Vom Bahnhof angeschwemmt - im Strom der Massen/Fiebernd von Schwindsucht deines letzten Gelds/Treibst du durch Reusen immer engrer Gassen,/Die abzweigen/Zu den Absteigen/Zu den kleinen Hotels. "56 Kaum hatte die Familie in einem solchen, vielleicht nicht ganz so heruntergekommenen kleinen Hotel, nicht weit vom „Etoile“, Unterschlupf gefunden ${ }^{57}$, als sie wegen eines Nazispions nach St. Germain-enLaye umziehen mußte ${ }^{58}$. Klepper und seine Frau kannten Paris von früheren Reisen. Nun waren sie Flüchtlinge wie viele andere auch ${ }^{59}$. Der Kontrast zwischen der sorglosen, lebendigen Stadt und dem sorgenvollen Leben der Emigranten war groß ${ }^{60}$, und doch hat die Stadt mit ihrem Charme, ihrer Kultur und ihrer Menschlichkeit wahrscheinlich auch über vieles hinweggetröstet, zumal es Sommer war. Dennoch: Neben der Fertigstellung der Artikelserie für die schwedische Wirtschaftszeitung und des Artikels zum 20. Juli 1932 für das Neue Tagebuc $b^{61}$ war das größte Problem, wie Klepper seine Familie angesichts der ständigen Auslieferungsbegehren der deutschen Regierung an Frankreich und der gleichzeitigen Bespitzelung durch nationalsozialistische Agenten irgendwo sicher unterbringen und Geld für ihren Unterhalt verdienen konnte ${ }^{62}$. Offensichtlich hatte Klepper nicht nur von früher gute Kontakte zum französischen Außenministerium ${ }^{63}$, sondern auch zur internationalen Liga für Menschenrechte, deren Rechtsberater für die französische Sektion ein ehemaliger Reichsbannerchef war, Ernst Strauss, der „engste Beziehungen" zu Klepper unterhielt ${ }^{64}$. Wahrscheinlich hat die Liga Klepper auch bei der Flucht aus Finnland geholfen, denn die Tochter erwähnt einen „Nansenpaß“. Auf der Suche nach der Lösung seiner Probleme ist Klepper, sei es durch Vermittlung des Völkerbundes, sei es durch andere Kontakte ${ }^{65}$, auf China gestoßen.

China versuchte zu Beginn der dreißiger Jahre, seine bis dahin gestörten Beziehungen zum Völkerbund zu verbessern und durch den Völkerbund vermittelte Berater aus aller

${ }^{56}$ Mehring, in: Loewy, Bd. II, S. $491 \mathrm{f}$.

${ }^{57}$ Hotel Farnèse, rue Hamelin 30. Gespräch mit dem letzten Pächter des Hotels, das nicht mehr existiert.

${ }^{58}$ Lebenslauf von Renate Klepper.

59 Grossmann, Emigration, S. 11: Paris beherbergte 1938400000 Fremde. Noth, S. 247: „Ich war noch viel zu betäubt, um die Schönheit dieser Stadt in mich aufzunehmen. Ich war ein Flüchtling; ich war entkommen."

${ }^{60}$ Vgl. u. a. Scheers Beschreibung von Paris, S. 85 ff. und Flügge, Paris ist schwer.

${ }^{61}$ Am 17.7. 1933 übersandte der deutsche Geschäftsträger, D.E.O. Meynen, den Artikel zur Kenntnisnahme nach Berlin (PA-AA, Dt. Botschaft Paris, A 5565, Bl. 38-46).

${ }^{62}$ Am 23. 6. 1933 erreichte RA Stange, daß wenigstens Bekleidung und Leibwäsche von der Generalstaatsanwaltschaft freigegeben wurde (Stange-Bericht).

${ }^{63}$ Bestätigt durch Landy-Degon.

${ }_{64}^{64}$ IfZ, Fb 226, Bl. 32 (Kopie von PA-AA, Ref. Pol. 5 N.E. adh. 4, Nr. 1, Bd. 1).

${ }^{65}$ Kersten weiß zu berichten, daß Henri de Hoppenot, später Frankreichs Vertreter bei der Uno, Klepper zur Flucht aus Frankreich verholfen habe. Dieser Hinweis wird bestätigt durch die Tatsache, daß Hoppenot 1932/33 Berater (Conseiller) an der französischen Botschaft in Peking war (Biographisches Lexikon, Paris, 1933). Zur Vermittlungstätigkeit des Völkerbundes und des von ihm geschaffenen Flüchtlingskommissariats vgl.: Grossmann, S. $54 \mathrm{ff}$. 
Welt für seinen neu gegründeten „National Economic Council“ zu gewinnen ${ }^{66}$. Dem Exekutiv-Komitee des Rates gehörten unter anderem General Chiang Kai-shek, der Ministerpräsident Wang Chin-wei und der Finanzminister T.V. Soong an; letzterer war Hauptinitiator und zunächst einflußreichster Motor des Rates. Ludvik Rajchmann, ein polnischer Jude, wurde zum Koordinator aller nicht-militärischen Aufgaben ernannt ${ }^{67}$. Er eröffnete sein Büro in Shanghai und hatte als enger Mitarbeiter T.V. Soongs offensichtlich Einfluß auf die Auswahl der Berater.

Die Verhandlungen mit Klepper müssen schon sehr früh, vielleicht sogar schon in Finnland, aufgenommen worden sein, denn am 21. Juni 1933, also kurz nach seiner Ankunft in Paris, erschien bereits ein Dementi von ihm in der Zeitschrift Deutsche Freiheit: „Die Meldung, daß [er] [...] durch die chinesische Regierung nach China berufen ist und bereits in den nächsten Tagen seine Ausreise nach China antreten wird, entspricht nicht den Tatsachen. "68 Dennoch kehrte diese Meldung immer wieder ${ }^{69}$ und erregte Aufsehen; vor allem bei der deutschen Regierung, die das Engagement angesehener Emigranten im Ausland unbedingt zu verhindern suchte. Denn ihre Berufung gehe „auf Kosten der Deutschen, die, den nationalen Staat bejahend, das Verständnis für ihn vermitteln und fördern könnten“, während Emigranten durch eine „unfreundliche, ja feindliche Stimmung gegenüber dem nationalen Deutschland“ ausländische Kreise ungünstig beeinflussen könnten ${ }^{70}$.

Zunächst versuchte das preußische Justizministerium über das Auswärtige Amt und die Deutsche Botschaft in Paris, bei den Franzosen einen Haftbefehl gegen Klepper zu erwirken, wobei man sich groteskerweise auf den Auslieferungsvertrag zwischen PreuBen und Frankreich aus dem Jahre 1845 berief! ${ }^{71}$ Doch die Franzosen lehnten eine Verhaftung und damit auch eine Auslieferung $a b^{72}$. Gleichzeitig versuchte das Auswärtige Amt in endlosen Schriftwechseln und Verhandlungen in Zusammenarbeit mit der Deutschen Botschaft in Peking/Nanking, das Engagement Kleppers und einiger anderer prominenter Sozialdemokraten in China zu verhindern ${ }^{73}$, was nur im Falle von Albert Grzesinski und Bernhard Weiß gelang, die entgegen anderslautender, von der Literatur

${ }_{66}$ BAP, D.B.Ch., Nr. 2260, Bl. 17: Artikel in: The North China Daily News, 20. 7. 1933.

${ }^{67} \mathrm{Nr} .2257$, Bl. 29: Personnel of the National Economis Council und Nr. 2260, Bl. 17.

${ }^{68}$ Deutsche Freiheit, Nr. 78, 1. Jg., 21. 6. 33 in: Dt.Bibl.

${ }^{69}$ Vgl. u. a. Der Gegenangriff, Nr. 11, 1. 10. 1933: „Wir sind nun in der Lage, die monströse Wahrheit über den Fall aufzuklären. Vor einigen Wochen hat ein Vertreter der Nankinger Regierung tatsächlich Verhandlungen in Paris mit den genannten Personen eingeleitet und zwar vor allem mit Dr. Klepper, der zusammen mit einem hohen Beamten der preuß. Girokasse nach Nanking gehen sollte, um die chinesische Finanzverwaltung zu reorganisieren“, andere hätten sich vorgedrängt, die Chinesen hätten zwar mit allen verhandelt, die Verhandlungen seien aber an zu hohen Geldforderungen gescheitert. "Nur Dr. Klepper scheint das Rennen doch gemacht zu haben" (Hervorhebung im Original).

70 Geheimer Erlaß an alle dt. Gesandtschaften vom 31. 1. 1934 (D.B.Ch., Nr. 2254, Bl. 179 c-e).

${ }_{71}$ Preuß. JustizM an AA (Crohne), 9. 9. 1933, PA-AA, R 42694, und Ref. D Pol. 5 NE adh 4 Nr. 1 (Beiband).

72 Ebenda, Ministère des Affaires Etrangères an die Deutsche Botschaft Paris, 18. 10. 1933, nochmalige Bestätigung vom 12.12.1933: „[...] au regard de la loi française, le caractère politique dans l'ensemble des faits reprochés à Klepper, apparaitrait nettement prédominant."

${ }^{73}$ Vgl. ebenda, Botschaftsberichte von Fischer und PA-AA, Inland II, A/B 83-75, Bd. 2. 
übernommener NS-Berichte ${ }^{74}$ nicht in China waren ${ }^{75}$. Klepper wurde zusammen mit dem von ihm vorgeschlagenen Kurt Bloch, mit Horst W. Baerensprung, dem ehemaligen Polizeipräsidenten von Magdeburg, sowie mit Max Brauer, dem früheren Oberbürgermeister von Altona, und seinem engen Vertrauten, Rudolf Katz, Rechtsanwalt und bis 1933 sozialdemokratischer Stadtverordneter in Altona, von T.V. Soong persönlich in $\mathrm{Pa}$ ris engagiert ${ }^{76}$. Damit war allerdings das Schicksal der Berater auch stark mit dem Soongs verknüpft, und Grzesinski sollte mit seinen Befürchtungen recht behalten, daß sie „keine reine Freude erleben werden, nachdem der chinesische Finanzminister Dr. Sung [...] aus dem Kabinett ausgeschieden ist " 77 . Neben diesen von den Chinesen selbst ausgesuchten Beratern gab es noch einen offiziell von der deutschen Regierung zur Verfügung gestellten Beamten, den Regierungspräsidenten a.D. Wolfgang Jaenicke, der beim Aufbau der chinesischen Verwaltung helfen sollte. Auch er trug nicht zur Freude der Beratergruppe bei, er lehnte jeden Kontakt mit ihr ab und arbeitete eng mit der deutschen Botschaft zusammen ${ }^{78}$.

Als Klepper Anfang Oktober 1933 am Quai von Marseille stand und sich von seiner Familie, die sich gleichzeitig nach Mallorca einschiffte ${ }^{79}$, verabschieden mußte, war er gewiß, was seine kommende Tätigkeit anbelangte, noch guten Mutes und gespannt auf das vollkommen Neue, das ihn erwartete. Was allerdings den Abschied von der Familie betraf, so muß man sich diesen sehr traurig vorstellen, höchstens gemildert durch die Tatsache, daß Klepper Geld verdienen und die Familie unterstützen würde ${ }^{80}$. Zudem würde die Trennung aller Voraussicht nach nur ein Jahr währen, und die Familie schien

\footnotetext{
${ }^{74}$ So z. B. Langkau-Alex, S. 269, Anm. 65.

75 Vgl. 1. Brief Grzesinskis an Hoegner aus Paris vom 30. 12. 1933, in dem er schreibt, daß Klepper und Brauer abgereist seien (IfZ, ED 120, Bd. 4 G). 2. Grzesinski, Inside, S. 173. 3. Grzesinski, Lebensweg, Bl. 352: Er beendet diese Erinnerungen mit dem 11. November 1933 in Paris. 4. T.V. Soong: „Ich bin durch Verzicht auf Weiss und Grzesinski in meinen Zugeständnissen soweit gegangen, wie ich konnte" (D.B.Ch., Nr. 2253, Bl. 3). 5. Endgültige Liste der ernannten Berater vom 11.6. 1934, ebenda, Nr. 2257, Bl. 29, in der neben 8 Beratern aus anderen Ländern die 6 oben genannten deutschen Berater erwähnt werden.

${ }^{76}$ Ebenda, Nr. 2253: „alle Einstellungen ohne Völkerbund durch Soong in Paris erfolgt“ (Bl. 164). Vgl. auch: Abschrift eines "Aide Memoire" (Bl. 22); Berichte vom 12. 12. und 14. 12. 1933 (Bl. $58 \mathrm{ff}$.) und Akte der mexikanischen Immigrationsbehörde mit einem ausführlichen Bericht über Kleppers Fluchtgeschichte vom 17.6. 1942: Dort heißt es, daß Klepper im August 1933 den Vertrag mit der chinesischen Regierung geschlossen habe (KNL).

77 IfZ, ED 120 , Bd. 4 G.

${ }^{78}$ Ebenda, Nr. 2253, Bl. 38 ff.: ausführlicher Bericht des Deutschen Botschafters in Peking, Oscar Trautmann, über Jaenicke, 23. 12. 1933. Vgl. Brauer (S. 132): Brief Katz an Brauer, 6. 12. 1933.

${ }^{79}$ Lebenslauf von Renate Klepper und Ankunftsstempel vom 7. 10. 1933 in ihrem Paß.

${ }^{80}$ In einem der Botschaftsberichte heißt es: „Wenn man für einen amerikanischen Sachverständigen monatlich 5000 \$ ausgeben müsse und für dasselbe Geld ein halbes Dutzend deutsche Experten von großem Ruf bekommen könne, so sei nach Lage der Dinge die Entscheidung ohne weiteres gegeben" (ebenda, Nr. 2253, Bl. 158). Er hatte also vielleicht ein Gehalt von etwa 1000 im Monat und einen Jahresvertrag. Laut Aussage des Sohnes sei geplant gewesen, daß die Familie nach China nachkommen sollte, was auch Katz in einem Brief vom 28. 5. 1934 an Brauer erwähnt, in: Brauer, S. 200.
} 
mit Hilfe amerikanischer Freunde sicher untergebracht und einigermaßen gut versorgt zu $\operatorname{sein}^{81}$.

Eine Schiffsreise nach China pflegte damals etwa drei bis vier Wochen zu dauern ${ }^{82}$. Wann Klepper abgereist ist, läßt sich nicht genau klären; jedenfalls wurde seine Ankunft in Shanghai in den Botschaftsakten unter dem 9. November 1933 verzeichnet. Rudolf Katz erwähnt in einem Brief an Max Brauer, der als einziger der Berater in Nanking wohnte, daß Klepper und Bloch in Shanghai angekommen seien, im gleichen Hotel, dem Cathay-Mansions, wohnten, ebenfalls von einem gewissen Amann betreut würden und Sprachunterricht bei Mrs. Macfarlane hätten ${ }^{83}$. Am 23. November hat Klepper sich bei Rajchmann in Shanghai im Büro des Nationalen Wirtschaftsrats vorgestellt ${ }^{84}$.

China, teilweise von Japan besetzt und in einen Bürgerkrieg verstrickt, war im Winter 1933 in einer sowohl politisch wie wirtschaftlich extrem schwierigen Situation ${ }^{85}$. Um wenigstens die wirtschaftlichen Probleme ansatzweise in den Griff zu bekommen, war im Sommer 1933 der Nationale Wirtschaftsrat von der Kuomintang-Regierung gegründet worden. Klepper sollte nun als einer der Beauftragten ein Gutachten für ein Programm des wirtschaftlichen Wiederaufbaus der befreiten Gebiete, mit Schwerpunkt auf dem Agrar-Sektor, verfassen.

Zunächst galt es, sich Kenntnisse über die Agrarsituation Chinas zu verschaffen. Schon in Paris und gewiß auf der langen Schiffsreise hatte er mit dem Studium der neuesten Bücher und Zeitschriften über die allgemeinen politischen und wirtschaftlichen Bedingungen und die agrarische Verfassung Chinas begonnen ${ }^{86}$. Nun verglich, ergänzte beziehungsweise korrigierte er das Gelernte in Gesprächen und durch eigene Beobachtungen. Sein Arbeitsschwerpunkt lag auf dem landwirtschaftlichen Sektor und insbesondere im Genossenschaftswesen, das in ersten Ansätzen existierte ${ }^{87}$. Außerdem konnte er sich bereits auf den von Max Brauer, A. Stampar und dem Dänen Eric Briand-Clausen

${ }^{81}$ In einem Brief nach dem Kriege schrieb Frau Klepper an Lübke: „Herbst 33, als mein Mann nach China fuhr", habe sie sich und die Kinder in Palma de Mallorca mit Hilfe amerikanischer Freunde, Nähen, Stricken und durch den Verkauf von Wertgegenständen über Wasser gehalten (BAK, NL-Lübke, Bl. 146 ff.).

82 Vgl. Brauer, Briefe „auf See“; 6.9. (S. 107) und 2.10. 1933 (S. 115).

${ }^{83}$ Ebenda, Rudolf und Agnes Katz an Max Brauer, 16. 11. 1933, S. 123 f.

${ }^{84}$ D.B.Ch., Nr. 2253 , Bl. 132 und Nr. 2256, Bl. 80.

85 Näheres zur Lage Chinas um 1933 und zum NEC siehe: Brauer, S. $31 \mathrm{ff}$.

${ }^{86}$ Die folgenden Bücher und Aufsätze über China befinden sich in Kleppers Nachlaß: T.V. Soong, The Financial Situation in China and Japan, published by the Press Bureau of the Chinese Delegation, Geneva; der Artikel war zuerst am 13. und 14. 2. 1933 im Manchester Guardian veröffentlicht worden. Frank J. Goodnow, China. An Analysis, Baltimore 1926. Nathaniel Peffer, China: The Coliapse of a Civilization, London 1931. Kinn Wei Shaw, Democracy and Finance in China. A Study in the Development of Fiscal Systems and Ideals, New York 1926. Kuo-fu Chen, The Co-Operative Movement in China, published by the China Co-Operator's Union, Shanghai 1933. Ardron B. Lewis and Chang Lu-Luan, Silver And The Price Level, Nanking, December 1933. Brauer berichtet: „Vom Völkerbund haben wir viel Literatur über China auf das Schiff bekommen“ (S. 117).

${ }^{87}$ In Kleppers Unterlagen befindet sich eine detaillierte Auflistung aller Maßnahmen und Vorkommnisse, die die Geschichte der Genossenschaft von Minghsiang seit dem Beschluß zu ihrer Gründung im Mai 1931 betreffen. Daraus gehen die unendlichen personellen, landwirtschaftlichen und politischen Schwierigkeiten hervor, mit denen eine Genossenschaft zu kämpfen hatte. Beigefügt sind auch eine Satzung, eine statistische Übersicht, eine Sparkassensatzung, incl. einer Kindersparkasse, Lehrlingswerbung und ein Ausbildungsprogramm (Akte China). 
verfaßten Bericht über eine von ihnen im Auftrag des Wirtschaftsrates im November/ Dezember 1933 unternommene Reise durch die Provinz Kiangsi stützen. Er enthielt eine Studie zur Art der Landverteilung, der Besteuerung und der landwirtschaftlichen Kooperativen $^{88}$.

Im Nachlaß Kleppers befindet sich ein zweiteiliges Gutachten; in dem ersten Teil setzt Klepper sich mit den von Chiang Kai-shek im Dezember 1933 formulierten Zielen für eine künftige Agrarpolitik auseinander. Für Chiang Kai-shek war das Hauptziel, eine gesellschaftliche Entspannung herbeizuführen und die Wiederholung revolutionärer Wirren auszuschließen ${ }^{89}$. Das Wiederaufbauprogramm Chiang Kai-sheks wurde durch Klepper kurz wiedergegeben und dann einer kritischen Prüfung unterzogen. Dabei kam Klepper zu dem Schluß, daß dieses Programm sich insofern selbst „ad absurdum“ führe, als der „einseitig agrarwirtschaftlich orientierte chinesische Staat weder finanziell noch administrativ in der Lage [sei], ein halb plan-, halb privatwirtschaftlich aufgebautes Wirtschaftsprogramm, das zudem den Bauern keinerlei Anreiz biete und die Neuverteilung des Bodens keineswegs garantiere, zu verwirklichen“. Es würden sich nur die so-

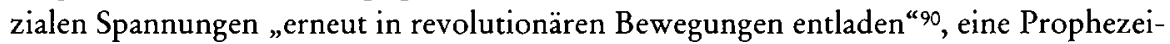
ung, die sich bald bewahrheiten sollte.

Im zweiten Teil des Gutachtens unterbreitete Klepper seine eigenen Vorschläge auf der Basis des chinesischen Rechts, das seiner Meinung nach die schätzenswerte Möglichkeit biete, „eine Landreform stufenweise zwischen dem kommenden und dem gehenden Eigentümer zu vollziehen “. Im Gegensatz zu der Methode westlicher Länder, Krisen durch währungspolitische Maßnahmen zu bekämpfen, sah Klepper für China aufgrund seiner effektiven Silberwährung die Möglichkeit, der Agrarkrise durch eine neue Wirtschaftspolitik konstruktiv zu begegnen. „Nach Schaffung der technischen Voraussetzungen wie Bodenverteilung, Gestaltung der Betriebsform und der Produktionsweise, sowie der erforderlichen Betriebsmittel“ müßten die Landwirte erst einmal durch „Prosperitätsanreize“ wie „Kleinkredite auf Genossenschaftsbasis“ und durch „provinzielle Agrarprivatbanken " kreditfähig gemacht werden, um dann als nicht mehr abhängige Pächter, die später selbständige Eigentümer werden sollten, vom Staat die notwendigen Kredite, die mit Kontrollen und Beratung verbunden sein sollten, erhalten zu können. „Auch die beste Finanzreform ist sinnlos, wenn die Landwirtschaft nicht gesund ist.“ Klepper sah für China die Chance, „über Bodenreform und Genossenschaften, über Agrarkredite sowie die Steigerung und Veredelung der Agrarproduktion zu einer breiten ökonomischen Entfaltung zu gelangen. Ein ernsthafter Anstoß durch die Regierungspolitik werde die wirtschaftliche Maschinerie zum vollen Laufen bringen, sie wäre der Schlüssel zur Konjunkturwende.“91 Wohl aufgrund seiner Währungsvorschläge

\footnotetext{
${ }_{88} \mathrm{Vgl}$. Brauer, S. $37 \mathrm{f}$.

${ }^{89}$ Ebenda, in französischer Übersetzung.

${ }^{90}$ Ebenda, Klepper Gutachten, S. 19.

${ }^{91}$ Ebenda, S. 25, „Zwischenformen zwischen Eigentum und Pacht, eine Art von Untereigentum, das in vielen Variationen praktisch vorkommt, auch unter dem Namen Yung-Tien Eingang in den Civil Code erlangt hat".
} 
hatte Klepper zusammen mit Bloch „einen einmaligen Auftrag bekommen, an der chinesischen Silberausfuhrzollfrage mitzuarbeiten" $"$.

Das Programm, das Klepper hier, auf die chinesischen Verhältnisse zugeschnitten, entwickelte, ähnelte durchaus demjenigen, das er für die ostdeutsche Landwirtschaft während der Weimarer Zeit gefordert hatte. Es ist fraglich, ob ein solches auf westliche Verhältnisse zugeschnittenes Reformprogramm überhaupt auf China übertragbar war, ein China, das durch den Krieg mit Japan und den Bürgerkrieg nicht nur in einer chronischen politischen, gesellschaftlichen und wirtschaftlichen Krise steckte, sondern auch ganz andere landwirtschaftliche Wirtschaftsweisen und Lebensformen kannte und nach wie vor von einer starren Bürokratie beherrscht wurde. Klepper wußte genau, daß China für diese gigantische Aufgabe sehr erhebliche Mittel und viel Zeit benötigen werde, aber er ahnte auch, was geschehen würde, wenn die Reformen nicht bald durchgeführt werden würden ${ }^{93}$. Als Klepper Chiang Kai-shek sein Reformprogramm überreichte, soll dieser es mit der Bemerkung, das habe noch hundert Jahre Zeit, in seine Schublade gelegt haben, worauf Klepper widersprochen und ihm gesagt haben soll, er habe nur noch wenige Jahre Zeit!94 Wie recht er damit hatte, beweist der Erfolg Maos aufgrund seiner Agrarreform.

Während Klepper für die chinesische Regierung arbeitete, versuchte die deutsche Regierung weiter, mit allen Mitteln Druck auf die Chinesen auszuüben, Klepper und seine Beraterkollegen zu entlassen und Klepper selbst nach Deutschland auszuliefern. Der Druck auf die deutsche Botschaft ${ }^{95}$ kam einmal von der deutschen Regierung und zum anderen offenbar auch von der deutschen Kolonie in Shanghai, die bei der NSDAP „lebhafte Klagen über das Auftreten gewisser Emigrantenkreise“ führte, wobei „insbesondere folgende Herren unliebsam von sich reden“ machten: „Brauer, Kratz [!], Klepper, Grimme, Grzesinski, Baerensprung und Weiß“96. Hier zeigt sich wieder einmal, wie schlecht die NSDAP informiert war, denn drei der genannten waren gar nicht in China! Auch scheint die deutsche Botschaft selbst, zumindest ihr Vertreter in Nanking, Botschaftsrat Martin Fischer, aus eigener Initiative gehandelt zu haben. Zunächst versuchte er, in mehreren Gesprächen mit Finanzminister Soong etwas zu erreichen. Dieser aber verhielt sich äußerst abweisend"7, während Ministerpräsident Wang Chin-wei sich trotz seiner Rücksichtnahme auf Soong im ganzen aufgeschlossener zeigte ${ }^{98}$. Als Fischer keinen Erfolg hatte, schrieb er am 13. Januar 1934 nach Berlin: „Ich möchte hiernach anre-

${ }^{22} \mathrm{Katz}$ an Brauer, 19. 12. 1934 (Brauer, S. 247). In der Akte befindet sich eine kurze Stellungnahme Kleppers zur chinesischen Abwertung des Silberdollars, die nach seiner Ansicht kein geeignetes Mittel zur Bekämpfung der Krise darstelle, weil diese nicht durch währungspolitische Maßnahmen zu bewältigen sei und weil der billigere Silberdollar den Bauern gar nichts nütze, denn die Kupferpreise blieben stabil, das Silber aber werde entweder gehortet oder fließe ins Ausland ab, weil dort der Silberpreis höher sei.

${ }_{93}$ Ebenda, handschriftlicher Schluß des 1. Gutachtens, S. $24 \mathrm{f}$.

${ }^{94}$ Kleppers Aussage gegenüber Gernot Gather.

95 Chef der Deutschen Gesandtschaft in Peking war Gesandter Oscar Trautmann, Chef der Botschaft in Nanking Botschaftsrat Fischer, außerdem gab es cin Generalkonsulat in Shanghai.

96 Mitteilung der NSDAP Hamburg vom 23. 2. 1934 an RJM, gez. Dr. Kranek (Rechtsstellenleiter): "Von unserer Ortsgruppe Shanghai und Hanckow treffen lebhafte Klagen" ein (Inland II, A/ B 83-75. Bd. 2).

97 D.B.Ch., Nr. 2253, Bl. 62 ff. und 70.

${ }^{98}$ Ebenda, Nr. 2254, Bl. 232 und Nr. 2257, Bl. 108 ff. 
gen, daß wir uns jetzt zunächst auf Klepper konzentrieren und mit dem Druck unsere weiteren Vorstellungen“ durchsetzen ${ }^{99}$. „Gegen ihn haben wir die stärksten Waffen in den ihm zur Last gelegten kriminellen Verfehlungen und dem aus diesem Grunde anhängig gemachten Strafverfahren. “ Die chinesische Regierung habe bereits Kenntnis von dem Material100, aber da Klepper und Rajchmann das Verfahren als längst erledigt bezeichnet hätten, sei es „schwierig, [dem] beweiskräftig entgegenzutreten“101. Fischer schlug eine Pressekampagne und Lancierung der Nachrichten über Radio Transozean $\operatorname{vor}^{102}$.

So begann im Frühjahr 1934 eine systematische Verleumdungskampagne gegen Klepper nach bekanntem Muster: Im Gespräch mit der chinesischen Regierung wird Klepper als einer bezeichnet, der „ohne sich irgendwie durch Leistungen auf dem ,Finanz'-gebiet ausgezeichnet zu haben, nur durch Parteimanipulationen zu einflußreichen Stellungen gelangt, sich in der Führung ihres Amtes aber in der unverantwortlichsten Weise und ohne Rücksicht auf das Staatswohl Parteiinteressen untergeordnet habe, mit dem Erfolg, $\mathrm{da} ß$ in kurzer Zeit der Staatshaushalt sich in größter Unordnung befunden habe, so sollte damit für jeden denkenden Menschen die Unfähigkeit einer solchen Persönlichkeit zur Mitwirkung bei der Reorganisation fremder Staatsfinanzen erwiesen sein“. Über seinen Werdegang heißt es: „Nachdem er sich als Rechtsanwalt in Berlin der Sozialdemokratischen Partei angeschlossen hatte, von der Regierung Braun, kaum 35jährig, in die verantwortungsvolle Stellung des Generaldirektors der Preußischen Zentralgenossenschaftsbank berufen wurde, als für Wahlzwecke ein der Partei absolut gefügiges Werkzeug an der Spitze dieses Geldinstituts gebraucht wurde. Die Voraussetzungen, die er für sein Amt mitbrachte, waren Befassung mit Genossenschaftsfragen in seiner Anwaltstätigkeit. Von der Genossenschaftsbank trat er Anfang 1932 an die Spitze des preußischen Finanzministeriums, wo er so willkürlich und verständnislos gewirtschaftet haben soll, daß die Beamten des Ministeriums schließlich mit Arbeitsniederlegung drohten. Nach Beseitigung des Ministeriums Braun entzog Klepper sich durch schleunige Abreise ins Ausland der weiteren Prüfung seiner Amtstätigkeit. Man sollte annehmen, $\mathrm{da}$, wenn diese Vorgänge und sonstiges Material bekannt werden, er als Sachverständiger in Finanzfragen ausgespielt haben wird."103

Wie stark sich nationalsozialistische Elemente nun auch in der deutschen Kolonie breitmachten, geht aus dem Bericht einer jungen englischen Ökonomin hervor, die zunächst aufgrund ihrer ersten Bekanntschaften mit Deutschen ein sehr positives Bild entworfen hatte, dann aber folgendes schreibt: „However, I had to modify my statement [about Germans] recently [...] I have met too many with an overabundance of nationalism, militaristic ideas, uncritical race-prejudices and small-town mentality." 104

\footnotetext{
99 Ebenda, Bl. 249.

100 Nr. 2253, B1. $135 \mathrm{f}$.

101 Ebenda, Nr. 2254, B1. 349.

102 Ebenda, Nr. 2253, Bl. 137 und Nr. 2254, Bl. 249.

${ }^{103}$ Ebenda, Nr. 2254, Bl. $161 \mathrm{ff.}$ und Nr. 2258, Bl. $110 \mathrm{ff}$., Zeitungsartikel über Klepper.

104 Joe Lederer war als Engländerin im Statistical Department of the American Oriental Finance Corporation in Shanghai beschäftigt und gehörte auch zum Freundeskreis Kleppers (vgl. Nachkriegskorrespondenz, März 1950). Sie hat einen sehr lebhaften Bericht über die Situation in China geschrieben (Akte China).
} 
Doch blieb es nicht bei der Verleumdungskampagne, es wurde erwogen, „ob nicht im Notfall noch stärkere Druckmittel ins Auge gefaßt werden sollten“"105. Ein solches Druckmittel war, die Bewilligung von Reichsgarantien für Eisenbahnbaukredite mit dem Auslieferungsbegehren zu verknüpfen. Klepper bezeugt dies im Pensionsverfahren von Baerensprung auf folgende Weise: „Unsere Entlassung aus dem Dienst der Regierung hing mit einem Kredit zusammen, den die Firma Otto Wolff in Düsseldorf für einen Bahnbau zu denselben Bedingungen stellte, zu denen seinerzeit die sogenannten russischen Wechsel gegeben wurden. Das heißt, das Deutsche Reich übernahm eine Garantie für den Kredit. Diese Transaktion hatte für die chinesische Regierung deshalb eine besondere Bedeutung, weil sie das bisherige Prinzip durchbrach, nach dem Anleihen der zur Rede stehenden Art seitens der westlichen Länder nur durch Verpfändung von Seezolleinnahmen gewährt wurden. Die Erteilung der Reichsgarantie war aber an die Bedingung geknüpft, daß die im Dienst der chinesischen Regierung beschäftigten deutschen Emigranten entlassen würden." So erkläre sich die im Sommer 1934 erfolgte Kündigung des Dienstverhältnisses der deutschen Berater. T.V. Soong habe ihm diesen Sachverhalt seinerzeit mitgeteilt und ihm vorgeschlagen, „eine Zeit lang aus dem Regierungsdienst auszuscheiden und nach Ablauf einer gewissen Zeit wieder in ihn einzutreten“. Das habe er "damals abgelehnt, weil [ihm] Soongs Zusage nicht genügt" habe ${ }^{106}$.

Nimmt man die oben bereits erläuterte Taktik des Reiches, Druck auf die Chinesen auszuüben, zusammen mit der Taktik, die Firma Wolff hinzuhalten und sie zunächst Verträge mit den Chinesen aushandeln zu lassen ${ }^{107}$, so ergibt sich daraus ein wirksames Druckmittel. Dem mußten die Chinesen schließlich erliegen, da ihnen der Eisenbahnbau, mit dem erst begonnen werden konnte, wenn die Reichsgarantien für mindestens $70 \%$ des Kapitals fest zugesagt waren ${ }^{108}$, wichtiger sein mußte als ein paar deutsche Berater. Besonders pikant wird dieses Pokern um Kredite, das gleichzeitig das Leben einiger deutscher Berater betraf, durch die Tatsache, daß Kleppers ehemaliger Untergebener bei der Preußenkasse, Rudolf Siedersleben, der in den Dienst der Nationalsozialisten getreten und von diesen als Generalbevollmächtigter in die Firma Wolff von oben hineingesetzt worden war, nun die Verhandlungen mit den Chinesen federführend zu leiten hatte ${ }^{109}$. Er hätte vielleicht etwas für Klepper und die anderen tun können, aber er tat nichts. Die Dienstverträge der von T.V. Soong engagierten Berater wurden gelöst, Klep-

${ }^{105}$ D.B.Ch., Nr. 2252, Bl. 136.

106 Klepper an Käthe Baerensprung, 3. 3. 1954: „Ich bin natürlich auch bereit, diese Dinge als Zeuge zu bekunden." Die Tatsache, daß die Firma Otto Wolff im Jahre 1934 um Reichsgarantien für die Finanzierung des Eisenbahnbaus Yushan-Nanchang-Pinghsiang nachgesucht hat, geht eindeutig aus den Akten der Firma Wolff, Stichwort: China, Bahn, hervor (Wirtschaftsarchiv Köln, K83-28, Bd. IV).

${ }^{107}$ Ebenda, vgl. u. a. Schreiben der Deutschen Revisions- und Treuhand-Aktiengesellschaft vom 31. 4. 1934 und 12.7.1934 an die Firma Wolff.

${ }_{108} \mathrm{Vgl}$. ein gemeinsames Memorandum der Chinesen mit Otto Wolff persönlich, der im Frühjahr 1935 zur Fortsetzung der Verhandlungen mit den Chinesen zum Bau eines weiteren Streckenabschnitts in China war (K82-35, 8. 3. 1935).

${ }^{109}$ Ebenda. 
pers Tätigkeit endete mit dem 30. Juni 1934110. Baerensprung wurde im Jahre 1937 erneut eingestellt ${ }^{111}$.

Der einzige Berater, der noch bis zum Ende des Jahres für die chinesische Regierung arbeitete, war Jaenicke, „das einzige Gegengewicht", wie Botschafter Trautmann nach Berlin kabelte, „gegenüber diesen schädlichen Elementen“ wie Klepper und „Konsorten"112. Jaenicke war wie Siedersleben ein kleiner Stein im Spiel der Nationalsozialisten gegen die demokratischen China-Berater. "Jaenickes Aufgabe war es, sich eine Position zu schaffen, die nicht nur jeden Gedanken einer Zusammenarbeit mit den unerwünschten Ratgebern ausschloß, sondern sich auch gegen den zunächst noch mächtigen Einfluß Rajchmanns behauptete. In enger und vertrauensvoller Zusammenarbeit mit der Botschaft ist Jaenicke aller dieser Schwierigkeiten Herr geworden. "113 Hinter diesen taktischen Manövern gegen die unliebsamen Emigranten standen weitreichendere Ziele. Es ging nicht nur darum, als deutsche Berater auf die chinesische Wirtschaft Einfluß zu gewinnen und damit auch der deutschen Wirtschaft neue Absatzmärkte zu erschließen, sondern langfristig ging es auch um politische Einflußnahme, zumindest um die Werbung für die nationalsozialistische Ideologie im Ausland ${ }^{114}$. Daß bei der Verfolgung derartiger Ziele deutsche Emigranten, zumal, wenn sie sich eines großen Ansehens erfreuten und Sachverstand besaßen, störten, läßt sich denken. Nur so ist es auch zu verstehen, daß ein derartiger Aufwand betrieben wurde, um die paar Berater aus China wieder zu entfernen.

Doch wie hinterhältig das taktische Spiel selbst den dienenden Helfern gegenüber gespielt wurde, zeigt wiederum der Fall Jaenicke. Nachdem er nämlich seinen Dienst, wie Trautmann bestätigte, zu aller Zufriedenheit erfüllt und mitgeholfen hatte, Klepper, Baerensprung und die anderen auszubooten, wurde auch er fallengelassen ${ }^{115}$, zu seinem eigenen Erstaunen, ja Entsetzen, denn er hatte sich in seine Aufgaben in der Provinz Shantung gut eingearbeitet und war mit seinem Projekt noch keineswegs zu Ende. ${ }^{116}$ In einem langen Brief, den er aus dem deutsch-chinesischen Krankenhaus in Tsinan, wo er mehrere Wochen mit einer fieberhaften Bronchitis lag, an den Botschaftsrat in Nanking, Fischer, mit dem er auch privat korrespondierte, schrieb, rätselt er über die Gründe sei-

${ }^{110} \mathrm{Zu}$ Kleppers Entlassung vgl. D.B.Ch., Nr. 2254, die Entlassung wurde amtlich bestätigt, 3. 7. 1934 (Bl. 125). Am 31.7. 1934 bestätigt Werner Junker (Nanking), daß Klepper in Shanghai sei (Bl. 100).

${ }^{111}$ Klepper an Käthe Baerensprung, 3. 3. 1954.

112 Trautmann an das AA Berlin, 10.7.34 (D.B.Ch., Nr. 2254, Bl. 105 ff.).

113 Ebenda, B1. 107. Bestätigt wird Jaenickes Einsatz durch seinen eigenen Bericht über sein Gespräch mit dem Generalsekretär des Komitees am 9. 11. 1933 (Nr. 2253, Bl. 156 ff.) und durch einen Brief Katz an Brauer, 6. 12. 1933, Brauer, S. 132.

114 Vgl. Trautmann-Bericht (ebenda).

115 Ebenda, was Trautmann zunächst mit dem Argument zu verhindern versuchte, daß der deutsche Beamtenstatus ,in den Augen der Chinesen ein ganz anderes Maß von Ansehen und Autorität gibt, als es abgebaute Leute genießen“, deshalb solle man Jaenicke, solange er in China arbeite, den Beamtenstatus lassen, „ob er später in Deutschland tatsächlich wieder verwendet werden soll", sei unwichtig.

116 In einem Brief Jaenickes an Rajchmann, 28. 12. 1934, heißt es, er fühle sich „einigermaßen überrascht" von der plötzlichen Kündigung seines Beratervertrages, obwohl ihn die Provinz Shantung noch für 1-2 Jahre zur Beendigung der Reformen behalten möchte. Dic Kündigung aller nicht vom Völkerbund engagierten und bezahlten Berater wurde offiziell mit finanziellen Schwierigkeiten begründet (BAK, NL-Jaenicke, 135/85). 
ner für ihn unverständlichen Entlassung aus dem chinesischen Dienst ${ }^{117}$. Neben der Vermutung, daß für den Nationalen Wirtschaftsrat kein Geld mehr da sei, nennt er als zweiten möglichen Grund „die Rache T.V. Soongs für seine abgehängten Experten Klepper und Konsorten“. Der Brief, in dem er noch drei weitere Gründe aufzählt und von seiner baldigen Abreise berichtet, zeugt von großer Verbitterung ${ }^{118}$.

Was Klepper anbelangt, so scheint er noch bis Ende Januar 1935 in Shanghai geblieben zu sein ${ }^{119}$. Da er gute Freunde dort hatte ${ }^{120}$ und sein Gehalt bis zum Ablauf seines Jahresvertrages bezahlt wurde, ist es zwar verständlich, daß er in diesem interessanten Land, wo er so viel lernen konnte, noch blieb, andererseits ist es auch erstaunlich, denn zum einen war er fern von seiner Familie und zum anderen fern von jeglicher Einflußmöglichkeit auf deutsche Geschicke. Ein Grund wird vielleicht gewesen sein, daß das Strafverfahren gegen ihn erst Mitte November 1934 wegen Abwesenheit eingestellt worden war ${ }^{121}$.

Ende Januar fuhr Klepper mit dem Schiff von Shanghai nach Los Angeles, wo er möglicherweise Karl Brandt traf, der inzwischen an der Stanford Univerity lehrte. Später reiste er dann durch das Land nach New York weiter ${ }^{122}$. Wie aus seiner Korrespondenz, vor allem aus Mallorca, hervorgeht, war ihm dieser Studienaufenthalt in den USA sehr

117 Ebenda, 135/28: Korrespondenz Jaenickes mit Fischer: u. a. 19. 4. 1935.

118 Ebenda.

119 Anlage zur USA-Reise 1953, und laut Alien Registration Form vom 2. 1. 1941, französisches Konsulat, Marseille, war Klepper nur 3 Monate in USA zum Studium des politischen Systems ab Januar 1935. Im Januar 1935 habe es noch einmal ein Ultimatum der deutschen Regierung zwecks Ausweisung Kleppers aus China gegeben (Akte Mexiko). Vgl. außerdem: autorisierter Lebenslauf (KNL). Damit wäre die Aussage von Langkau-Alex, S. 269, Anm. 65, widerlegt.

${ }^{120}$ Aufgrund der Nachkriegskorrespondenz können folgende Personen nachgewiesen werden: W. V. Blewett (England), er schreibt an Klepper nach dem Kriege, 25.2.(?): „My dear Otto Klepper, How many times have I said I must write to my old friend Otto Klepper? I always think of you as a friend, for during those exciting days in China we found we had a great deal in common. A lot has happened since we parted in Shanghai. "Blewett war noch zweimal dort, 1942/3 als „Economic Intelligence“ at the British Ambassy. Zu Kleppers Tod schrieb er „I accompanied him to N.W.China in 1934 and formed a high opinion of him". Käthe Baerensprung, die mit ihrem Mann in China war, schrieb am 1.11. 1952 an Klepper: „Wie alt sind wir geworden und wie weit liegt Shanghai hinter uns. Es war doch richtig, daß Sie mir abrieten, in den schlammigen Wanspoo zu springen, trotz allem." Frau Bloch, die ebenfalls ihren Mann begleitet hatte, schickte Klepper nach dem Kriege sein kleines Neues Testament, das sie für ihn seit China bewahrt hatte (Dankesbrief Kleppers vom 27. 1. 1955); und Joe Lederer, die oben erwähnte Ökonomin. In Nanking verkehrte er auch im Hause von Pearl S. Buck, dies schrieb Klepper seinem Sohn, 16. 3. 1947, anläßlich eines Buches, das er von ihr auf dem Schiff gelesen und das ihn tief bewegt hat.

121 12. 11. 1934 Einstellung des Strafverfahrens wegen Abwesenheit auf Antrag des Generalstaatsanwalts, Beschlagnahme des Mobiliars wird aufgehoben. Die Möbel wurden unter Aufsicht von Kalinowski und RA Stange verpackt und in das Lager der Firma Knauer gebracht, das Haus wurde vermietet. Um die Lager- und Versicherungskosten zu zahlen, mußte ein Teil der Möbel verkauft werden. Kalinowski hat sie zum Taxpreis gekauft, das übrige Vermögen blieb beschlagnahmt (Stange Ber.). Die Verleumdungskampagnen in Shanghaier deutschen Zeitungen hielten bis in den Februar 1935 hinein an (D.B.Ch., Nr. 2258, Bl. 110 ff.).

122 Angaben für die Visa-Abt. des amerikanischen Generalkonsulats, Frankfurt/M., 25. 2. 1954 und autorisierter Lebenslauf, S. 2: „Klepper spent several months in the United States in 1935, travelling across the country and studying its political system. " Durch den Brief Kleppers an Hermes, 1. 5. 1935, New York wird Kleppers Aufenthalt in den USA ebenfalls bestätigt (Hermes-NL, I090-004). 
wichtig, einmal für seine gedankliche Klärung und sein Informationsbedürfnis und zum anderen zur finanziellen Unterstützung seiner späteren Vorhaben, die er in Mallorca konzipiert und in Paris zu verwirklichen versucht hat. Eine Schlüsselrolle spielte dabei B. Charney Vladeck, ein 1886 in Rußland geborener Jude, der nach dem Ersten Weltkrieg in die USA ausgewandert war und sich dort für die Arbeiterbewegung und die Juden einsetzte. Aus diesem Engagement heraus unterstützte er auch den Kampf gegen Hitler, spendete und sammelte für den "Anti-Fascist Fund“, aus dem auch Klepper Geld für die Finanzierung der Deutschen Freiheitspartei erhalten hat. Außerdem war Vladeck Herausgeber des Daily Forward, für den auch Klepper Artikel schrieb ${ }^{123}$. Vladeck muß ein ungeheuer beliebter und geachteter Mann gewesen sein. Dies geht aus einem zu seinem 50. Geburtstag erschienenen Buch hervor ${ }^{124}$. Vermutlich hat Klepper durch Vladeck Oswald Garrison Villard, den späteren Schatzmeister der von Hubertus Prinz zu Löwenstein gegründeten Hilfsorganisation „American Guild for German Cultural Freedom", kennengelernt, der Klepper auch geholfen hat ${ }^{125}$.

Die Tatsache, daß Klepper zwei Erdteile bereist hatte, bevor er nach Europa zurückkehrte, war für ihn von ausschlaggebender Bedeutung. Er lernte, die Welt als eine Einheit zu begreifen und in globalen Zusammenhängen zu denken. In China hatte er auf seinem eigenen Fachgebiet, dem Agrar-, Genossenschafts- und Finanzsektor, arbeiten können, dies aber unter ganz andersartigen, für ihn völlig neuen politischen, wirtschaftlichen und sozialen Bedingungen getan. Er hatte die Auseinandersetzungen zwischen den Reformversuchen der Kommunisten und denen der Kuomintang beobachten und miterleben können, wie dieses riesige, von Kriegen geschüttelte Land versuchte, sich von seiner kolonialen und gleichzeitig seiner feudalen Vergangenheit zu lösen. In Amerika sah er praktisch die Welt von morgen, die einmal Europa nach Hitler prägen würde. Diese Erfahrungen bestätigten seine schon in der Weimarer Zeit vertretene Überzeugung, daß ein vereintes Europa geschaffen werden mußte, und legten den Grundstein für seine nach dem Kriege entwickelte Konzeption einer „Offenen Welt“"126.

${ }^{123}$ Vgl. Mallorca-Korrespondenz, bestätigt durch Aussage des Sohnes und der Tochter.

${ }^{124}$ Vladecks Buch gehört mit einer persönlichen Widmung zum Nachlaß Kleppers.

${ }^{125}$ Ebenda, Ovation für Vladeck von Oswald Garrison Villard. Über Villard schrieb Klepper unter der „Überschrift: Friedensoffensive?“ am 1.3. 1940 einen Artikel in: Die Zukunft (3. Jg., 9): „Villard ist französischer und deutscher Abkunft, er entstammt hugenottischen Réfugiés, die in der Rheinpfalz Zuflucht fanden, sein Vater aber wanderte nach 1848 als politischer Emigrant in die Vereinigten Staaten aus. Villard war lange Zeit Herausgeber von The Nation, wo er regelmäßig seine Artikel veröffentlichte. Nach Kriegsausbruch begab sich der gewiß über Siebzigjährige nach Europa, und zwar geradewegs nach Deutschland, wo man ihn als Gegner des Nationalsozialismus gut kennt. Von London aus hielt er später im Rahmen der deutschsprachigen Sendungen der BBC eine Ansprache nach Deutschland hinüber, deren warnender Ernst den Hörer stark berühren mußte."

${ }^{126}$ Vgl. auch den Titel der von der Wipog herausgegebenen Zeitschrift: Offene Welt. In der 1. Hattenheimer Resolution der Wipog vom Juni 1948 heißt es u. a.: „Beschränkungen unserer Souveränität, die sich aus dem Erfordernis eines übernationalen, weltpolitischen Organismus' ergeben, werden wir uns nicht zu entziehen suchen. “ Außerdem wurde ein Bekenntnis zu einer „ungehemmten weltwirtschaftlichen Arbeitsteilung “ abgelegt. Schon in den frühen fünfziger Jahren vertrat die Wipog den Gedanken einer Entwicklungshilfe für die Dritte Weit. 


\section{Frankreich: Politische Konzepte für die Volksfront}

"Auf dem Wege über China und Amerika bin ich auf dem Anmarsch nach Paris", schrieb Klepper am 4. Juli 1935 aus Zürich an Carl Spiecker ${ }^{127}$. Kurz darauf traf er dort ein und wohnte bei seinem Freund, Ludwig Aron, mit dem er schon beim Reichsausgleichsamt nach dem Ersten Weltkrieg zusammengearbeitet hatte und der später als Anwalt zu Klepper in die Preußenkasse gekommen war ${ }^{128}$. In Paris traf er mit vielen Leuten, alten Bekannten, ehemaligen Mitarbeitern und Freunden aus Berlin zusammen, tauschte Eindrücke und Erfahrungen aus und besprach Pläne für die Zukunft. Vor allem suchte er Einblick zu gewinnen in die bisherige politische Tätigkeit der Emigranten. Er muß einen sehr zwiespältigen Eindruck gewonnen haben, denn just bis zu jenem Sommer 1935 bot „die Vielzahl der Aktionen, Ausschüsse und Organisationen, in denen deutsche Emigranten in Paris seit Frühjahr 1933 die Arbeit gegen die nationalsozialistische Herrschaft in Deutschland aufnahmen, [...] das Bild eines kaum entwirrbaren Geflechts". In den ersten Jahren hatte offenbar hauptsächlich "das Erstaunen oder Erbittertsein über den Sieg des Nationalsozialismus in Deutschland vor[geherrscht]; waren die Gedanken meist rückwärts gerichtet; mündete die Frage, wie es dazu hatte kommen können, in Betrachtungen und Anklagen - selten Selbstanklagen. Gedanken über den Sinn der Emigration waren noch selten" ${ }^{129}$.

Dies war eine Klepper eher fremde Einstellung und Haltung. Ihm war der ,Sinn der Emigration“ längst klargeworden: Es kam vor allem darauf an, aus den Fehlern der Vergangenheit zu lernen und Konzepte für ein Deutschland nach Hitler zu entwickeln. Er brannte nun darauf, etwas gegen Hitler zu unternehmen. Er hatte in den USA Pläne für eine Bekämpfung des Hitlerregimes entwickelt und versucht, dort Anhänger und Geldgeber dafür zu finden ${ }^{130}$. Außerdem kam er gerade aus Zürich, wo er seine Freunde, unter anderem Lauffer, getroffen hatte, der wie andere noch in Deutschland lebte. Sie haben Klepper nicht nur gut über die Verhältnisse in Deutschland informiert, sondern auch gesagt, daß die Regimegegner in Deutschland dringend Informationen von außen und Ermutigung bräuchten ${ }^{131}$.

Klepper kam mit seinen Initiativen nicht zu spät, noch hatte sich kein aktionsfähiger Kreis gebildet. Im Gegenteil, die erste Phase der Emigration war von dem Wunsch der meisten Emigranten bestimmt gewesen, sich zuerst einmal persönlich und politisch zu orientieren, an alte Verbindungen anzuknüpfen und die vorhandenen parteipolitischen

127 BAP, 90 Sp2 (Nachlaß-Spiecker), Klepper an Spiecker, Zürich, 4. 7. 1935 (Bl. 1).

${ }_{128}$ Brief Arons an Martin Schumacher, 17. 10. 1961 (KNL).

129 Langkau-Alex, S. 50 und 127. Vgl. besonders Kapitel II: „Mikrokosmos von Organisationen und Aktionen in Paris, 1933-1935" (S. 50 ff.).

${ }^{130}$ Hinweise in fast allen Briefen an Spiecker, der dort auftauchende Name ist mit V. oder Vl. abgekürzt. Es handelt sich um B. Charney Vladeck.

131 BAP, 90 Sp2, Bericht Kleppers (Bl. 2-14), den er für einige „amerikanische Freunde über die Eindrücke von [seiner] Reise“ geschrieben hat und den er mit dem Brief vom 18.7.1935 an Spiecker (Bl. 15) schickte, S. 6: „Vorweg muß ich bemerken, daß es ja kaum noch jemanden geben kann, der einen zentralen Überblick besitzt. Immerhin habe ich mit einer größeren Anzahl von Leuten, die noch in. Deutschland leben, insbesondere mit alten Freunden, die mich in der Schweiz besucht haben, lange und eingehend gesprochen." Vgl. dazu übereinstimmend: Gross, S. 308 und Gutachten Lauffers für Schmidt, 15. 9. 1948 (KNL); dies bestätigt auch die Reisen Lauffers in die Schweiz. 
Organisationen zu festigen ${ }^{132}$, was vor allem für Kommunisten und Sozialdemokraten galt. Daraus hatte sich eher ein Gegen- als ein Miteinander ergeben. Willi Münzenberg, der schon in der Weimarer Zeit bekannte große kommunistische Agitator und einer der Aktivsten unter den Emigranten ${ }^{133}$, hatte sich „seit Jahren [...] bemüht, gemeinsame Aktionen mit Sozialisten und linksorientierten Bürgerlichen ins Leben zu rufen, und [war] immer wieder [...] in seinen Bemühungen durch starre wirklichkeitsfremde Beschlüsse behindert worden"134. Nun aber waren die Dinge in Gang gekommen, und Konrad Heidens Ruf „Heraus aus der Zersplitterung!“ wurde nicht nur gehört, sondern sein Appell wurde verstanden ${ }^{135}$.

Drei Ereignisse trugen dazu bei, daß in jenem Sommer 1935 verstärkt Versuche unternommen wurden, alle Hitlergegner in einer Volksfront zusammenzuschließen. Der eine Anstoß kam von der Saar, wo die Volksabstimmung vom 13. Januar 1935 eine Welle von antifaschistischen Flüchtlingen, unter ihnen viele aktive Widerstandskämpfer, nach Frankreich gebracht hatte ${ }^{136}$. Der zweite Impuls kam aus Frankreich selbst, wo sich die Stimmen für einen „Front Populaire“ zu mehren begannen ${ }^{137}$, und der dritte, wohl wirksamste Anstoß wurde durch die offizielle Weisung des VII. Weltkongresses der Komintern, für eine „Einheitsfront von oben“ zu kämpfen, gegeben ${ }^{138}$. „Münzenberg nahm die Verkündigung der neuen Linie mit zwiespältigen Gefühlen auf“, er vermochte ihr nur bedingt zu trauen ${ }^{139}$, erkannte aber dennoch in ihr eine wirksame Unterstützung seiner eigenen Bemühungen.

Klepper konnte zunächst nicht in Paris bleiben, seine Familie, die sich inzwischen in einem kleinen Häuschen in Palma/ Mallorca installiert hatte, erwartete ihn. Einerseits mag er ungern aus dem aktiven Zentrum Paris abgereist sein, andererseits zog es ihn zu seiner Familie, zu der inzwischen auch Hedwig v. Kalinowski gestoßen war ${ }^{140}$. Zudem

132 Vgl. Langkau-Alex, S. $127 \mathrm{ff}$. und „Mit dem Gesicht nach Deutschland“. Eine Dokumentation über sozialdemokratische Emigration, hrsg. von E. Matthias, Düsseldorf 1968.

${ }^{133}$ Das wichtigste Buch über Willi Münzenberg ist nach wie vor das seiner Lebensgefährtin Babette Gross. Das Interesse an ihm hat nie nachgelassen, wovon u. a. ein Münzenberg-Kolloquium in Aix-en-Provence im Frühjahr 1992 zeugt. (Eine Ausstellung mit Begleitheft zu dem Kolloquium in Aix war im Herbst 1992 im C.A.R.A.N. zu sehen.) Vgl. auch die Arbeiten von Rott, Kersten, Paul, Wessel und Koestler.

${ }^{134}$ Gross, S. 289.

135 Vgl. die detaillierte Beschreibung der Bildung des „Vorläufigen Ausschusses“ („Aktionsausschuß für Freiheit in Deutschland“), dem vor allem Schriftsteller und Journalisten wie Heinrich Mann, Lion Feuchtwanger, Georg Bernhard angehörten, und seine Verbindung mit dem Kreis um Münzenberg, Langkau-Alex, S. $79 \mathrm{ff}$.

136 Zum Beispiel Walter Habicht, den Klepper im Internierungslager Catus kennenlernte (s.u.). Er war 1934 mit anderen als kommunistischer Widerstandskämpfer aus Deutschland geflohen, nachdem er bereits im Gefängnis gesessen und Mißhandlungen über sich hatte ergehen lassen müssen. Vgl. auch: Gross, S. 285 und Mallmann, S. $172 \mathrm{ff}$.

137 Vgl. Gross, S. 283 f. 1936 kam dann das Volksfront-Kabinett unter Léon Blum zustande, hielt sich allerdings auch nur ein Jahr.

${ }^{138}$ Der Weltkongreß der Komintern fand von Juni bis August 1935 in Moskau statt und forderte die Kommunistischen Parteien auf, gemeinsam mit den Sozialdemokraten und den bürgerlichen Parteien gegen den Faschismus zu kämpfen, Gross, S. 286 ff. Gross beschreibt ihre und Münzenbergs Ankunft und die beklemmende Atmosphäre in Moskau sehr anschaulich. Es wird deutlich, daß sie beide die Diskrepanz zwischen Parole und Realität durchschauten.

139 Vgl. u. a. Gross, S. 289.

${ }^{140}$ BAP, 90 Sp2, Klepper an Spiecker, 18.7.35 (Bl. 15). 
bot der ruhige Platz die Chance, seine reichen Erfahrungen aus China und den USA auszuwerten und seine Pläne zu entwickeln und zu Papier zu bringen. Diese eineinhalb Jahre in Mallorca waren, vor allem aus der Rückschau betrachtet, eine letzte Oase des Friedens und des Familienlebens, soweit Klepper überhaupt dazu fähig war. Gewiß genoß er das Frühstück in der Sonne, wenn, wie er im Oktober 1935 an Spiecker schrieb, „die Hitze [...] vorbei und es [...] für mitteleuropäische Verhältnisse angenehm sommerlich" war, wenn er mit seiner Tochter morgens im Meer baden oder auch mit seinem Sohn spazierenging, aber, so berichtet heute sein damals elfjähriger Sohn, dann war nicht etwa von Dingen, die den Sohn beschäftigten, die Rede, sondern von Politik und Wirtschaft. Das öffentliche Geschehen, sprich das Schicksal Deutschlands hatte für Klepper immer den Vorrang vor dem privaten Schicksal seiner Familie und seiner selbst. Was das für eine Ehefrau und die Kinder bedeutet, läßt sich ahnen. Hier liegt auch die tiefere Ursache dafür, daß die Familie nie wieder zusammenfinden sollte, obwohl auch Klepper selbst sehr darunter gelitten hat. Es war so, wie er es in einem Brief an Spiecker formulierte: „Sachlich brenne ich wirklich darauf, nach Paris zu kommen. Persönlich ist der Tausch weniger reizvoll.“ Er wollte sich selbst aktiv an den verschiedenen Aktionen beteiligen, beziehungsweise sie maßgeblich beeinflussen, obwohl er andererseits, auf seine Insel zurückgekehrt, immer wieder feststellen mußte, daß man dort doch besser nachdenken und ruhiger miteinander reden konnte ${ }^{141}$. Er hat diese Zeit intensiv zur gedanklichen Vorbereitung des Kampfes gegen den Nationalsozialismus genutzt. Zu diesem Kampf gehörte der Versuch, eine Volksfront zu bilden, genauso wie die Planung der sogenannten Freiheitspartei und die spätere Mitarbeit an der Zeitschrift Die Zukunft. Er verstand diese Zeit mit all ihren „Episoden“ als „Vorbereitungszeit des neuen Reiches. Was ich kann, will ich dazu tun, daß es so wird“, schrieb er an Spiecker im Dezember $1935^{142}$.

Die in diesen anderthalb Jahren entstandenen Entwürfe, Analysen und Artikel ergeben zusammengenommen eine Analyse der wirtschaftlichen und politischen Lage 1935/36 vor dem Hintergrund der Geschichte des 19. und 20. Jahrhunderts ${ }^{143}$ und ein Konzept für die zukünftige politische, wirtschaftliche und soziale Verfassung Deutschlands nach Hitler. Somit enthalten diese Schriften nicht nur die gedanklichen Grundlagen für Kleppers Kampf gegen den Nationalsozialismus und die Erklärung für sein zeitweiliges Engagement für die Volksfrontidee, sondern bieten auch die Basis für das Verständnis von Kleppers publizistischer Arbeit nach dem Kriege. Darüber hinaus dokumentieren die Briefe eine rege Korrespondenz unter anderem mit Amerika, um Geld für seine Arbeit zu organisieren, mit der Schweiz, von wo er Nachrichten aus Deutschland

${ }^{141}$ Ebenda, Klepper an Spiecker, u. a. 31. 10. 1935 (Bl. 58), 24. 1. 1936 (Bl. 77). Vgl. auch Klepper an seine Schwiegertochter Mary Beth, 26. 12. 1947.

142 Ebenda, Klepper an Spiecker, 11.12. 1935 (Bl. 62).

${ }^{143}$ Ebenda. Klepper war davon überzeugt, daß zu einem Konzept für die Zukunft unabdingbar die Analyse der jeweils gegenwärtigen Realität gehörte, die wiederum nicht, wie er immer wieder betonte, ohne den historischen Rückblick zu verstehen war (Klepper, Freiheit und Volk, Bl. 137). 
erhielt, und mit Paris, um mit Spiecker, Münzenberg und anderen den Kampf gegen Hitler zu organisieren ${ }^{144}$.

Im Dezember 1936 bezeichnete er in einem Artikel mit dem Titel: „Europäische Freiheit" die europäische Politik seit 1918 „als den Abschnitt des pseudo-pazifistischen Rekonstruktionsversuches“, der sich nun „offensichtlich seinem Ende“ nähere ${ }^{145}$. Aufgrund veränderter ökonomischer Bedingungen wäre eine gesellschaftliche Umwälzung schon im 19. Jahrhundert notwendig gewesen, denn aus der Französischen Revolution sei die bürgerliche Gesellschaft und aus der industriellen das Industrieproletariat hervorgegangen, das „anstelle der Freiheit [...] die Fron des Arbeitsmarktes“ vorgefunden habe, womit wiederum eine Klasse vom Genuß der durch die Französische Revolution propagierten persönlichen Freiheit ausgeschlossen worden sei. "So entdeckte man“, nach Klepper, „daß es wirkliche persönliche Freiheit für die Masse ohne Verankerung im ökonomischen Gebiet nicht gibt“, das heißt, es könne „keine wahre persönliche Freiheit ohne Gewähr für ein Mindestmaß an ökonomischer Unabhängigkeit geben“. Claude Henri de Saint-Simon, Charles Fourier und andere französische Frühsozialisten versuchten, die Freiheit neu zu stabilisieren. Lorenz v. Stein nahm ihre Bemühungen auf und „trug in Deutschland die Theorie der sozialen Bewegung mit heute noch eindrucksvollem Appell an die Besitzenden vor", und wenn auch die damaligen Entwürfe einer neuen Gesellschaft überholt seien, so meinte Klepper, wirke doch „die hinter ihnen stehende Idee eines Sozialismus der klassenmäßigen Syntbese“ fort. Seit dem Ausbruch der russischen Revolution versuche nun die marxistische Arbeiterbewegung, „den klassenmäßig beschränkten Sozialismus" zu propagieren und zu verwirklichen, um den bisherigen Klassenfeind zu vernichten.

Entsprechend deutete Klepper das „Auftauchen“ Mussolinis, „Hitlers Berufung zur Macht“ und „was jetzt Spanien verwüstet“ als „Gegenstoß gegen die russische Revolution“, ein erneuter Sieg des „Prinzips der Unfreiheit“. „Die Erfinder der sogenannten totalitären Staatssysteme hätten versucht, die Gegensätze der Klassen durch die Mystik eines ,Führertums ' und einer ,Gefolgschaft ${ }^{c}$ fortzuillusionieren, [...] Klassengegensätze sind [aber] eine Realität. Die politische Haltung der Klassen“, die von der ökonomischen Entwicklung ,erzeugt, gehalten und zerstört“ werden, „wird durch die Lage ihrer Interessen bestimmt, [ihr] Ziel [...] ist, die politische Macht in den Dienst ihrer Interessen zu stellen. Das Spiel dieser Kräfte zu steuern, ist der Gegenstand der Politik. "146

Klepper beschreibt nun, wie die Freiheit in jedem Falle unterdrückt werde, je nachdem, welche Klasse, die „absterbende“ oder die „aufziehende“, Grundlage eines Regimes sei. Entweder versuche das Regime, „die Dynamik der Epoche zu brechen“, indem es wie im Kaiserreich versuche, der okönomischen Entwicklung und der damit ver-

${ }^{144}$ Ebenda, der 1. Brief aus Mallorca stammt vom 18.7. 1935 (Bl. 15), der letzte vom 18. 7. 1936 (Bl. 101). Außerdem liegen der Korrespondenz folgende schriftliche Ausarbeitungen Kleppers bei: 1) Bericht für Amerika (Bl. 2-14); 2) Analyse der politischen Lage, die Grundlage seines Vortrages vor dem „Lutetia-Kreis“ am 22. 11. 1935 war (Bl. 27-56); 3) Artikel: „Die Dynamik der nationalsozialistischen Wirtschaftspolitik“ (Bl. 106-131); 4) Entwurf für die Programmdiskussion der Volksfront (Bl. 81-83); 5) Programmentwurf für die Volksfront: „Die programmatische Aufgabe der Volksfront“ (Bl. 84-95); 6) Entwurf eines Freiheitsbriefes für den „Bund Freiheit und Vaterland“ (Bl. 102-104) und 7) Artikel „Freiheit und Volk“ (Bl. 137-142). Alle Texte werden im folgenden durch Blatt-Angabe zitiert.

145 Klepper in: NTB, 26. 12. 1936 (alle folgenden Zitate stammen aus dem Artikel).

146 BAP, 90 Sp2, Klepper, Freiheit und Volk, Bl. 139. 
bundenen „sozialen Umwälzung“ auszuweichen, beziehungsweise wie in der Zeit der Republik vor ihr zurückzuscheuen, oder es versuche, „eine Stufe der Entwicklung zu überspringen“ und einen nur auf eine Klasse beschränkten Sozialismus mit Gewalt durchzusetzen wie in der Sowjetunion. „Zwischen diesen Extremen“, so meinte Klepper, „liegen Übergänge“, entsprechend biete das Regime „den größtmöglichen Freiheitsgehalt [...], das auf der Synthese der Interessen der von der Entwicklung getragenen und der kommenden Klassen“ beruhe. "Jede Reaktion [dagegen] ist nur ein Versuch, den Strom des entwicklungsmäßigen Fortschritts zu stauen. Das einzig gewisse Ergebnis dieses Unterfangens ist der Bruch des Damms. “147

Aus diesem Grunde war Klepper auch fest davon überzeugt, daß das nationalsozialistische Regime früher oder später fallen mußte. So bot ihm „der Blick von 1789 auf 1937 [...] den Schlüssel zum Verständnis dafür, wie die weltpolitischen Fronten etwas zögernd, aber in einer bereits unabänderlichen Bewegung, sich herauszubilden im Begriff“ seien. Nach seiner Meinung schieden sich die Geister an der Stellung zum „Prinzip der Freiheit", das „uns zu Herren unserer Lebensführung machen“ wolle, „soweit das mit der Staatsräson vereinbar" sei. Dagegen stelle „das Prinzip der Unfreiheit, dessen lügenhaftester Ausdruck das Geschwätz von Blut und Boden ist, [...] die Staatsräson in den Dienst des Versuches, uns dieser Selbstbestimmung zu entäußern“. „Rußland“, meinte Klepper, sei „an die Sache der Freiheit gebunden“, da „das Ziel auch des klassenmäßig beschränkten Sozialismus [...] die Freiheit" sei. Deshalb müsse, selbst wenn „der abendländisch-humanistischen Welt [...] die Gesichtszüge Sowjetrußlands nicht vertraut" seien, „die Kreuzzugsparole gegen Rußland verhallen und deshalb werden“, so prophezeite er, „in der entscheidenden Stunde die Demokratien und Sowjetrußland auf derselben Seite den in der Gestalt von ,Führern' verborgenen Mächten der Unfreiheit gegenüberstehen“. Offensichtlich war Klepper sich zu dem Zeitpunkt noch nicht darüber im klaren, ob die "große strategische Wendung der Kommunistischen Partei bewußt geschieht“, ob sie auf „Erkenntnis“, „Instinkt“" oder Taktik beruhte; für ihn zählte zu dem Zeitpunkt allein die Beseitigung der reaktionären Diktatoren und die „Rückkehr zum klassenmäßig synthetischen Sozialismus“, der 1789 begonnen wurde und nun mit dem „Aufbau der europäischen Gesellschaft" vollendet werden sollte ${ }^{148}$.

Wie nun schätzte Klepper die wirtschaftliche und politische Situation in Deutschland 1935/36 ein ? $^{149}$ Die wirtschaftliche Lage entlarvte er als "künstliche Konjunktur“. Der zweifellos feststellbare und von Klepper mit Zahlen belegte wirtschaftliche Aufschwung habe zwei Ursachen, zum einen werde „das neue Regime [...] von weiten Kreisen aller Schichten mit großer Hoffnung begrüßt; es hatte von vornherein einen gewissen goodwill. Hieraus gewannen Produktion und Konsum einen neuen Antrieb“, zum anderen, und das sei „die wesentliche Ursache der Besserung“, habe es „alle die Maßnahmen, die man unter dem Begriff der Arbeitsbeschaffung von Staats wegen zusammenfassen“ könne, ergriffen ${ }^{150}$. Diese hätten mit Beihilfen zur Instandsetzung von Häusern begon-

147 Ebenda.

148 Klepper, Europäische Freiheit (NTB). Zur Diskussion seiner Einschätzung Rußlands und der Ziele der Kommunistischen Partei vgl. weiter unten die Diskussion zum Versuch der Volksfrontbildung 1935/36.

149 Vgl. vor allem die Berichte nach Amerika, Bl. 2 ff., 27 ff., 63 ff., 106 ff., sowie: „Die Aufgabe der Volksfront" und "Freiheit und Volk" (BAP, $90 \mathrm{Sp} 2)$.

150 Ebenda, Bl. 2 f. 
nen, sich mit der Förderung der Ersatzstoffindustrie gesteigert und sich schließlich vor allem auf die Rüstungsindustrie und alles, was mit dem Heerwesen zu tun habe, konzentriert. Im einzelnen wies Klepper die Finanzierung durch Arbeitsbeschaffungs- und Rüstungswechsel sowie andere Finanzierungsmittel nach und gelangte zu dem Schluß, daß die ganze Konjunktur, die von vielen Deutschen als „echt“ bezeichnet werde, trotz einer Steigerung des Konsums und der Verminderung der Arbeitslosigkeit „künstlich“ genannt werden müsse ${ }^{151}$. Künstlich, weil sie in dem Augenblick zusammenbreche, wenn „die Aufrüstung ihre natürliche Grenze“ erreicht habe und die „Finanzierungsmöglichkeiten des Staates“ erschöpft seien; künstlich auch, weil das nationalsozialistische Regime den Aufschwung nicht genutzt habe, um an „der falschen Grundtendenz der deutschen Wirtschaftspolitik“ etwas zu ändern ${ }^{152}$. Weder habe es eine Strukturreform auf dem Agrarsektor und in der Schwerindustrie durchgeführt ${ }^{153}$, noch habe es die zu Ende der Republik bereits aufkommenden „Autarkiebestrebungen“ nicht nur nicht abgebaut, sondern durch den Ausbau des handelspolitischen Gegenseitigskeits- statt des Meistbegünstigungsprinzips, durch zollpolitischen Schutz statt Öffnung des nationalen Marktes noch verstärkt ${ }^{154}$. Kleppers Einschätzung der wirtschaftlichen Lage unterscheidet sich nicht grundlegend von der anderer Emigranten, geht aber viel mehr ins Detail und bezieht auch die vor 1933 angelegten, nun weiterwirkenden strukturellen wirtschaftlichen Mängel mit ein. Vor allem aber diente ihm die Analyse des augenblicklichen Zustandes als Kontrastfolie für Reformen in der Zeit nach dem Nationalsozialismus ${ }^{155}$.

Ausgehend von der Tatsache, „daß das deutsche Volk auf einem engen Raum, der nicht mit bemerkenswertem natürlichem Reichtum ausgestattet ist, eingezwängt " lebt, gebe es „zwei entgegengesetzte politische Konzeptionen“, die „beide expansiv“ seien, um auf diese Situation zu reagieren. Die eine, die Klepper „die hanseatische Konzeption“ nannte, ziele auf eine „optimale Ausnutzung der eigenen Produktionsmittel durch volle Eingliederung in das weltwirtschaftliche Spiel“ und strebe somit „die Erweiterung der deutschen Basis auf dem Wege der kommerziellen Expansion“ an. Die andere, „die alldeutsche“ Konzeption erstrebe dagegen „die territoriale Ausdehnung der Volkswirtschaft" mit dem „Endziel [...] eines relativ autarken, großdeutschen Wirtschaftsraumes“, der praktisch nur durch Krieg zu erreichen sei ${ }^{156}$. „Beide Konzeptionen schließen sich gegenseitig aus.“ Nur in der Ära Stresemann sah Klepper Ansätze für eine „kommerziell-expansive Richtung“, die aber schon in der „Ära Hindenburg schnell abgedrängt" wurde ${ }^{157}$ und nun endgültig aufgegeben worden sei. Die Ankurbelung der Konjunktur ohne gleichzeitige Wirtschaftsreformen hat zu einer so großen Staatsverschuldung, nämlich von „20 Milliarden RM fester Schuld und 16,5 Milliarden RM schwebender Schuld“"158, geführt, daß, so vermutete Klepper, „in einem demokratischen Staat [...]

${ }^{151}$ Ebenda, Bl. 30.

152 Ebenda, Bl. $3 \mathrm{f}$.

${ }^{153} \mathrm{Vgl}$. ebenda ausführlich: Bl. $30 \mathrm{ff}$.

154 Ebenda, Bl. 49.

${ }^{155}$ Vgl. dazu Langkau-Alex, S. $96 \mathrm{ff}$.

156 BAP, 90 Sp2, B1. 142.

157 Ebenda, Bl. $33 \mathrm{f}$.

158 Ebenda, Bl. 53 f.: „Diese Beträge sind Mindestschätzungen, die hinter den in Berliner Großbankenkreisen kursierenden Ziffern weit zurückbleiben. Die Unterstellung einer Fehlergrenze nach oben von 10 bis $20 \mathrm{v}$. H. dürfte deshalb nicht übertrieben sein." 
unter gleichen Verhältnissen wahrscheinlich schon längst eine offene Inflation ausgebrochen [wäre]. In Deutschland wird die Lage bisher nur durch das merkwürdige, an das Mystische grenzende Vertrauen gehalten, welches das Volk zu der Person Hitlers hat; er verspricht immer wieder, es kommt keine Inflation, und man glaubt ihm. "159

Wenn Klepper auch nicht von einem theoretischen Ansatz ausgegangen ist wie Kirchheimer, sondern eher aus der Beobachtung und seiner politischen Erfahrung heraus geurteilt hat und dabei nicht zu so umfassenden Analysen wie Kirchheimer gelangt ist, so kommt er doch zu einem ähnlichen Fazit wie dieser: „Soweit die Änderungen des Verwaltungs-, Arbeits- und Bauernrechts den Anschein erwecken, als ob Linderung der durch die Krise hervorgerufenen wirtschaftlichen Schwierigkeiten beabsichtigt wäre, haben sie nur persönliche Umschichtungen, das heißt Besserung von Einzelexistenzen in der Wirtschaft und Bürokratie auf Kosten der Allgemeinheit hervorgerufen. Der Mißerfolg der Maßnahmen, welche die Regierung Hitler zur Behebung der Krise anwandte, wird offenkundig. Das kann" so fügte Kirchheimer in seinem um die gleiche Zeit wie Klepper, 1935, geschriebenen Aufsatz hinzu, „den nicht überraschen, der den Nationalsozialismus seiner politischen Herkunft nach als reaktionär und seinem gesellschaftlichen Auftrag nach als ausschließlichen Vertreter der Interessen einer hauchdünnen Oberschicht erkennt." 160

Zusammengefaßt sah Kleppers Lagebericht folgendermaßen aus: „Das nationalsozialistische Regime ist insofern stabilisiert, als es in vollem Besitz der Machtmittel ist und einer aktivistischen Opposition nicht gegenübersteht. Es ist aber insofern nicht stabilisiert, als es im Bewußtsein des Volkes noch keineswegs als etwas Endgültiges, Selbstverständliches verankert ist. In eigentlich allen Schichten der Bevölkerung herrscht eine ständige Spannung. Man wartet auf irgend etwas Neues; man fragt, wie einer meiner Freunde sich ausdrückte, immer noch: ,werden die Nazis es schaffen?' Gleichzeitig hat das Regime aber mit einer weitverbreiteten Mißstimmung zu kämpfen“, die „sich aber nur gegen das Regime, nicht gegen die Person Hitlers“ richtet; daneben „herrscht unter den unmittelbaren Nutznießern, dem riesigen Funktionärsapparat, Begeisterung “161.

Damit sah Klepper schon 1935 klar voraus, worauf die nationalsozialistische Politik hinauslief, um so mehr, als er erkannte, daß einerseits „die Nationalsozialisten gewiß bereit sind, große Opfer zu bringen, um an der Macht zu bleiben“, andererseits aber unfähig „zu einer allgemeinen außenpolitischen Verständigung“, so daß ein „allgemeiner europäischer Konflikt" praktisch vorprogrammiert sei, allein schon deshalb, weil die Nationalsozialisten damit versuchen, „den inneren Schwierigkeiten aus dem Wege zu gehen “. Diese Situation könne, so meint Klepper, jederzeit eintreten, und dann ergäbe sich „die Chance für den Sturz Hitlers, [...] gewissermaßen über Nacht“. Für diesen Augenblick gelte es gerüstet zu sein ${ }^{162}$.

Im nachhinein wird immer wieder kritisiert, daß die Emigranten die Lage in Deutschland falsch eingeschätzt hätten, so wie es Klaus Harpprecht beschrieb: „Heinrich Manns Täuschungen - nicht nur die seinen - über die vermeintliche Schwäche der Diktatur wa-

159 Ebenda, Bl. 11.

160 Kirchheimer, Staatsgefüge. Vgl. dazu den Aufsatz von Saage, der Kirchheimers Analyse mit kontroversen Thesen Ernst Fraenkels, Friedrich Pollocks und Max Horkheimers vergleicht sowie mit anderen totalitarismustheoretischen Ansätzen.

161 BAP, $90 \mathrm{Sp} 2, \mathrm{Bl} .7 \mathrm{ff}$.

162 Ebenda, Bl. 5, 7 und 11. 
ren schrecklich. Sie erklärten sich aus der Trauer und aus der Einsamkeit, die das Geschick fast aller Emigranten bestimmten. Sie wollten nicht wahrhaben, daß sich die Herrschaft Hitlers bis tief in den Krieg auf eine wachsende Zustimmung der Deutschen stützte. Sie wußten es nicht. Sie wollten es nicht wissen. " 163 Auffällig bei dieser Beurteilung ist einmal der fast mitleidige Ton, zum anderen wird unzulässig verallgemeinert, ie unzählige Beispiele, nicht nur das Kleppers, zeigen, und drittens saßen die Emigranten nicht in einem neutralen Warteraum, aus dem sie abgeholt werden würden, wenn, der Spuk' vorüber war, sondern sie haben in ihren jeweiligen Gastländern unter den dort jeweils herrschenden politischen Bedingungen gegen das Hitlerregime gekämpft, vor ihm gewarnt, sich damit häufig unbeliebt gemacht und versucht, die Menschen innerhalb Deutschlands aus ihrer Lethargie zu reißen, wofür sie einen gewissen Zweckoptimismus brauchten.

Ausgehend von der Analyse der politischen und wirtschaftlichen Lage Nazideutschlands vor dem entsprechenden historischen Hintergrund, war für Klepper der nächste Schritt die Erarbeitung eines Rahmenprogramms, und zwar einmal, um für die Sammlung aller Gruppierungen klare Richtlinien, und zum anderen, um im Falle eines Endes der nationalsozialistischen Herrschaft ein Konzept zum Handeln und eine Basis für eine neue Verfassungsdiskussion zu haben. Unter dem Titel „Die programmatische Aufgabe der Volksfront" entwarf er ein solches Rahmenprogramm, das er in seinem Artikel „Freiheit und Volk“ noch weiter präzisierte. Vier Punkte galt es vorrangig zu klären: „1. den verfassungsmäßigen Charakter des Staates, 2. die Wirtschaftspolitik, 3. die auBenpolitische Richtung und 4. den Schutz vor Gegenrevolution“164. Ausgangspunkt und Ziel aller Überlegungen war für Klepper die Freiheit, doch da, wie „der Leidensweg des deutschen Volkes“ gelehrt habe, „die staatsrechtliche Proklamation der Freiheit allein eine leere Form ist", müsse man einen Schritt weitergehen. Klepper definierte Freiheit in einem erweiterten aktiven Sinne, indem er sie als „Möglichkeit, die eigene Persönlichkeit zu entfalten“, bezeichnete. Diese "Chance [aber tatsäcblich] zu eröffnen, ist nur eine Staatsmacht imstande, die sich mit den gesellschaftlichen Schichten verbindet, deren Lebenskraft dem Zuge der Entwicklung selbst entstammt; denn nur eine solche Staatsmacht steht unter dem natürlichen Gebot, auch die wirtschaftliche Grundlage des Volkslebens den Bedürfnissen dieser Entwicklung anzupassen. Ohne Verankerung in diesem Grunde aber gibt es nun einmal keine Freiheit." 165

Die nächste Frage sei, welche „sozialen Schichten in dieser Weise gegenwärtig zur Macht berufen sind“? Die „überkommene klassenmäßige Einteilung" hilft nach Kleppers Meinung nicht weiter, denn weder bestimmen „die Gegenüberstellung von Bourgeoisie und Proletariat“ oder von „Besitz und Besitzlosigkeit [...] die sozialen Standorte verläßlich“, noch seien „die gesellschaftlichen Wandlungen, welche die Nachkriegszeit begleiten, abgeschlossen“ oder hätten gar im „Bewußtsein der Betroffenen einen endgültigen Niederschlag gefunden“. „Wir benötigen“ deshalb, so meinte Klepper, „ein anderes Merkmal.“ Er versuchte dieses aus der „Erfahrung des letzten Vierteljahrhunderts“,

${ }^{163}$ Harpprecht, Bruder Heinrich, in: Die Zeit, 21. 2. 1992, S. 72.

${ }_{164}$ BAP, 90 Sp2, Bl. 88.

${ }^{165}$ Ebenda. Wie der Rechtsstaat die staatsbürgerliche Freiheit garantiert, definierte Klepper so: „Die Unantastbarkeit von Person, Heim und Eigentum; die Gleichheit Aller vor dem Gesetz ohne Ansehung des Standes, der Religion und der Rasse; die Freiheit des Denkens und Glaubens, des Wortes und der Vereinigung" (BL. 140). 
also seit dem Beginn des Ersten Weltkrieges, zu entwickeln und kam zu dem Ergebnis, daß „die Gesamtheit der Gehalts- und Lohnempfänger, die Angehörigen der freien geistigen Berufe, die gewerblichen Mittelschichten und das Bauerntum existenzmäßig bedingt sind durch ihre individuelle Leistung, nicht durch die Arbeit ihres Kapitals“. Da dieser „akapitalistische Teil des Volkes“ aber „der geistigen Planung, der organisatorischen Anlage und der Ausführung nach den wesentlichen Teil der nationalen Arbeitsleistung" bewirke, stehe er, „von keinem rückläufigen Interesse gefesselt $[, \ldots]$ bereits auf der sich neu entwickelnden Grundlage“ und qualifiziere sich damit als „Repräsentant des kommenden Regimes"166.

Da „im freiheitlichen Staat [...] die Freiheit der staatsbürgerlichen Willensbildung eine politische Notwendigkeit“" sei und „sein Ziel ist, den entwicklungsmäßig lebendigen Kräften Spielraum zu schaffen“, „benötigt der freiheitliche Staat eine Volksvertretung, deren Wirksamkeit die langfristige Dynamik des Regimes mit den Bewegungen der öffentlichen Meinung verbindet“, das bedeute, wie es im Entwurf für die Volksfront heißt, in einer „Demokratie der Arbeitenden“ müsse „die politische Macht [...] in den Händen der Schichten des Volkes liegen, deren wesentliche Einkommensquelle ihre Arbeitskraft ist", und das seien nach Klepper 70 bis $80 \%$ der Bevölkerung ${ }^{167}$. Deshalb sollte neben das durch allgemeines, gleiches, direktes und geheimes Wahlrecht gewählte Parlament eine „erste Kammer“ von „100 Mitgliedern (Mindestalter 40 Jahre) " treten, in der die Repräsentation der oben erwähnten Schichten gewährleistet sei. Sie werden durch die „Berufsgenossenschaften“ gewählt und abberufen. „Die Beschlüsse der Volksvertretung kommen nur durch Übereinstimmung beider Häuser zustande.“ Die Tatsache, daß Klepper die Kammern auch „Ober- und Unterhaus“ genannt hat ${ }^{168}$, gibt den Hinweis auf das englische System und erläutert seine Vorstellung, daß er auf diese Weise einer parteilich nicht gebundenen Elite politische Mitsprache verschaffen wollte. Nur rekrutierte ,seine' Elite sich nicht aus dem Adel, mit dem Deutschland in den letzten Jahrzehnten nicht die besten Erfahrungen gemacht hatte, sondern aus den ,Besten' jeden Berufsstandes, also eine Art Wirtschaftselite, die sich aber nicht nur aus der ,Managerkaste‘, sondern aus allen sozialen Schichten rekrutieren und zur Zusammenarbeit im Sinne des Gemeinwohls verpflichtet sein sollte.

Es wäre zwar verkehrt, hier direkt an den Gedanken des Kooperativstaates anknüpfen zu wollen oder an Vorstellungen von Bismarck oder auch des Vereins für Sozialpolitik ${ }^{169}$, aber es läßt sich nicht leugnen, daß Kleppers Denken hier noch im 19. Jahrhundert verhaftet war. Hinzu kommt, daß die negativen Erfahrungen mit den Parteien zur Zeit der Weimarer Republik Kleppers Vertrauen in die Kontrollmechanismen der parlamentarischen Demokratie nicht gerade gestärkt haben. Er bedachte nicht, daß seine Vorschläge sehr wohl auch für undemokratische Ziele hätten benutzt werden können. Klep-

166 Ebenda, vgl. auch den Volksfrontentwurf, dort zählte Klepper folgende Gruppen auf: „Arbeiter, Angestellte, Beamte, gewerblicher Mittelstand, Bauern, Intellektuelle und Künstler, Universitäten, Religionsgesellschaften“ (Bl. 88).

${ }^{167}$ Ebenda, Bl. 141, 88 und 86: „Begreift man den Sozialismus vormarxistisch, schlechthin als eine nur auf der Arbeit beruhende Ordnung des Besitzes, so ist sogar eine ausgesprochen sozialistische Tendenz sichtbar, wie das der sozialen Struktur entspricht."

${ }^{168}$ Ebenda, Bl. 141. Die Wahl kann auf Lebenszeit sein, und „das Staatsoberhaupt kann bewährte, aber nicht mehr aktive Politiker in das Oberhaus berufen".

$169 \mathrm{Vgl}$. Dahrendorf, Gesellschaft und Demokratie in Deutschland, München 1966, S. $50 \mathrm{ff}$. 
per war kein Theoretiker, ihm dienten wirtschaftliche, soziale oder politische Theorien als eine Art Steinbruch, aus dem er sich das herausholte, was er meinte für die jeweilige Situation brauchen zu können. Er dachte pragmatisch und suchte pragmatische Lösungen. Seine Vorschläge, wie auch dieser, setzen bei den Betroffenen stets ein gewisses Verantwortungsbewußtsein für das Gemeinwohl voraus. Das wichtigste Anliegen war ihm, daß diejenigen, die die Hauptarbeit für die Gesellschaft leisteten, auch an ihrer Mitgestaltung beteiligt sein sollten. Im übrigen bleiben seine Vorstellungen in diesem Punkt sehr vage. Auch sein Vorschlag, die Länder in Verwaltungsbezirke umzuwandeln ${ }^{170}$, ist zu kritisieren, denn dies käme einer Abschaffung des Föderalismus und damit der Beseitigung einer weiteren Kontrollinstanz gleich. Dieser Idee, die er durch die Forderung ergänzte, Preußen aufzulösen und aus Berlin einen eigenen Verwaltungsbezirk zu machen, ist ganz offensichtlich auf seine Erfahrungen während des Staatsstreiches von 1932, als die Länder als Kontrollinstanz versagt hatten, zurückzuführen.

In Bezug auf den Reichspräsidenten schlägt Klepper vor, daß dieser nicht vom Volk, sondern von beiden Kammern gewählt werden sollte. Alle Volks- und Regierungsvertreter sollten „bei ihrer Nominierung auf Wahrung der Verfassung und auf Unterdrükkung reaktionärer Tendenzen vereidigt werden“, und als Grundrechte könnten im wesentlichen die der Weimarer Verfassung gelten. Weitere Bestimmungen waren: „Trennung von Staat und Kirche“ und die „Unterordnung der Armee unter die politische Führung, auch bei Ausnahmezustand"171.

„Die wirtschaftspolitische Neugestaltung, welche die Errichtung des freiheitlichen deutschen Staates zu begleiten hat, richtet sich nach dem Bedürfnis der sozialen Schichten, die ihn tragen. Wohlstand bringt Freiheit, Armut erzeugt Knechtschaft"; entsprechend sollten nach Klepper die beiden vorrangigen Ziele einer künftigen Wirtschaftspolitik „die Erhöhung des Ertrages der Volkswirtschaft und die dem geleisteten Beitrag entsprechende gerechte Beteiligung des einzelnen“ sein, was vor allem durch eine Priviligierung des „Arbeitseinkommens gegenüber dem Kapitaleinkommen“ erreicht werden solle. Neben die „größtmögliche Beteiligung aller Arbeitenden am volkswirtschaftlichen Ertrag“ stellte Klepper das Ziel der „optimalen Eingliederung der deutschen Wirtschaft in den weltwirtschaftlichen Güteraustausch“, wozu es einer von Klepper bereits zur Weimarer Zeit geforderten Strukturreform auf dem Agrar- und dem Industriesektor bedürfe ${ }^{172}$. „Den privatwirtschaftlichen industriellen Sektor“ wollte Klepper zur "Veröffentlichung von Bilanz und Ertragsrechnung“ verpflichten und „eine Änderung der Ertragsordnung in der Weise [erreichen], daß die Rangfolge ist: Reserven, Lohn und Gehalt, Kapitalzins“. Schließlich solle „die prinzipielle Linie der Steuerpolitik [...] zur Entlastung des Verbrauchs und innerhalb des Bereichs der direkten Steuer von der Entlastung des Einkommens zur Belastung des Besitzes, insbesondere beim Erbfall“ führen, im landwirtschaftlichen Bereich solle nur eine „progressive Grundsteuer erhoben werden" ${ }^{173}$.

In der Außenpolitik plädierte Klepper für den „Wiederanschluß an den Völkerbund. Keine territoriale Expansion. Dagegen allgemeine Rückkehr zum Prinzip der offenen

\footnotetext{
170 BAP, $90 \mathrm{Sp} 2, \mathrm{~B} 1.88$.

171 Ebenda.

172 Ebenda, Bl. $89 \mathrm{ff}$. und $141 \mathrm{f}$.

173 Ebenda, B1. 91.
} 
Tür“, und natürlich „die Eingliederung Deutschlands in ein friedliches Europa“. „Zur Abwehr gegenrevolutionärer Bestrebungen“ empfahl Klepper detaillierte Maßnahmen zur gerichtlichen Verfolgung und vor allem zur konsequenten Ausschließung aller ehemaligen Nationalsozialisten und ihrer Kollaborateure, sowie die Absetzbarkeit von Beamten $^{174}$

Dieser Programmentwurf setzt bei aller Kürze und erkennbaren Kompromißbereitschaft doch einige klare Akzente, die nicht als ein Nachgeben gegenüber kommunistischen Forderungen zu verstehen, sondern durchaus auf eigene Vorstellungen Kleppers zurückzuführen sind, die er schon früh entwickelt und auch zur Grundlage seiner Politik in der Weimarer Zeit gemacht hatte. Besonders auffällig ist zum einen seine Entschiedenheit, die tatsächliche Ausübung der politischen Macht der tatsächlichen Zusammensetzung der Gesellschaft anzupassen, wobei sein Ansatzpunkt eher praktisch als theoretisch ist, und zum anderen sein Versuch, gegen den allzu beherrschenden Einfluß der politischen Parteien ein Gegengewicht zu schaffen, da diese nach seiner Meinung die Ideologie des Klassenkampfes oft über die eigentlichen Bedürfnisse der Menschen stellten und in keiner Weise die ganze Breite der Bevölkerung repräsentierten.

Die Frage, wer die Liquidation des nationalsozialistischen Erbes und den Neuaufbau danach übernehmen sollte, hat Klepper sehr beschäftigt, und er hat sie im Zusammenhang gesehen mit der Frage, welche Rücksichten man auf typisch deutsche Neigungen zu nehmen habe. Als einen wesentlichen Umstand bezeichnet er die Tatsache, daß die Deutschen keine „Rationalisten wie etwa die Franzosen“ seien und deshalb „das politische Handeln in einer metaphysischen Verbindung sehen " müßten. Da besonders nach „der Zwangsjacke des Hitlerismus [...] die natürlichen Individualitäten wieder verstärkt zum Vorschein kommen“" werden, wird „das vierte Reich von einer ausgesprochenen Toleranz gegenüber den ideologischen Niederschlägen sein müssen, die der besonderen Zusammensetzung des deutschen Volkes entsprechen. [...] Gerade weil wir verschiedenartige ideologische Dispositionen in einer bestimmten Richtung konkretisieren müssen, brauchen wir aber kein Programm von weltanschaulicher Färbung. Wir könnten so etwas gar nicht gebrauchen.“ Es könne sich nur darum handeln, „die ideologischen Voraussetzungen innerhalb des religiösen und des intellektuell-liberalen Sektors im Sinne des sozialen Freiheitsgedankens zu fruktifizieren, also das zu schaffen, was in der Republik embryonal geblieben ist"175. Eine „Wiederbelebung der christlichen Religiosität als Gegenwirkung gegen den nazistischen Barbarismus und das ,Neuheidentum “ könne er sich noch am ehesten vorstellen ${ }^{176}$. Auf der anderen Seite neigten die Deutschen seiner Meinung nach zu „sachlicher Systematik, die von dem nervös-unklaren Mystizismus der Nationalsozialisten nur zeitweilig übertönt werden konnte", so daß schließlich der Wunsch nach einer klaren und nach außen friedlichen Regelung der deutschen Verhältnisse wieder durchkommen werde.

Wer sollte dieses Programm in dem künftigen Deutschland realisieren helfen? Klepper hielt es für „absolut utopisch, zu glauben, unsere republikanischen Parteien seien zu regenerieren “177, denn es sei „auf absehbare Zeit unmöglich [...], daß eine der Parteien, die

\footnotetext{
${ }^{174}$ Ebenda, Bl. 92 f. und 13 (Europa).

175 Ebenda, Klepper an Spiecker, 16. 4. 1936 (Bl. 97 f.).

176 Ebenda, Bl. 12.

${ }_{177}$ Ebenda, Klepper an Spiecker, 16. 4. 1936 (Bl. 97).
} 
[...] von den Nationalsozialisten in der bekannten beschämenden Weise geschlagen worden sind, in der Volksstimmung soviel Kredit finden wird, daß sie die Führung des neuen Staates übernehmen könnte. Das gilt besonders von den Sozialdemokraten“, die zwar gewiß noch Anhänger hätten und neue gewinnen werden, aber die, so meinte er, „nicht die Kraft [bätten], die Former des kommenden Neuen zu werden. Daran wird sie [...] die kampflose Kapitulation von ehemals" hindern. Dieses Urteil ist offensichtlich stark von seinen eigenen Erfahrungen vor allem im Juli 1932 geprägt, aber auch von dem Bild, das die Exil-SPD im Jahre 1935 bot: in sich uneins, zögernd und mutlos. Klepper stellte sich als geeignetste Gruppierung eine vor, die von einer „christlich-sozialen Grundposition“ ausgeht, „denn es ist von dieser Plattform aus ebenso möglich, den Kontakt zu halten mit Sozialisten wie mit Konservativen“, und die konfessionelle wie die landsmannschaftliche Vielfalt der Deutschen könnte so am ehesten berücksichtigt werden. Außerdem sah Klepper hier noch den brauchbarsten Ansatzpunkt, um eine Oppositionsbewegung im Reich von „draußen“ politisch zu aktivieren. Im ganzen glaubte er trotz partieller Unzufriedenheit in einzelnen Schichten der Bevölkerung und trotz der Untergrundorganisation der Kommunistischen Partei nicht an einen Sturz des Regimes von innen ohne Hilfe von außen ${ }^{178}$.

Betrachtet man die politischen Vorstellungen Kleppers und berücksichtigt man sein traditionelles Mißtrauen gegen jegliche Ideologie und die sie vertretenden Parteien, kann man verstehen, daß Klepper zunächst, wie viele andere bürgerliche Demokraten, dem Gedanken einer Volksfront gegenüber aufgeschlossen war und versucht hat, mit Münzenberg und anderen zusammen ein brauchbares Instrument im Kampf gegen das NSRegime aus ihr zu formen ${ }^{179}$. Er machte sich keine Illusionen über die Wirkung der Volksfront nach außen, im Dezember 1935 schrieb er an Münzenberg: „Nüchtern gesehen wird man sich sagen, daß sich eine Anzahl politischer Einzelgänger um die Kommunistische Partei gruppiert hat, um gegen den Nationalsozialismus zu protestieren." Mit einem solchen Image aber sei die Volksfront als Instrument unbrauchbar, sie müsse vielmehr „dokumentieren, daß die beiden sozialistischen Parteien und die gesamte nichtreaktionäre bürgerliche Welt einen Pakt geschlossen haben, dessen Grundrisse klar erkennbar sind“ "180. Dazu bedürfe es eines klar umrissenen Programms, nicht langatmiger Verfassungsentwürfe ${ }^{181}$, sondern allgemeinverständlicher Richtlinien. Nur wenn man diese klar herausstelle, sei eine Chance gegeben, den „Bolschewistenschreck“ sowohl bei den Sozialdemokraten wie vor allem bei den Bürgerlichen, die „bisher überhaupt noch nicht organisiert" seien, zu überwinden. „Macht man aber den Versuch, entweder die früheren Liberalen, oder die Katholiken, oder die renitenten Protestanten als Einzelgruppen zu organisieren, so wird man wenig Erfolg haben, denn weder die Liberalen,

${ }^{178}$ Ebenda, Bl. $7 \mathrm{ff} ., 11 \mathrm{ff}$.

179 Vgl. dazu: Langkau-Alex, S. $136 \mathrm{ff}$.

${ }^{180}$ BAP, 90 Sp2, Klepper an Münzenberg, 28. 12. 1935 (Bl. 75 f.).

${ }^{181}$ Er spielte wohl auf die beiden Verfassungsentwürfe von Georg Bernhard und Leopold Schwarzschild (abgedruckt bei Langkau-Alex, Anhang, S. 183 ff.), und auf Emil J. Gumbels, von Heinrich Mann ergänztes Mindestprogramm (Langkau-Alex, S. 179 ff.), an, das ihn „einigermaßen entsetzt“ habe, „eine Mischung von alten sozialdemokratischen Requisiten und Emigrantenressentiment“. Er zeigte sich „erschrocken darüber, daß Heinrich Mann es als ausgezeichnet bezeichnet" habe, aber, so fuhr er fort, „auch das werden wir überstehen" (Klepper an Spiecker, 24. 1. 1936, Bl. 77 f.). Zu Gumbel vgl.: Brenner. 
noch die Katholiken, noch die Bekenntnisfreunde werden glauben, daß sie imstande seien, das System umzuwerfen. “ Die einzige wirklich effiziente Untergrundorganisation im Reich sei zur Zeit die der kommunistischen Partei. Folglich gebe es nur die Möglichkeit, wolle man die bürgerlichen Kreise aktivieren und vermeiden, daß sich „die oppositionellen Kräfte in Deutschland“ ebenso wie „bisher“ in der Emigration „zum großen Teil gegenseitig aufheben“, ein Programm aufzustellen und dann eine „Koalition von der Art der Volksfront" zu bilden ${ }^{182}$.

In diesem Zusammenhang machte Klepper im Dezember 1935 seinen oben skizzierten Vorschlag zur Schaffung einer Volksfront ${ }^{183}$, nachdem er bereits am 26. September zu der ersten Sitzung des „Lutetia-Kreises“, benannt nach dem Tagungsort Hotel Lutetia, das makabererweise später das Hauptquartier der Gestapo werden sollte, am 26. September 1935 eingeladen worden war. Zwar konnte Klepper zu dieser „erste[ $n]$ größere $[n]$ politische $[n]$ Sitzung in der Emigration " ${ }^{184}$ wegen einer Verabredung in der Schweiz nicht kommen ${ }^{185}$, doch wurde er in das „kleine Büro“ gewählt, wodurch er sich in eine „schwierige Lage“ versetzt fühlte. „Auf der einen Seite glaube ich, daß man sich sachlich in der richtigen Linie bewegt hat. Auf der anderen Seite ist die personelle Zusammensetzung des Gremiums [...] wenig repräsentativ. Solange ich in Palma sitze, kann es meines Erachtens nur schädlich sein, wenn ich dem Ausschuß angehöre. Käme ich nach Paris, so würde sich die Sache vielleicht anders ansehen lassen. Ich denke es mir nicht schwer, entscheidenden Einfluß zu gewinnen und das Ganze dann glücklicher auszubauen." 186 „Aus der geräumigen Distanz" seiner Insellage, wie er es selbst nannte ${ }^{187}$, scheint er die Schwierigkeiten etwas unterschätzt zu haben. Der Prager Parteivorstand der SPD wollte sich nicht mit der KPD einigen; einmal saß das aus der Zeit der Weimarer Republik stammende Mißtrauen gegen die Kommunisten noch zu tief, zum anderen fürchtete man, dadurch die Bürgerlichen zu verlieren. Allerdings war, wie ein Brief Rudolf Breitscheids, des führenden Kopfes der Pariser SPD-Gruppe, an Wilhelm Hoegner beweist, das Zutrauen zu den Bürgerlichen auch nicht sehr groß. Er sei, so schrieb Breit-

182 BAP, 90 Sp2, Klepper an Münzenberg, 28. 12. 1935 (Bl. 75 f.).

${ }^{183}$ Seit dem Sommer 1935 tauschten Klepper und Münzenberg Informationen und Gedanken aus (Klepper an Spiecker, 2. und 8.8. 1935). Münzenberg schickte ihm alle Einladungen, Rundschreiben etc. und plante, Klepper in Barcelona oder Madrid zu treffen, um in Ruhe reden zu können, wofür Klepper ihm spanische Einladungen besorgte, doch wurde aus dem Treffen nichts (18.5. 1936, B1. 99, BAP, 90 Sp. 2).

${ }^{184}$ Langkau-Alex, S. 86. Die Liste der Teilnehmer ist abgedruckt bei: Pech, Exil, S. 520, Anm. 11: Es sind 22 Sozialdemokraten, 4 Funktionäre der KPD und 25 Persönlichkeiten aus anderen politischen Richtungen, Klepper wird nicht genannt.

${ }^{185}$ Das Treffen mußte allerdings kurzfristig wegen Vladeck auf den 16. September verschoben werden. $\mathrm{D}_{\mathrm{a}}$ Klepper erkrankte, mußte er bei Freunden in Winterthur bleiben. „Auf diese Weise konnte ich Münzenberg mit gutem Gewissen absagen (Klepper an Spiecker, 4. 10. 1935, Bl. 57). Somit stimmt die Angabe von Langkau-Alex (S. 86) u. a., Klepper habe teilgenommen, nicht. Vgl. außerdem zum Besuch in der Schweiz und der parallelen Sitzung in Paris: Klepper an Spiecker, 21./22. und 28.8. sowie 2. und 9. 9. 1935.

186 BAP, 90 Sp2, Klepper an Spiecker, 4. 10. 1935 (Bl. 57), vgl. Pech, Exil, S. 90: außer Klepper gehörten H. Mann (Leiter), G. Bernhard, Max Braun, Emil J. Gumbel, W. Münzenberg, L. Schwarzschild und 2 namentlich noch nicht festgelegte Vertreter der Katholiken und der Gewerkschaften zum Kleinen Büro, „das weitere Zusammenkünfte organisieren sollte“. Vgl. Bilder und Kurzbiographien der genannten Personen bei: Sassin.

${ }^{187}$ Ebenda, Klepper an Spiecker, 16. 4. 1936 (Bl. 97). Vgl. auch Brief vom 24. 1. 1936 (Bl. 77). 
scheid, „gegen eine Front mit den Bürgerlichen ohne vorherige Verständigung, denn die Bernhard, Klepper, Schwarzschild und anderen, die man heranzieht, vertreten nichts als sich selbst" 188 .

Klepper hatte bald selbst Gelegenheit, sich einen Eindruck zu verschaffen, er sollte auf der zweiten Sitzung des „Lutetia-Kreises“, am 22. November 1935, einen Vortrag über die wirtschaftliche und finanzielle Lage in Deutschland halten ${ }^{189}$. Klepper wunderte sich in einem Brief an Münzenberg, daß dieser 40 Leute eingeladen hatte, ,ich kann mir gar nicht denken, daß es in Paris so viele Leute gibt, bei denen man offen reden kann “ ${ }^{190}$. Vielleicht konnte man ja offen miteinander reden, aber ob man einander verstand, bleibt zweifelhaft. Maximilian Scheer gibt einen Stimmungsbericht der Sitzung: „Ich sehe noch vor mir einen Saal mit vielen Menschen: nicht eigentlich einen Saal, vielmehr zwei große, mit breiter Öffnung verbundene Räume [...] Am Tisch der Leitung sitzt und spricht Heinrich Mann: souverän, verhalten, überlegen, präzis gegenwärtig und immer wie aus einer Welt der Vision - der dichterischen Vision vom kommenden Deutschland. [...] Ich sehe Männer um und an dem Vorstandstisch. Einige sind sehr geschäftig. Sie flüstern einander zu, ihre Blicke sind flink, spähend, hektisch, zielstrebig - wie Insekten um das ruhige Licht des souveränen Dichters. Einen erkenn ich noch. Es war Leopold Schwarzschild. [...] Dieses Irrlicht flatterte, flackerte um den Vorstandstisch. Es verirrte sich bald wieder in völliger Isolation." ${ }_{191}$ Wenn man den Bericht von Langkau-Alex liest, so muß es ein fürchterliches Durch- und Gegeneinander gewesen sein. Die Tagesordnung war umgestellt worden, so daß Klepper seine Rede statt am Anfang erst halten konnte, nachdem Münzenberg sein Referat, „das offensichtlich darauf zielte, vor allem das kommunistisch-bürgerliche Bündnis zu festigen", gehalten hatte und Schwarzschild und Bernhard, weit über ihr Thema hinausgehend, längere Ausführungen über ihre Verfassungsentwürfe gemacht hatten ${ }^{192}$.

Über Kleppers Vortrag und das Echo darauf wird nirgends berichtet, so als existiere er gar nicht. Um so interessanter ist seine eigene Reaktion. Mitte Dezember - er war noch bis Ende November in Paris geblieben - schrieb er an Spiecker: „Inzwischen habe ich viel über die Pariser Eindrücke nachgedacht. [ ... ] Ich weiß natürlich nicht, ob es uns gelingt, die sogenannte Volksfront zu einem wirklichen Lebewesen zu gestalten. Vorläufig ist sie das ja noch keineswegs. Ich bin aber fest davon überzeugt, daß es zu dem Erfolg keinen anderen Weg gibt. Wir müssen alles, was von den Kommunisten, sagen wir, zu dem alten Zentrum reicht, nicht als Koalition von politisch Schiffbrüchigen, sondern als

${ }^{188}$ IfZ, ED 120, Bd. 4, Breitscheid an Hoegner, 10. 12. 1935. Breitscheid war bei der ersten LutetiaSitzung nicht anwesend.

189 BAP, 90 Sp2, Klepper an Spiecker, 7. 11. 1935 (B1. 59): Er hatte eine Einladung von Münzenberg bekommen und schrieb nun an Spiecker: „Glauben Sie, daß ich kommen soll? An sich würde ich es sehr gerne tun, nicht nur wegen der Sitzung, sondern auch, um einen Eindruck von der Sache zu bekommen." Doch hatte er finanzielle Schwierigkeiten und mochte sich die Reise ungern von anderen zahlen lassen. Das Landgericht hatte ihn am 15.10. 1935 auf Schadensersatz von 30000 RM gegenüber der Zentralgenossenschaftskasse verurteilt. Klepper verlangte Berufung und Nachsuchung um Armenrecht, was am 17. 2. 1936 abgelehnt wurde (Stange-Bericht). Am 16. November sagt Klepper dann doch zu, „nur für Paris, nicht für Brüssel“. Er wohnte bei Spiecker, für dessen „liebenswürdige Gastfreundschaft" er sich später bedankte (11.12. 1935).

190 Ebenda, Klepper an Münzenberg, 16. 11. 1935 (Bl. 60).

191 Scheer, S. 147.

192 Langkau-Alex, S. $138 \mathrm{ff}$. 
Kampftruppe für ein geschlossenes Programm zusammenbringen. Ich weiß genau, wie utopisch das klingt, wenn man nüchtern auf die augenblickliche Sachlage blickt. Es gibt aber keine andere Möglichkeit, die Gangster aus der Macht zu werfen, als diese große concordatio discordantium [...] zustandezubringen. Münzenberg hat das, wie ich glaube, auch verstanden. Schließlich sind wir ja auch ein paar Leute wenigstens, die wissen, was sie wollen; und es ist solchen Leuten schon öfter gelungen, aus der Utopie von heute die Wirklichkeit von morgen zu machen." ${ }^{193}$ Am liebsten würde er das Programm weder in dem „sogenannten Präsidium der Volksfront“ noch im „weiteren LutetiaKreis“, sondern allein mit Münzenberg, Spiecker und einem „noch auszuwählenden Sozialdemokraten“ ausarbeiten, weil er glaubt, daß diese vier sich „verhältnismäßig leicht verständigen würden“. Wenn dann das Programm „von den beiden sozialistischen Parteien und einer Anzahl ernstzunehmender bürgerlicher Politiker [...] autorisiert worden sei, ließe sich „eine starke Einheitsbewegung in Deutschland selbst in Gang bringen“, wobei „die Existenz der erwähnten, wenn ich so sagen darf, engsten Verschwörergruppe, überhaupt nicht bekannt werden“ dürfe ${ }^{194}$.

Warum Klepper am liebsten zuerst einmal feste Vereinbarungen in einer kleinen Gruppe getroffen hätte, ergibt sich aus seinem Urteil über die verschiedenen Gruppierungen. Über den sozialdemokratischen Parteivorstand in Prag äußerte Klepper sich recht ironisch, er habe "keine positiven Vorstellungen“ von dem, „was geschehen soll. Hitlers Sturz wünscht er natürlich. Am liebsten dürfte es ihm aber sein, es tauchte jemand auf, den man, wie früher Brüning, ,tolerieren' könnte. Dabei spielt immer wieder der - zudem irrige - Gedanke eine Rolle, vielleicht werde Hitler von der Armee gestürzt und durch einen Monarchen oder einen General abgelöst." 195 Während die SAP196 die Auffassung vertrete, „daß nur eine rein proletarische Bewegung berufen sei, die kommende Entwicklung zu bestimmen“, treibe die SPD der Zweifel sowohl an der Zuverlässigkeit der Kommunisten wie an der Kraft der Arbeiterschaft, allein den Umschwung zu erzwingen, um. Beides, wie Klepper meinte, seien berechtigte Zweifel. Zugleich warnte er davor, den Einfluß „aller Splittergruppen“ innerhalb der SPD zu überschätzen, denn „so sonderbar es ist, und so wenig die Prager Herren persönlich wohl noch für eine Funktion in Deutschland in Betracht kommen mögen, so ist doch der Parteivorstand die autorisierteste sozialdemokratische Stelle im Ausland. Das hängt", so fügte er ironisch hinzu, „mit dem deutschen Sinn für Disziplin zusammen."197

In der Wendung der Kommunisten zur Volksfront sah Klepper zunächst mehr als einen „taktischen Trick“ Moskaus, „bei aller kritischen Zurückhaltung“ sei es „eine kluge Politik“, die mit einer Wendung in der gesamten russischen Politik übereinstimme. Diese sei, „nachdem die Schichten, aus denen reaktionäre Gefahren drohten, vernichtet sind, imstande, die Diktatur aufzulockern“ und sich zum „Promotor“ einer „Organisa-

193 BAP, 90 Sp2, Klepper an Spiecker, 11. 12. 1935 (Bl. 62, Hervorhebung im Original).

194 Ebenda, Klepper an Münzenberg, 28.12.35 (Bl. 76), und er fügte hinzu: „Ich weiß nicht, ob Ihnen mein Plan einleuchtet. Mit Ihrem augenblicklichen Vorgehen, bei dem Sie ja wohl im wesentlichen vorhaben, die Dinge nicht einschlafen zu lassen, wäre er aber vereinbar. "Im übrigen bat er Münzenberg, „den Brief vertraulich zu behandeln“, nur Spiecker erhalte einen Durchschlag.

${ }^{195}$ Ebenda, Bl. 66.

196 Sozialistische Arbeiter Partei, vgl. Grossmann, S. 38.

${ }^{197}$ BAP, 90 Sp2, Bl. 67. 
tion zur Erhaltung des Friedens “ ${ }^{\text {“ }}$ zu machen ${ }^{198}$. Diese Interpretation der russischen Politik entsprach der Ansicht vieler zu jener Zeit, als sich „die wirtschaftlichen Verhältnisse spürbar gebessert" hatten, Rußland in den Völkerbund eingetreten war, die Schauprozesse noch kaum begonnen hatten und weder in ihrem Ausmaß noch in ihren Auswirkungen zu durchschauen waren ${ }^{199}$. Auch hatte die KP im Herbst 1935 auf einer Konferenz in Brüssel offiziell und selbstkritisch ihre Politik während der Weimarer Republik verdammt. „Es sei falsch gewesen, daß die KPD gegen die Preußenregierung Braun-Severing gekämpft hatte, daß sie nicht die drohende Nähe der faschistischen Terrorherrschaft gesehen hatte und dadurch gehindert wurde, eine wirklich großzügige Einheitsfrontpolitik zu treiben, in deren Mittelpunkt zuerst die Verteidigung der demokratischen Rechte und Freiheiten hätte stehen müssen. "Im ,Manifest von Brüssel" hieß es: „Die deutsche Volksfront kämpft für eine demokratische Republik, sie ist kein Manöver, mit dem die Partner getäuscht werden sollen."200

Schließlich begann sich auch im Nachbarland Spanien gerade eine Volksfront zu formieren. Eine große Zahl europäischer und amerikanischer Intellektueller engagierte sich für die kommunistische Seite und nahm an dem im Sommer 1936 ausbrechenden Spanischen Bürgerkrieg teil201. Meinte Klepper auch, man müsse diese „abgewandelte russische Aktivität“ „ernst" nehmen und „dementsprechend in das Kalkül jeder antifaschistischen Politik“ einsetzen, so zeigt doch seine Reflexion über die Motive dieser Politik, daß er sich seine Skepsis bewahrte. „Man kann“, so meinte er, in der sowjetischen Politik „eine Prophylaxe gegen äußere Angriffe auf die Sowjetunion sehen. Man kann hinter ihr den Versuch vermuten, nach faschistischem Muster den Kampf um die Macht mit den Mitteln der Demokratie zu führen." Sie kann auch aus der Einsicht resultieren, daß es der Arbeiterschaft in absehbarer Zeit "nicht gelingen wird, die Macht der Bourgeoisie in den kapitalistischen Ländern zu brechen“, da „in Mittel- und Westeuropa die liberalen Errungenschaften - gerade infolge der faschistischen Regierungsmethoden auch innerhalb des Proletariats - doch so heimisch sind, daß ein Regime, welches auf die Dauer bestehen will, sie nicht ausradieren kann"202.

Was die bürgerlichen Kreise anbelangt, so meinte Klepper, sei „man dem Gedanken des Zusammengehens mit den Kommunisten nicht so abgeneigt, wie man denken sollte. Man setzt nur voraus, daß die Kommunisten ihre Stellung zu den Fragen des Rechtsstaates, der demokratischen Verfassung, der Glaubensfreiheit usw. deutlich erkennen lassen, und daß feste Vereinbarungen über die Zeit nach dem Sturze der Nationalsozialisten mit Autorisation Moskaus getroffen werden. [...] Unter diesen Voraussetzungen“ wären

198 Ebenda, Bl. 65.

199 Gross deutet das „Unbehagen hinter dieser Fassade“ an (S. 286). Vgl. Langkau-Alex, S. 112 ff.: „Eine Gretchenfrage, die sich [...] sowohl der SOPADE als auch der KPO stellte, war die nach den demokratischen Verhältnissen in der Sowjetunion." $\mathrm{Zu}$ bedenken ist die in jeder Weise schwierige Nachrichtenvermittlung.

200 Wilhelm Pieck auf der Brüsseler Parteikonferenz im Oktober 1935, zitiert bei Gross, S. 290. Der Brief des ZK der KPD an den Prager Parteivorstand der SPD zwecks Einigungsverhandlungen ist als Abschrift in der Spiecker-Korrespondenz.

201 So erschien auch am 25.12. 1936 in der P'TZ ein von H. Mann, G. Bernhard, O. Klepper, R. Breitscheid, M. Braun, G. Denicke, F. Dahlem, K. Funk und W. Münzenberg unterzeichneter Aufruf an das Deutsche Volk, die Unterstützung Francos durch Hitler mit allen Mitteln zu hintertreiben.

202 BAP, 90 Sp2, Bl. 65. 
sowohl die Liberalen wie die Katholiken „zu einem Pakte bereit“, in der Annahme, daß es sich um „kaum etwas anderes handeln würde, als es die frühere Koalitionspolitik mit den Sozialdemokraten war“. Außerdem gebe es in Deutschland bisher überhaupt keine bürgerlich-oppositionellen Gruppen, die sich, nach Klepper, „von der hier geschilderten Plattform aus bilden lassen“203.

Spiecker, der bedauerte, daß Klepper „in ultimo Thule" lebe, schrieb wenig Erquickliches über die Volksfront. „Mir ist völlig unklar, was dabei Brauchbares herauskommen soll. Je unbekannter und verschwiegener dieser Makkabäertross ${ }^{204}$ arbeitet um so besser, so wie unsere Emigration nun einmal gebaut ist, macht ihre Tätigkeit im Dunkeln sicherlich mehr Eindruck als in der Sonne“, wenn man nämlich „drüben“ erst wisse, „an wen man sich hüben mit Namen klammern kann, werden auch die schönsten Leistungen nachher ins Lächerliche gezogen“. Außerdem habe er „den Eindruck, daß je länger je mehr auch unsere Freunde Willi [Münzenberg] und Leopold [Schwarzschild] Angst kriegen vor den Geistern, die sie gerufen haben und jetzt nicht mehr loswerden “205. Klepper antwortete ihm: „Vielleicht ist Ihr Pessimismus doch zu weitgehend. Wenn man der Sache so nahesteht wie Sie, ist man dem deprimierenden Eindrucke, den die Unzulänglichkeit[en] der agierenden Persönlichkeiten vermitteln, ja stärker ausgesetzt als auf die geräumige Distanz, in der ich mich befinde“, und so meinte er von sich, daß er trotz des in den USA noch nicht bewilligten Geldes „alles in allem [...] nicht pessimistisch“ sei, da „sich viel mehr regt, als es noch vor einem Jahr der Fall war“, ja selbst Brüning scheine „sich nun als Gegner des Regimes bekannt zu haben“206. Eine typische Reaktion für Klepper, es mußte gemacht werden, also mußte alles dafür getan werden. Daß das kein leeres Gerede war, zeigt die Tatsache, daß er „ein Angebot der Regierung von Columbien, als Berater dorthin zu gehen“, ablehnte, was er in einem Brief an Spiecker einen Monat später mit dem Satz kommentierte: „Es kostet doch Nerven, wenn man so auf eigenes Risiko versucht, dabei mitzuwirken, daß Utopien von heute Wirklichkeiten von morgen werden. [...] und darin, daß man sich so in die Sache verbeißt, liegt gewiß eine Erfolgschance an sich. “ ${ }^{207}$ Diese Zuversicht rang er sich immer wieder ab, obwohl er gleichzeitig, wie ein für Amerika verfaßter Bericht über die Pariser Eindrücke zeigt, die verschiedenen Volksfrontgruppierungen und ihre Beziehungen untereinander recht nüchtern beurteilte und damit nur bedingt Anlaß zu Optimismus bot!

Am 2. Februar 1936 hatte die dritte Sitzung des Lutetia-Kreises stattgefunden, und man hatte eine Resolution zum Zusammenschluß aller Friedenskräfte verabschiedet ${ }^{208}$, die Klepper, „obwohl, oder vielleicht gerade, weil sie nicht viel besagt, recht geschickt“ fand. Münzenberg hatte sich Klepper gegenüber „sehr befriedigt über den Verlauf der

\footnotetext{
203 Ebenda, Bl. 67.

204 Gemeint sind die Mitarbeiter des Lutetia-Kreises, worunter viele Juden waren.

205 Ebenda, Spiecker an Klepper, 27. 1. 1936 (Bl. 78).

206 Ebenda, Klepper an Spiecker, 16. 4. 1936 (Bl. 97).

207 Ebenda, Klepper an Spiecker, 24. 1. 1936 (Bl. 77).

208 Abgedruckt bei Langkau-Alex, S. 210, vgl. außerdem das Manifest für eine gemeinsame Amnestieaktion (S. 209) sowie Verlauf der Konferenz (S. 155 ff.). Bereits am 20. 12. 1935 war der 1. gemeinsame Aufruf von KPD und dem Pariser Teil der SPD zustande gekommen, von dem Heinrich Mann etwas euphorisch sagte: „[...] mit ihr aber beginnt die Volksfront der Deutschen“ (Pech, Exil, S. 92 f.). Zu den parallel laufenden Verhandlungen zwischen SOPADE und KPD vgl. Langkau-Alex, S. $142 \mathrm{ff}$.
} 
Sitzung“ geäußert ${ }^{209}$ und Anfang April „erfreuliche Nachrichten“, die Volksfront betreffend, angekündigt ${ }^{210}$. Wahrscheinlich spielte er auf die allmählich zustandekommende Einigung zwischen Sozialdemokraten und Kommunisten an. Die vierte LutetiaSitzung fand erst Ende April statt. Diesmal wurde ein Exekutivorgan aus 15 Persönlichkeiten gebildet zur Verbesserung seiner Wirksamkeit, und am 9. Juni wurde der LutetiaKreis umbenannt in „Ausschuß für die Vorbereitung einer deutschen Volksfront" 211.

Klepper war nicht mehr dabei. Die Gründe dafür finden sich in seinen Briefen. Zum einen schätzte er die Chancen, daß die Gesamtgruppe der Emigranten zu wirksamen Aktionen gelangen könne, immer geringer ein ${ }^{212}$. Zum anderen scheinen seine seit der Rückkehr aus Amerika im Sommer 1935 verfolgten Pläne, ein Informations- und Agitationsnetz im Deutschen Reich aufzubauen, in dieser Zeit konkrete Gestalt angenommen zu haben. Im Mai 1936 war er noch einmal in Paris und besprach alle Einzelheiten ausführlich ${ }^{213}$.

Die Frage, warum bürgerliche Intellektuelle damals im Kampf gegen den Nationalsozialismus mit den Kommunisten in der Volksfront zusammengearbeitet haben, läßt sich in Bezug auf die Person Kleppers klar beantworten. Das Motiv war pragmatisch, es ergab sich aus der historischen Situation und den Prioritäten, die Klepper setzte. In die historische Betrachtung des Problems sind einmal die Erfahrungen der Weimarer Zeit einzubeziehen; sie hatten zu der Erkenntnis geführt, daß eine derartige Zersplitterung der demokratischen und linken Parteien dem Gegner nur nutzen konnte. Zum anderen ist zu bedenken, daß die politische Situation von 1935/36 nicht mit der von 1938/39 zu vergleichen war, das schlimmste Übel war für Klepper und andere der Nationalsozialismus, und der mußte zuerst bekämpft werden, denn Nationalsozialismus und Freiheit waren absolut unvereinbare Gegensätze. Der Kommunismus strebte dagegen, zumindest in der Theorie, die Freiheit wenigstens für eine Klasse an. Wie Kleppers Analysen zeigen, beruhte seine Bereitschaft, mit den Kommunisten zusammenzuarbeiten, nicht auf Illusionen, sondern erwuchs aus dem Selbstbewußtsein, daß jeder der Partner, der bürgerliche wie der kommunistische, seinen Teil bei der Verfolgung eines gemeinsamen Zieles beizutragen habe.

Die Art, wie Heinz Abosch die Zusammenarbeit der Intellektuellen und bürgerlichen Politiker mit den Kommunisten zu erklären versucht, trifft weder auf Klepper noch auf andere Intellektuelle und Politiker wie zum Beispiel Hans Sahl, Schwarzschild, Spiecker oder Weichmann zu. Abosch schreibt: „Zögernden, orientierungsschwachen Intellektuellen imponiert eine Partei, die Selbstbewußtsein und Sendungsbewußtsein ausstrahlt. Für stets Suchende und Zweifelnde ist das attraktiv, es bietet sich als wohltuende Entlastung an, für viele ist es eine glückliche Entdeckung, für manche ein Rettungsanker." 214

209 BAP, 90 Sp2, Klepper an Spiecker, 14. 2. 1936 (Bl. 79). Zum Ergebnis vgl. Langkau-Alex, S. 161.

${ }^{210}$ BAP, 90 Sp2, Klepper an Spiecker, 16. 4. 1936 (Bl. 97). Außerdem hatte Münzenberg Klepper eine Reise zur "parlamentarischen Konferenz nach Amerika" angeboten, aus der aber nichts wurde.

211 Am 22. 4. 1936 und 9. 6. 1936, vgl. Pech, Exil, S. 98 ff.

212 BAP, $90 \mathrm{Sp} 2$, Klepper an Spiecker, 18. 5. 1936 (Bl. 99).

213 Ebenda, Klepper an Spiecker, 18. 7. 1935 (Bl. 15), auszugsweise Abschrift eines Briefes von Klepper an Aron, 18.7. 1936 (Bl. 101), und Klepper an Spiecker, 18. 5. 1936 (Bl. 99).

${ }^{214}$ Abosch, S. 30. Im übrigen trennt der Autor nicht klar zwischen dem französischen Front Populaire und dem deutschen Versuch, eine Volksfront zu bilden, und zitiert französische Autoren über eine französische Sitzung, als handele es sich um eine Sitzung des Münzenbergkreises. Vgl. auch das neue Buch von Abosch, Das Ende der großen Visionen, Hamburg 1993 und dazu die Rezension von Heidbrink, in: Die Zeit, 28. 5. 1993, S 19. 
Die andere Ursache, warum Klepper ohne Vorbehalte mit Kommunisten zusammengearbeitet hat, liegt in seiner Persönlichkeit; er orientierte sich an den Menschen, nicht an der Ideologie, die sie vertraten. Das war schon in der Weimarer Zeit so, und das war auch nach dem Kriege so. Immer hat er sich damit größten Anfeindungen und Verdächtigungen ausgesetzt, was ihn aber nicht störte, weil er seinem eigenen Urteil mehr vertraute als dem Urteil seiner Kritiker ${ }^{215}$. Obwohl Klepper sich von der Volksfront recht bald wieder distanzierte, weil er erkannte, daß sie keinerlei Wirkung hatte, so hat er doch mit Münzenberg, den er als Persönlichkeit schätzte ${ }^{216}$, bis zum Schluß zusammengearbeitet und mit Babette Gross eine lebenslange Verbindung behalten.

Abosch wird einer Persönlichkeit wie Münzenberg nicht gerecht, weil er sie mit ideologischen Scheuklappen betrachtet. Dabei beruft er sich auf Arthur Koestler als Kronzeugen, obwohl ein ganz anderes Bild von Münzenberg dabei herauskommt als bei Koestler. Abosch schreibt: „Seine [Münzenbergs] Methode bestand darin, Leute mit klangvollen Namen, Schriftsteller, Bischöfe, Lords einzusetzen für eine Sache, die sie nicht durchschauten und deren Drahtzieher ihnen unbekannt blieben. [...], Sich nicht demaskieren': Das war nun die große Losung der Kommunisten. Sich verbergen hinter betrügerischen Phrasen, die demokratisch-humanistische Tarnkappe tragen, um möglichst viele manipulieren zu können. Es unterliegt keinem Zweifel, daß diese Methode der Täuschung, des agitatorischen Phrasenkultes, der Mobilisierung von Emotionen unter Verdrängung wirklicher Sachfragen dem Verhalten des Faschismus, der bekämpft werden sollte, durchaus ähnelte. [...] Das demokratische Bekenntnis war ein Aushängeschild, das mit echtem demokratischem Verhalten nichts gemein hatte. “217

Bei Koestler liest sich das etwas anders: „Willi war die graue - oder besser gesagt: rote - Eminenz und der unsichtbare Organisator des weltweiten antifaschistischen Kreuzzugs. Er war in der Nacht des Brandes aus Deutschland geflohen, hatte sein Hauptquartier in Paris aufgeschlagen und einen Feldzug begonnen, der eine einmalige Leistung in der Geschichte der Propaganda darstellt. In der Kominternhierarchie hatte Willi eine ungewöhnliche Position inne und zwar aus zwei Gründen: Erstens war er nicht Politiker, sondern Propagandist, nicht ,Theoretiker', sondern ,Aktivist'. Er nahm an den Fraktionskämpfen in der Partei nicht teil, intrigierte nicht, und die Streitigkeiten über

215 Vgl. die Arbeitsteams bei der Domänenbank und der Preußenkasse. Ein Beispiel für die Nachkriegszeit ist Kleppers enge Verbindung mit Ruth Fischer, der ehemaligen kommunistischen Reichstagsabgeordneten. Er wurde immer wieder kritisiert, daß er sie zu Vorträgen vor der Wipog einlud, so z. B. von Artur W. Just, der es ablehnte, einen Vortrag vor dem Freiheitsbund für Deutsch-Russische Freundschaft zu halten, da dieser engen Kontakt zur Wipog habe „und die dort maßgebenden Herren, Dr. Klepper und v. Pufendorf [...] engste Verbindungen zu der bekannten ehemaligen Kommunistin Ruth Fischer unterhalten oder unterhielten. Die ideologischen Bindungen dieser Kreise sind mir nicht sympathisch, und ich möchte mit ihnen nichts zu tun haben" (Just an den Freiheitsbund, 25. 11. 1953, in: K/Kor.). Klepper an Just, 27. 11. 1953: „Schließlich glaube ich, daß Sie Frau Fischer ungerecht beurteilen. Sie ist eine streitbare Frau und hat Verstand für drei Männer. Ich kenne sie auch persönlich näher und habe viel Achtung vor ihr". An Paul Hertz, Senator in Berlin, schrieb er am 8. 12. 1954: „Sie waren etwas reserviert im Urteil [über R. Fischer]. Ich kenne sie aber sehr genau, und ich halte nicht nur politisch, sondern auch menschlich sehr viel von ihr." Das Entschädigungsamt habe ihren Restitutionsantrag „mit der lächerlichen Begründung“ abgewiesen, „sie sei nach wic vor nur eine abweichende Kommunistin".

216 Hallgarten über Münzenberg: „im Grunde seines Herzens [ein] ehrlicher Mann“, S. 209.

${ }^{217}$ Abosch, S. 31 und 33. 
die Parteilinie ließen ihn kalt. Zweitens stand Willi einer mächtigen Organisation vor, der ,Internationalen Arbeiterhilfe (IAH), in der Parteisprache als der ,MünzenbergKonzern“ bekannt. Die IAH wurde von Moskau aus als autonome Organisation geleitet und unterstand nicht der Kontrolle der örtlichen kommunistischen Parteien. Willi erfreute sich daher eines größeren Maßes an Unabhängigkeit auf internationalem Gebiet als irgendein anderer Kominternführer. Ungestört von der lähmenden Kontrolle der Parteibürokratie konnten die Zeitungen, Zeitschriften, Film- und Theaterproduktionen des Münzenberg-Konzerns einfallsreiche Propagandamethoden anwenden, die in schroffem Gegensatz standen zur pedantischen, sektiererischen Sprache der offiziellen Parteipresse. Willis Erfolge, seine unorthodoxe Einstellung, seine kaum verhehlte Verachtung für Schmeichelei und Haarspalterei brachten ihm die tief verwurzelte Feindschaft der Parteibürokratie ein." 218

Indem Abosch Münzenberg mit anderen Kommunisten gleichsetzt, verfälscht er nicht nur die Aussagen seines Kronzeugen Koestler, der ein anderes, sehr viel differenzierteres Bild Münzenbergs entwirft, sondern vermag dadurch auch nicht zu erklären, warum so viele bürgerliche Intellektuelle und Politiker wie zum Beispiel Klepper Vertrauen zu Münzenberg hatten und gerne mit ihm zusammenarbeiteten. Die Tatsache, daß Münzenberg 1939 endgültig mit Moskau gebrochen hat, eine Entwicklung, die sich schon lange vorher angebahnt hatte ${ }^{219}$, beweist unter anderem seine innere Unabhängigkeit. In einem für die französischen Behörden geschriebenen Lebenslauf beschreibt er, wie ihn ab 1937 mehrfach ein GPU-Agent aufgesucht und auszuschalten versucht habe, und er fügt hinzu: „Je me souviens d'une gratitude profonde de la protection des autorités françaises qui ont empêché un coup de force menaçant. “220 Das Ende seines Lebens ist in der wissenschaftlichen Literatur äußerst umstritten 221 , wobei die Erörterung der Frage, ob er von Stalinagenten ermordet worden ist oder sich selbst das Leben genommen hat, nicht ganz frei von der politischen Einstellung der jeweiligen Autoren zu sein scheint.

Kleppers Zeit in Mallorca ging ihrem Ende zu. Schon im April hatte er geschrieben, daß sich zwar „die hiesigen politischen Vorgänge [...] auf unserer Insel nur undeutlich bemerkbar“ machen, daß aber „hinter der spanischen Volksfront [...] offenbar viel mehr Elan“ stecke, als er gedacht habe. „Man spürt das atmosphärisch.“222 Nun war es soweit. Am 17. Juli 1936 brach der Spanische Bürgerkrieg aus. Die Militärrevolte unter General Francisco Franco in Spanisch-Marokko griff rasch auf das Festland über, am 30. Juli

${ }^{218}$ Koestler, Zeuge, S. 195.

219 Die These, daß Münzenberg schon in der Berliner Zeit harte Auseinandersetzungen mit der Komintern hatte und nie ein gefügiger moskauhöriger Kommunist war, wird durch ganz neues, noch unveröffentlichtes Material bestätigt. (Auskunft von Mitgliedern der Weichmann-Stiftung).

${ }^{220}$ C.A.R.A.N., F/7, 15129, 3(3). Übersetzung: Ich erinnere mich mit tiefer Dankbarkeit des Schutzes der französischen Behörden, die dadurch einen Gewaltanschlag (auf mich) verhindert haben. Der Lebenslauf wurde nach Kriegsausbruch geschrieben, da Münzenberg die Internierung einiger Mitarbeiter beklagt.

221 Die Mord-These wird u. a. von Gross und Rott vertreten sowie von Roland Lewin und Jacques Droz, beides Teilnehmer des Münzenberg-Kolloquiums in Aix-en Provence im Frühjahr 1992, für wahrscheinlich gehalten. Die Selbstmord-These wird vor allem von Paul und Wessel vertreten.

222 BAP, 90 Sp2, Klepper an Spiecker, 16.4. 1936 (BI. 98). 
wurde bereits eine nationale Gegenregierung in Burgos begründet, und am 30. September 1936 wurde Franco zum Chef der nationalspanischen Regierung und des spanischen Staates erklärt. Die Deutschen, die Franco von Beginn an militärisch unterstützt hatten, stellten natürlich auch Auslieferungsanträge für deutsche Emigranten. So war Klepper wieder einmal extrem gefährdet, einmal als gesuchter deutscher Antifaschist, zum anderen als Sympathisant der spanischen Republikaner, der mit dem republikanischen Außenminister Alvarez del Vayo zusammengearbeitet habe ${ }^{223}$. Mit Hilfe des französischen Konsuls in Palma, der ihn gewarnt und ihm einen Platz auf einem französischen Schiff nach Marseille besorgt hatte, konnte er gerade noch im August 1936 nach Frankreich entkommen 224 . Diese erneute Trennung von der Familie muß vor allem für Frau Klepper und ihre drei Kinder nicht nur schmerzlich, sondern bedrohlich gewesen sein. In Spanien tobte der Bürgerkrieg, und die Familie war finanziell völlig ungesichert. „Diese ständige Ungewißheit und das Leben von der Hand in den Mund“ zehrte an den Nerven aller Beteiligten ${ }^{225}$. Doch für Klepper, der sich anderthalb Jahre relativ fern vom Geschehen auf den Kampf gegen den Nationalsozialismus vorbereitet und seinen geistigen Standort gefunden hatte, war es, bei allem Schmerz, die Familie erneut im Ungewissen zurücklassen zu müssen, vielleicht auch eine Befreiung aus der „Insellage“, eine Möglichkeit zu bisher entbehrter Aktivität.

\section{Die Deutsche Freiheitspartei}

Im Spätsommer 1936 traf Klepper in Paris ein, wieder einmal von der Gestapo gesucht. Das Konsulat in Palma teilte Anfang November mit, daß er vermutlich in Paris sei ${ }^{226}$. In der Tat wohnte er bei seinem Freund Ludwig Aron in Neuilly und erhielt zu Anfang des Jahres 1937 eine französische Identitätskarte für Ausländer ${ }^{227}$. Diesmal bedeutete der Aufenthalt in Paris etwas ganz anderes als vorher mit der Familie auf der Durchreise von Finnland nach China. Die politische Lage hatte sich in diesen wenigen Jahren sehr verändert, und Klepper hatte seinen eigenen Blickwinkel erweitert. Auch schien er zum ersten $\mathrm{Mal}$ in seinem ruhelosen Wanderleben an einen Ort gelangt zu sein, wo er nach menschlichem Ermessen nun zunächst bleiben würde und mit seiner Identitätskarte zumindest in einer gewissen Sicherheit leben konnte. Paris war zudem eine Stadt, in der er

\footnotetext{
${ }^{223}$ Akte Mexiko, KNL.

${ }_{224}$ Ebenda und autorisierter Lebenslauf.

${ }^{225}$ BAP, 90 Sp2, Klepper an Spiecker, 16. 4. 1936 (B1. 98f.). Vgl. auch die Berichte der drei Kinder für das Entschädigungsamt, aus denen eine sehr große Not spricht. Alle drei mußten irgendwie versuchen, Geld zu verdienen. Außerdem war am 27. 2. 1936 Kleppers Antrag auf Bewilligung des Armenrechts zur Durchführung eines Berufungsverfahrens auf Beschluß des Kammergerichts Berlin „wegen Aussichtslosigkeit der Rechtsverfolgung zurückgewiesen“ worden. Das Strafverfahren wurde schließlich „wegen Abwesenheit des Beschuldigten“ eingestellt (StangeBericht), jedoch ließ damit die Verfolgung durch die Nationalsozialisten nicht nach.

226 PA-AA, Dt. Botschaft Paris, Mitteilung vom 4. 11. 1936, zitiert im Bericht Müller, 26. 11. 1936.

227 27, avenue de Longchamps. Ab 5.1. 1937 war er offiziell dort gemeldet. Zu dem Zeitpunkt wurde sein Dossier eröffnet, und er erhielt eine "Carte d'identité d'étranger, valable jusqu'au 9 août 1939 (Auskunft des Préfet de Police vom 27. 12. 1990). Zur Praxis der Ausstellung von Identitätskarten vgl. Grossmann, S. 11 ff. Außerdem bestätigen die Briefe von Frau Margot Aron aus USA an Klepper nach dem Kriege, daß sie dort zusammengelebt haben.
} 
sich wohl fühlte, wo er mitten im Geschehen war und an allem teilnehmen konnte, frei, ungebunden, allerdings auch ohne die wärmende Nähe seiner Familie und ohne finanziell sichere Basis. „Es ist doch eine Lust zu leben“, schrieb er als letzten Satz seines programmatischen Artikels über „Europäische Freiheit“ im Dezember $1936^{228}$, nachdem er wieder einmal sein „Gepäck hinter sich gelassen“ hatte229.

Auch in seinem Viertel scheint er sich heimisch gefühlt zu haben, etwa in dem Sinne wie Elsbeth Weichmann es beschreibt: „Eine fast beruhigende Erfahrung in der erdrükkenden Größe der Millionenstadt, die wir mit unseren armseligen Sprachkenntnissen und unzulänglichen Hilfestellungen zu erobern versuchten, bildete die Abgeschlossenheit jedes Arrondissements, das gleichsam wie eine Stadt für sich sein Eigenleben führte. "230 Neuilly war damals ein ländliches Vorstädtchen von Paris. Die Leute kannten sich untereinander, und auch „Monsieur avec les blessures“ - Der Herr mit dem Schmiß - war bald im Viertel bekannt und beliebt ${ }^{231}$. Wie muß man sich seinen Tageslauf vorstellen? Auch da kann man sich auf Frau Weichmanns Bericht stützen, denn für Klepper galt Ähnliches, um so mehr, als Klepper Weichmanns aus Berlin gut kannte, und, wie sich aus der freundschaftlichen Nachkriegskorrespondenz der beiden Männer ergibt, hatten beide eine ähnliche menschliche Haltung und politische Einstellung. „Die tägliche Arbeit begann mit Zeitunglesen, eine wirklich schwere Arbeit bei den spärlichen französischen Sprachkenntnissen, die wir besaßen." ${ }^{232}$ Gewiß hat auch Klepper sich ein Archiv angelegt, „um die technische Grundlage für journalistische Arbeit zu schaffen " ${ }^{233}$, und in der aus den Archiven Münzenbergs hervorgegangenen Deutschen Freiheitsbibliothek am Boulevard Arago gearbeitet ${ }^{234}$. Vor allem aber hat er geschrieben: zahllose Briefe, Artikel und Vorträge. Da er wohl, wie aus seiner Korrespondenz mit der Redaktion der Zukunft hervorgeht ${ }^{235}$, Mühe mit dem Schreiben hatte und da er alles selber tippen mußte, kostete das Zeit. Schließlich mußte er auch für seine Ernährung sorgen, es sei denn, er aß bei Frau Aron, bei anderen Freunden oder im Bistro um die Ecke bei Monsieur Jean.

${ }^{228}$ NTB, 4, 52, 26. 12. 1936, S. 1238.

229 Das Motto dieses Kapitels war Motto des oben erwähnten Artikels.

${ }^{230}$ E. Weichmann, S. 43.

231 Frau Aron an Klepper, 27. 8. 1948, sie berichtet von Freunden, die in Paris waren und M. Jean besucht haben, „[...] der selbstverständlich nach dem ,Monsieur avec les blessures' gefragt hat [...] Mme Jean kocht noch immer, der dicke Hund hat den Krieg nicht überstanden, und wer nun in Ihrem Zimmer wohnt, weiß ich nicht", und in einem weiteren Brief vom 17. 7. 1949 heißt es: „Der erste Besuch galt Neuilly und Mme Jean. Sie erkannte uns sehr freundlich“ (K/Kor.).

232 Klepper konnte nicht gut Französisch, obwohl er bei Degon Unterricht gehabt hatte. Wie Madame Landy-Degon berichtet, habe sie mit Klepper meist deutsch oder englisch gesprochen, da sein Französisch sehr schlecht gewesen sei.

${ }^{233}$ E. Weichmann, S. $44 \mathrm{f}$.

${ }^{234}$ Vgl. Koestler, der auch zeitweilig dort gearbeitet hat (S. 200), und Gross, S. 253. Außerdem: Schiller, S. 203-220. Die Bibliothek war unter der Schirmherrschaft von Heinrich Mann, wie die PTZ am 11. 5. 1934 berichtete, eröffnet worden. Sie gab Mitteilungen heraus und wurde in einer zur Weltausstellung 1937 veröffentlichten Broschüre mit dem Titel „Was jeder Besucher von Paris und der Internationalen Ausstellung 1937 wissen muß" als „einzige rein deutschsprachige öffentliche Bibliothek" bezeichnet (ebenda, S. 203).

${ }^{235}$ Klepper an den Redakteur Thormann, 1. 3. 1939: „Den nächste Artikel, von dem ich hoffe, daß er wesentlich besser wird, würde ich gern für die übernächste Nummer schreiben. Ich würde ihn auch rechtzeitig abliefern" (C.A.R.A.N., F/7, 15123, K). Auch im April 1940 kamen Korrekturen von ihm zu spät zum Druck. 
Bei den großen Entfernungen war es sehr zeitaufwendig, zu Besprechungen, Treffen und Veranstaltungen zu fahren, dennoch war dies unbedingt nötig, denn menschliche Kontakte und der Meinungsaustausch waren das Wichtigste, sowohl für die Arbeit wie für die menschliche Solidarität, die jeder gerade in solchen Zeiten brauchte. „Die Schicksale der Emigranten und die Kontakte zu ihnen wurden ein Teil unseres Pariser Lebens. Man traf sich meist in Cafés, in der, Coupole', in ,Les deux Magots' und sprach über den moralischen und materiellen Trümmerhaufen, in dem man leben mußte. Jeder hatte andere Selbsterhaltungs- und Selbstzerstörungskräfte, jeder durchlebte eine individuelle menschliche Tragödie, die Tragödie moralischer Kampfbereitschaft, der die Welt den Kampf nicht erlaubte. Der tägliche Umgang mit Emigranten und Emigrantenschicksalen schuf neue Dimensionen menschlicher Beziehungen. Zunächst bewirkte der Kameradschaftsgeist einer Notgemeinschaft eine stärkere Unmittelbarkeit der Kontakte zu anderen, eine größere Zuverlässigkeit der freundschaftlichen Hilfe, menschlicher Wärme und des geduldigen Rats. Die deutsche Emigration brachte aber noch andere Akzente in diese Notgemeinschaft der Verfolgten und Verwundeten: Alle hatten ihre Standeskleidung, ihre Ruhmeskränze und ihre Besitzpodeste verloren, alle besaßen nichts mehr als den nackten Mut weiterzuleben. Die menschliche Substanz eines jeden erkannte unschwer Kraft und Schwächen und erwarb so eine ungeahnte Kenntnis von Menschen, zu denen man Mitleid und Toleranz entwickelte. “236

Klepper kannte viele der Emigranten noch aus Berliner Zeiten; mit dem Prinzen Löwenstein, der mit seiner Frau Helga ein offenes Haus in Paris führte ${ }^{237}$, verband ihn der gemeinsame Kampf gegen Papen 1932, mit anderen hatte er neue Kontakte geknüpft; hinzu kamen seine Beziehungen zu Franzosen teils aus der Zeit der Zusammenarbeit mit dem Crédit Agricole, teils neu entstanden durch das „Institut d'Histoire de l'Emigration Politique Contemporaine“, eine der internationalen, aber vor allem auch der deutschfranzösischen Begegnung, dem politischen Gedankenaustausch, der historischen Forschung und der Dokumentation gewidmete Institution ${ }^{238}$. Solche und ähnliche Institutionen, wie der von Münzenberg ins Leben gerufene und von dem schwedischen Finanzier Olof Aschberg, mit dem Münzenberg schon seit langer Zeit befreundet war ${ }^{239}$, unterhaltene "Circle des Nations" 240 sowie die Freiheitsbibliothek waren ebenfalls wichtige Begegnungsstätten und boten vor allem ein geeignetes Forum, vor dem man seine Gedanken vortragen konnte ${ }^{241}$.

${ }^{236}$ E. Weichmann, S. $53 \mathrm{f}$.

${ }^{237}$ Gespräch mit Prinzessin Löwenstein im November 1990. Drei Wochen vor Kriegsbeginn, am 10. 8. 1939, gaben Löwensteins einen Empfang zum 20. Jahrestag der Weimarer Verfassung; im Gästebuch sind die Namen von Babette Gross und Münzenberg, von Feuchtwanger, Olden, Hermann Kesten und vielen anderen zu lesen; allerdings nicht der von Klepper. Sie konnte sich nicht erinnern, ob er an diesem Abend dabeigewesen war.

${ }^{238}$ Ein ursprünglich rein französisches Institut, dessen ständiger Generalsekretär Marcel Paon war und dem 1937 eine deutsche Sektion angegliedert wurde. Dazu gehörten u. a.: Ernst Feder, Ehepaar Münzenberg, Chefredakteur Georg Bernhard, Spiecker, Klepper, Schwarzschild u. a. (NLFeder, Bl. 4). Vgl. dazu PTZ, 27.12. 1937.

${ }^{239}$ Gross, S. 279.

${ }^{240}$ Vgl. Grossmann, S. 38.

${ }^{241}$ So berichtet die Gestapo von einem Vortrag Kleppers am 30. Juni 1939 vor dem "Circle des Nations“ über „das kommende Deutschland und die europäische Frage“. Zusammenfassung des Vortrags mit Programmankündigung in: BAK, R 58/627, Bl. 42-51, Berichte vom 15. und 21.7. sowie 25. 8. 1939. Siehe auch: IfZ, Ma 644, Bl. $7750 \mathrm{ff}$, dort werden 85 Teilnehmer erwähnt. 
Dennoch scheint Klepper eher zurückgezogen gelebt zu haben. In einem sehr nachdenklichen Artikel über den Zusammenhang von Judentum und Freiheit schrieb er einen auf das Judentum bezogenen Satz, mit dem er offensichtlich auch sehr viel über sich selbst aussagte: „Wenn ein Volk sich zerstreut, seine Individualität jedoch durch Jahrtausende bewahrt, so muß das eine der Einmaligkeit der Erscheinung entsprechende Resonanz hervorrufen. In dem nachdenklichen, seiner selbst gewissen Menschen klingt eine verwandte Seite an, die wohl mit dem Gefühl seiner letztlichen Einsamkeit zusammenhängt. Dagegen wird in dem Menschen, dem diese Vorzüge abgehen, die Furcht wach, die ihm das Rätselhafte überhaupt einflößt." ${ }^{242}$ Aus dem Artikel, in dem er den Antisemitismus als eine Furcht vor dem freien Spiel der Kräfte erklärt, geht hervor, daß er sich in diesem Punkt mit dem Judentum identifizierte, "weil sein Geschick untrennbar an den Grad der Freiheit geknüpft ist, zu dem sich das Freiheitsmotiv in der Geschichte realisiert". Auch im folgenden Satz spricht er versteckt von seiner eigenen Motivation, den Kampf für die Freiheit aufzunehmen: „Gewiß hat das Judentum alle Stürme überdauert, gewiß ist die letzte Schlacht für die Freiheit gewonnen worden, und gewiß ist schließlich ein solcher Glaube, dessen Gegenstand jenseits des individuellen Geschicks liegt, der echteste Antrieb, der uns gegeben werden kann. Es wird aber auch von uns gefordert, daß wir den Augenblick begreifen und nach seiner Weisung handeln. " ${ }^{243}$ In keinem seiner anderen Artikel werden die Umrisse seiner Persönlichkeit so deutlich wie in diesem: seine Einsamkeit, sein Selbstbewußtsein, seine Furchtlosigkeit, sein Freiheitsdrang und sein Glaube. Dies sind Bausteine seiner Persönlichkeit, die es schwer machen, sich anderen mitzuteilen, die eher Distanz erzeugen als unkomplizierte menschliche Nähe. Er hielt sich die Menschen bewußt vom Leibe, er liebte, ja er brauchte wohl die Distanz. Er ließ es zu, daß man ihn Herr Minister nannte, und bezeichnete diese Form selbst als „ein Mittel der Distanzierung "244. Klepper brauchte lange, bis er Vertrauen faßte, und vor allem war es wohl schwer, seinen Respekt zu verdienen. Gelang das nicht, zog er sich selbst zurück und verharrte in kühler Höflichkeit, die auf manch einen verletzend wirken konnte. Kurz, er war den Menschen, die ihn nicht näher kannten, nicht geheuer. Offensichtlich drängte er sich auch nicht sehr in den Vordergrund, betrieb, wie man heute sagen würde, keine Imagepflege, obwohl ihm gerade das immer wieder unterstellt wurde. Zu dieser Unterstellung kam es leicht, weil Menschen eher dazu neigen, bei anderen niedere Motive zu vermuten, als zu glauben, daß einer wie Klepper bereit war, alles für die Sache zu tun, wenn nötig, also auch Menschen, die ihn bei der Durchsetzung seiner Ziele störten, vor den Kopf zu stoßen, oder seinen Titel beziehungsweise seine Verbindungen hervorzukehren, um der Sache zu nützen.

Kleppers Sache war zu jener Zeit die Deutsche Freiheitspartei (DFP). Schon in seinem ersten Brief aus Mallorca hatte Klepper von "gewisse[n] Pläne[n]" gesprochen, die er in seinem „Kopf herumwälze“ und für die er versuche, „das Nötigste aufzutreiben, womit [er] zur Zeit beschäftigt“ sei, und er hatte hinzugefügt: „Ich kann mir denken, daß Sie

242 Klepper, Gegenstoß, in: NTB, April 1938.

${ }^{243}$ Ebenda, S. 377.

${ }^{244}$ Klepper an Engelmann, 20. 2. 1950: „Zum Schluß darf ich noch eine Bitte aussprechen. Sie verwenden neuerdings wieder die Titulatur in unserem Briefwechsel. Das sollten Sie nicht tun. Ich sträube mich hier in Deutschland nicht dagegen, weil es ein Mittel der Distanzierung ist. Davon abgesehen, ist es mir aber ganz egal“ (KNL). 
meiner Idee mit einer gewissen Skepsis gegenüberstehen. "245 Anfang August 1935 hatte er von "recht günstigen Nachrichten aus Amerika" berichtet, so daß er hoffte, sich „demnächst, wenn auch mit bescheidenen, so aber doch mit Mitteln, ganz in die Sache stürzen“ zu können. In dem Falle müßte er allerdings von Mallorca fort, entweder nach Zürich, was günstig für die Verbindung mit Leuten aus dem Reich sei, oder nach Paris, wo man ungenierter agieren könne ${ }^{246}$. Mitte September 1935 hatte ein Treffen in der Schweiz, im Hause von Hans Walter Schmidt, dem ehemaligen Direktor der Domänenbank, in Oberhofen am Thuner See stattgefunden, an dem Spiecker, Lauffer sowie zwei andere Freunde Kleppers aus Deutschland und vor allem der Amerikaner V[ladeck] teilgenommen hatten und wo die Pläne Kleppers besprochen worden waren ${ }^{247}$. Im Oktober wurde diskutiert, ob man „die Korrespondenz“, das heißt nach Deutschland illegal einzuführende Aufklärungsschriften, die späteren Freibeitsbriefe, zunächst, solange die Finanzierung nicht gesichert sei, „unregelmäßig“ herausbringen und von der Schweiz aus verteilen solle ${ }^{248}$, oder ob sie, wie Klepper gemeint hatte, erst erscheinen sollten, wenn dies "sachlich und finanziell auf längere Zeit gesichert" sei. Außerdem hatte er vorgeschlagen, daß man „einen größeren board of editors“ bilden sollte, der aus Deutschen, die ihren Namen hergeben, und aus Ausländern bestehen würde. „Dieses Gremium, das sich als Treuhänder der anonymen Leute in Deutschland auszugeben hätte, würde einmal die ganze Sache glaubwürdiger machen, gleichzeitig aber den Zugang zu der Auslandspresse erleichtern. "249 Allerdings sollte man erst an die Leute, von denen er einige aufgezählt hatte - Thomas Mann, Pater Hermann Muckermann, Professor v. Hildebrand, Fritz Demuth -, herantreten, wenn „sicher ist, daß wir die Sache zustandebringen“. Offenbar hatte Klepper inzwischen mit Münzenberg gesprochen, denn den ",technischen Teil" sollte dieser nun übernehmen, nicht mehr Freunde in der Schweiz ${ }^{250}$. Mitte Februar hatte V[ladeck] Klepper mitgeteilt, daß „seine Bemühungen gescheitert“ seien, worauf Klepper an Spiecker schrieb: „Ich habe aber nicht locker gelassen und ihm ungefähr geschrieben, die Sache müßte eben geschafft werden“, und er hatte hinzugefügt: „Wenn ich mich richtig hinter eine Sache gekniet habe, bin ich bisher immer zum Ziele gekommen und so muß es auch diesmal sein. “251 Außerdem hatten beide einen genauen Plan samt Budgetentwurf in die USA geschickt, wobei sie für ihre Berechnungen den von Spiecker bereits herausgegebenen katholischen Nachrichtendienst, „Kulturkampf“, zugrunde gelegt hatten ${ }^{252}$.

In seinem letzten Brief aus Mallorca hatten die Pläne bereits konkrete Gestalt angenommen: „In der Zwischenzeit habe ich hin- und herüberlegt, wie der Start, über den

${ }^{245}$ BAP, 90 Sp2, Klepper an Spiecker, 18. 7. 1935, Bl. 15.

246 Ebenda, Klepper an Spiecker, 5. 8. 1935 (Bl. 17).

247 Ebenda, Klepper an Spiecker, 21. 8. 1935 (B1. 20).

${ }^{248}$ Ebenda, Klepper an Spiecker, 4. 10. 1935 (Bl. 57).

${ }^{249}$ Genau das forderte Kluthe, Mitarbeiter der DFP, laut Bouvier im Juli 1938, S. $124 \mathrm{f}$.

250 BAP, 90 Sp2, Klepper an Spiecker, 31. 10. 1935 (Bl. 58).

${ }^{251}$ Ebenda, Klepper an Spiecker, 16. 4. 1936 (B1. 98).

${ }^{252}$ Ebenda, Klepper an Spiecker, 14.2. und 21. 3. 1936 (Bl. 96) Klepper schlug vor, Spieckers „jetzige Korrespondenz entsprechend $[z u]$ erweitern" auf "den doppelten bis dreifachen Umfang, etwa 1000 Exemplare nach Deutschland und vielleicht dieselbe Zahl ins Ausland" zu verschicken (vgl. 14. 2. 1936, Bl. 79). Bei der "Kalkulation“, so meinte er, „müssen wir wohl davon ausgehen, daß wir alles allein bezahlen, also auch das Technische und die Übersetzung in Englisch und Französisch“ und das Gehalt einer Sekretärin. 
wir in Paris so viel gesprochen haben, in praxi vor sich gehen soll. Ich glaube auch, zu einem Ergebnis gekommen zu sein. "Und zwar dachte er daran, „eine Serie von ganz kurzen Flugblättern in monatlichen Abständen" zu verbreiten. Nach einigen Monaten sollte „an Ort und Stelle kontrolliert werden, ob und welche Wirkung eingetreten“ sei. „Bei der technischen Seite müssen uns die Kommunisten helfen. Hinsichtlich des Transportes und der Verbreitung der Flugblätter werden wir wohl dauernd auf sie angewiesen sein. Am Anfang müssen sie aber auch die Sache finanzieren. Ich bin überzeugt", so schreibt er, „daß ich, wenn wir zwei drei Mal die Flugblätter nach Deutschland befördert haben, die ganze Sache in Amerika finanzieren kann. Das Interesse der Amerikaner scheint ernsthafter zu sein, als ich hoffte." Angesprochen sollten nicht die „in der Reichweite der beiden Arbeiterparteien“ liegenden Schichten werden, da sie sozusagen versorgt seien, sondern vor allem diejenigen, "von denen ein Widerstand gegen Hitler zu erhoffen war“. Er dachte dabei nicht daran, „innerhalb der Oberschicht die älteren Jahrgänge“ anzusprechen, denn, so meinte er, "wer Frau und Kinder hat, ist für riskante Dinge dieser Art nicht mehr brauchbar“, sondern „die akademische Jugend und die jüngeren Jahrgänge des Offizierscorps“253.

Aus dem beigelegten Entwurf für einen ersten „Freiheitsbrief“ geht hervor, wie er sich das im einzelnen vorstellte. Die „Flugschriften [...] werden keine Nachrichten übermitteln“, da es weder auf die Korrektur einiger „Regierungs- oder Parteilügen“ mehr oder weniger ankomme noch auf die „Auseinandersetzung über die Wirksamkeit des nationalsozialistischen Regimes [...]. Wichtig ist allein, die Grundlinie dessen aufzuzeigen, was nach seiner Beseitigung zu geschehen hat.“ Deshalb werden die Flugschriften „nur die grundsätzlichen Fragen der künftigen deutschen Politik erörtern und zwar demnächst: die Neugestaltung der Wirtschaftspolitik, Fragen der Staatsverfassung, kulturpolitische Probleme - geistige Freiheit und Staatsräson -, die Judenfrage. Die Flugschriften werden so verteilt werden, daß sie zwar nicht mehrmals an dieselbe Person, wohl aber in ihre Reichweite gelangen. Hieran soll sich selbsttätig die Bildung kleiner Kreise von Freunden unseres Bundes anschließen. Diese Kreise beschränken sich auf Gedankenaustausch. Jede aktivistische Tätigkeit aus ihnen heraus würde im jetzigen Stadium schädlich sein. Eine andere Verbindung als die durch unsere Flugschriften hergestellte, wird zunächst zwischen den Kreisen und unserem Bund ebenfalls nicht bestehen. Nach einigen Monaten wird sich diese Taktik ändern. “ Die „Losung von morgen“ heißt „Freiheit und Vaterland“254. So nannte sich zunächst auch der Bund, von dem die Flugschriften ausgehen sollten. Es tauchten auch andere Namen auf wie „Freiheitsbewegung" und „Freiheit und Volk“. Unter diesem Motto erschien eine Broschüre, in der Heinrich Mann eine kurze Antwort auf die Frage „Wer ist deutsch?" gab, offensichtlich in Anspielung auf die Ausbürgerung seines Bruders Thomas, der seinen berühmt gewordenen Brief an den Dekan der Bonner Universität in eben dieser Broschüre veröffentlichte. Mit seiner Antwort unterstrich Heinrich Mann zugleich das Motto: „Deutsch sein wird die Verbindung von Freiheit und Volk in der Zukunft, die wir schmieden“, und er zählte als Definitionen dessen, was deutsch sei, auf: „die Geistigen, die Freiheit für

\footnotetext{
${ }^{253}$ Ebenda, Klepper an Aron (Abschrift an Spiecker), 18. 7. 1936 (Bl. 101).

${ }^{254}$ Ebenda, Beilage zum Brief vom 18. 7. 1936, Bl. 102-105.
} 
den Gedanken fordern, [...] die Gläubigen, [...] die durch wachsende Not zum Angriff geeinten Bürger, Bauern und Arbeiter, [...] die Aufrechten drinnen und draußen“255.

In diesen Zusammenhang gehört die viel zitierte „Deutsche Freiheitspartei“, die keine Partei im eigentlichen Sinne, sondern eine lose Organisation für den Kampf gegen Hitler und für die Freiheit war. Ihre Entstehung muß im Zusammenhang mit dem Scheitern der Deutschen Volksfront gesehen werden ${ }^{256}$. Seit Mitte 1936 hatte sich, wie es sich auch in Kleppers Briefen widerspiegelt, herausgestellt, daß eine Volksfront kaum zwischen den Arbeiterparteien ${ }^{257}$, geschweige denn zwischen diesen und den Bürgerlichen zu bilden war, denn, wie Münzenberg feststellte, ist „in keinem anderen Land [...] die Schaffung der Einheits- und Volksfront so schwer wie in Deutschland. In keinem anderen Land war die Kluft zwischen den Arbeiterparteien so tief und ist der bürgerliche Partner für die Volksfront so zersplittert wie in Deutschland. “258 Leopold Schwarzschild hatte „das Volksfront-Experiment“ bereits Ende Dezember 1936 in seinem Neuen Tagebuch für gescheitert erklärt ${ }^{259}$. Klepper hatte in der gleichen Nummer des NTB „eine neue politische Bewegung“ auf der Basis des „Freiheitsgedankens" gefordert.

Münzenberg, der immer stärker in Gegensatz zum Moskauer Kurs geraten war, zog sich auch allmählich aus der Arbeit des Volksfrontausschusses zurück, da diese immer stärker unter den Einfluß der moskauhörigen Kommunisten geriet ${ }^{260}$. Im März 1937 gab er Klepper auf der unabhängigen Kundgebung des „Aktionsausschusses der deutschen Emigration in Paris" ${ }^{261}$ Schützenhilfe, indem er dessen Anregung aufgriff, und meinte, es liege „im Zuge der Entwicklung, endlich eine fortschrittliche deutsche bürgerliche Bewegung oder sogar Partei zu schaffen, die freilich anders aussehen müßte, als die verunglückte Staatspartei“. Die Arbeiterklasse, so Münzenberg, brauche keine „neue politische Bewegung“, wohl aber "das deutsche Bürgertum, [das] keine heroische Tradition" besitze und dessen Geschichte „keine siegreichen revolutionären Umwälzungen auf[weise], wie zum Beispiel die Geschichte Frankreichs und Englands, dagegen aber viele verpfuschte, steckengebliebene Freiheitsbewegungen vom Bauernkrieg bis zum feigen Untergang der Demokraten der Nationalversammlung von 1848“. Das lag ganz auf Kleppers Linie, und die folgenden Worte Münzenbergs hätten auch von Klepper stammen können: „Ein bedeutender Fortschritt für die deutsche Entwicklung wäre heute die Sammlung aller bürgerlichen Hitlergegner um eine Fahne und in einer Partei, die im Bündnis mit den deutschen Arbeiterparteien den Sieg über das Hitlerregime erringen hilft. Aber“, so fügte Münzenberg mahnend hinzu, „das ist eine Aufgabe, die

\footnotetext{
${ }^{255}$ Ebenda, Bl. 134-142. Klepper, „Freiheit und Volk" erschien in derselben Broschüre.

256 Bouvier, S. 8.

${ }^{257}$ Vgl. Breitscheid, Bilanz eines Kampfjahres, in: Mitteilungen der deutschen Freiheitsbibliothek, S. $12 \mathrm{ff}$.

${ }^{258}$ Ebenda, Münzenberg, Angreifen!, S. 3.

${ }^{259}$ Schwarzschild, Lehren, in: NTB, 26. 12. 1936. Vgl. auch Gross, S. 305 f.

${ }^{260}$ Gross, S. 306. Koestler, Vorwort. Am 8. Januar 1937 war noch ein großer „Aufruf zur Bildung der deutschen Volksfront für Frieden, Freiheit und Brot“ im Wortlaut in der PTZ abgedruckt worden, und am 2. März berichtete die PTZ von einer großen Kundgebung ,im Zeichen der deutschen Volksfront“ (Paris, BN, D 141).

261 PTZ, 22. 3. 1937.
} 
nicht die Funktionäre der deutschen Arbeiterorganisationen, sondern die Repräsentanten des freiheitlichen deutschen Bürgertums selbst lösen müßten. “262

Klepper löste die Aufgabe und gründete mit Spiecker und anderen zusammen, gemäß dem bereits skizzierten Plan und so, wie Babette Gross es als unmittelbare Zeugin beschreibt, „unter strenger Beachtung der Regeln konspirativer Tätigkeit ein Gremium, das sich ,Deutsche Freiheitspartei' nannte und mit der Veröffentlichung der Freiheitsbriefe begann“. Der erste Freiheitsbrief erschien - von Klepper verfaßt - im März 1937263. In seinem für die französischen Behörden geschriebenen Lebenslauf bestätigte Münzenberg seine Beteiligung an der Organisation der DFP, nachdem er ungefähr 1937 eingesehen habe, daß eine Reform der KP unmöglich sei. „En mème temps je me raillie à plusieurs leaders bien connu de l'opposition allemande bourgeoise en organisant avec eux le Deutsche Freiheitspartei."264 Seiner eigenen Absicht und Kleppers Vorstellungen entsprechend hat er sich weder um die geistige Konzeption noch um die personelle Zusammensetzung, sondern nur um die technische Durchführung, vom Druck der Flugschriften in seiner Edition Carrefour bis zu ihrer Verteilung in Deutschland, gekümmert ${ }^{265}$, letzteres in Zusammenarbeit mit Karl Emonts, einem seiner alten Mitstreiter $^{266}$, der seinerseits seinen Neffen Georg Walter, der „vor 1933 zur Stennes-Opposition in der NSDAP gehört" hatte, und andere Mittelspersonen in Berlin einschaltete ${ }^{267}$. Georg Walter und Oskar Wagner wurden 1939 verhaftet ${ }^{268}$. Aus der Anklageschrift des Oberreichsanwalts beim Volksgerichtshof und den teilweise identischen zahllosen Berichten der Gestapo über die Tätigkeit der Deutschen Freiheitspartei ${ }^{269}$ geht hervor, wie man sich die Verteilung der Briefe vorstellen muß. Teils wurden sie per Post verschickt, teilweise von Flugzeugen ${ }^{270}$ abgeworfen oder auch mit Hilfe von Luftballons mit dem Wind über die Grenze getrieben ${ }^{271}$, was bei den Briefen aus ganz leichtem Dünndruck-

${ }^{262}$ Mitteilungen der deutschen Freiheitsbibliothek, Münzenberg, Angreifen, S. 4 f. Vgl. Gross, S. $306 \mathrm{ff}$.

${ }^{263}$ Gross, S. 308 und Kersten, Klepper: „Später nahm er [Klepper] an der amüsantesten Gründung teil, die wir unternommen haben, nämlich der mysteriösen ,Deutschen Freiheitspartei“." Vgl. auch Sassin, S. 93.

${ }^{264}$ C.A.R.A.N., F/7, 15129, 3(3). Gross bestätigt die Zusammenarbeit mit Münzenberg: „Klepper und Spiecker forderten ihn zur Mitarbeit auf" (S. 309).

${ }^{265}$ BDC, Anklageschrift, W49, Bl. 20 f. und 32.

266 BAP, 90 Sp2, Klepper an Münzenberg, 8. 8. 1935 (Bl. 19): Klepper schreibt, „ich weiß gar nicht, wer [...] Karl Emonts“ ist. Zu Emonts vgl. Gross, S. $310 \mathrm{f}$.

${ }^{267} \mathrm{Vgl}$. die Anklageschrift, in diesem Zusammenhang fällt auch der Name Strasser.

${ }^{268}$ Georg Walter wurde 1939 ,als Kurier abgefangen. In der Untersuchungshaft unternahm er zwei Selbstmordversuche. Die Festnahme Walters löste eine Reihe weiterer Verhaftungen aus. Im Hochverratsprozess vor dem Volksgerichtshof wurden die beiden Angeklagten [Georg Walter und Oskar Wagner] am 8. 11. 1939 zu zehn beziehungsweise vier Jahren Zuchthaus verurteilt“ (Gross, S. 310 f.). Das war der erste größere Schlag gegen die DFP.

269 Vgl. BAK, R 58: DFP und Die Zukunft (645); Deutscher Freiheitsbrief Nr. 24 und Pressestimmen zur Freiheitspartei (678); Münzenberg Aufrufe und die Gruppe um Die Zukunft/DFP (627) und die Folgen der Freiheitspartei in Südafrika (17). Die dortigen Freiheitsbriefe waren mit „Ulrich von Hutten" unterzeichnet, hinter dem Pseudonym verbarg sich Karl Walter (H. A. Kluthe bedankte sich am 24. 6. 1939 als Ausschußvertreter der DFP bei ihm für den ,Freiheitsbrief', der allen eine "Herzensfreude" war, BAK, NL-Kluthe, Bl. 516).

${ }_{270}$ R 58/645, Bl. 39. Laut Anklageschrift hat die Gestapo 75\% der von ihr beschlagnahmten Freiheitsbriefe durch Postüberwachung erlangt (Bl. 32). Vgl. auch Bouvier, S. $61 \mathrm{ff}$.

${ }^{271}$ Ebenda, Bl. 67. 
papier möglich war. Koestler zitiert eine diesbezügliche Anweisung Münzenbergs: „Dann kauf ein Buch über Meteorologie, Hans, studier die Hochs und Tiefs und so weiter, find heraus, wie viele Flugzettel, Kleinformat, wir an einem Luftballon befestigen können, in welcher Gegend von Deutschland die Luftballons vermutlich landen werden und so weiter. Dann, Hans, setz du dich mit ein paar Luftballonfabrikanten in Verbindung. Sag ihnen, es handelt sich um Export nach Venezuela, verlang Kostenvoranschläge für zehntausend Luftballons. “272 Außerdem wurden die Briefe vor allem an die internationale Presse verteilt, damit diese über die Partei berichtete und man im Ausland sehen konnte, daß das Wort ,Freiheit' auch in Deutschland noch nicht vergessen war ${ }^{273}$.

Tatsächlich wurde zum großen Ärger der Nationalsozialisten in der zweiten Aprilwoche in allen europäischen Zeitungen über die Freiheitspartei berichtet und Hoffnungen an die Tatsache geknüpft, daß ausgerechnet in Berlin, vor den Augen der Gestapo, eine Partei mit dem Namen Freiheit entstanden war ${ }^{274}$. Die Gestapo versuchte dem durch sofortige Beschlagnahme der Zeitungen entgegenzuwirken ${ }^{275}$, was wenig fruchtete, wie Babette Gross berichtet: „Das Echo im Reich war über Erwarten stark. Wir erfuhren, $\mathrm{da} ß$ an den Universitäten, im Heer, in den Jugendorganisationen in Deutschland damals über die Freiheitsbriefe soviel diskutiert wurde, daß sich auch die Parteifunktionäre gezwungen sahen, gegen die Infiltration Stellung zu nehmen. “276

Die Nationalsozialisten starteten einen Propagandafeldzug gegen die DFP unter geschickter Ausnutzung der vor dem Hintergrund der Moskauer Schauprozesse immer heftiger werdenden Auseinandersetzungen zwischen Volksfrontanhängern und Volksfrontgegnern. Raffiniert versuchten sie die verschiedenen Aktionen der Emigranten zu vermischen, eine Gruppe gegen die andere auszuspielen und daraus für die Anklage von Georg Walter einen Bericht zusammenzuschustern ${ }^{277}$, der zwar einigermaßen logisch klang, aber mehr auf „Vermutungen“ als auf gesicherten Informationen beruhte ${ }^{278}$. Babette Gross berichtet darüber folgendes: „Die Deutsche Freiheitspartei und die Frei-

272 Koestler, Vorwort, S. V.

${ }^{273} \mathrm{Vgl}$. BAP, $90 \mathrm{Sp}$, Klepper an Spiecker, 31. 10. 1935 (Bl. 58) und 21.3. 1936 (Bl. 96).

${ }^{274} \mathrm{Im}$ Ce Soir vom 22. 4. 1937 heißt es im Vorspann zu Kleppers Interview: „Zürich, 20 avril: Le monde de la politique et de la diplomatie a connu, il y a quelques jours, des émotions dont la cause est de nature à donner un autre visage à l'Europe: on a appris l'existence d'un Parti allemand de la Liberté, à l'intérieur du IIIe Reich. Un beau matin de la semaine dernière, les correspondants de Berlin de la grande presse internationale ont trouvé dans leur courriers, un manifeste de ce parti. Le ministère de la Propagande, M. Goebbels, a dû prendre position et faire une déclaration à ce sujet" (BN, D 106, Hervorhebung im Original).

275 Über 20 Zeitungen werden für die Beschlagnahme im Gestapobericht aufgezählt (R 58/678, Bl. 28).

${ }^{276}$ Gross, S. 309.

277 Nach der Darstellung in der Anklageschrift gegen Georg Walter (Bl. 21 ff.) wurde der Streit um die DFP und die Rolle Münzenbergs und Emonts' zwischen der KP, vertreten durch ihr Organ Runa (vgl. Nr. 241), dem Volksfrontausschuß und der PTZ (vgl. Nr. 483 vom 9.10.37) ausgetragen (Bl. $21 \mathrm{ff}$.).

278 PTZ brachte am 20. 5. 1937 unter der Überschrift „Neuer Appell der Deutschen Freiheitspartei“ folgende Meldung, die offensichtlich auf den gleichen Vorgang, aber mit anderem Ziel anspielt: „Die DFP, deren vor einigen Wochen in Hitler-Deutschland illegal verbreitete Rundschreiben und Aufrufe sowohl im Inland wie im Ausland beträchtliches Aufsehen erregt haben, meldet sich erneut mit 2 Rundschreiben zu Wort, deren Originale uns vorliegen. In dem einen grenzt sich die DFP gegen Personen im Ausland ab, die sie mit Unrecht für sich in Anspruch nehmen. Das andere Flugblatt nimmt zu den Guernica-Greueln Stellung." 
heitsbriefe beschäftigten seit dem Frühjahr 1937 Behörden und Parteistellen des Dritten Reiches. [...] Die Gestapo zeigte sich dabei zum Teil recht gut orientiert, zum Teil aber tappte sie im Dunkeln, behalf sich mit - oft unrichtigen - Kombinationen. “279

In der Tat war die Gründung der DFP in den Strudel des Streites zwischen Volksfrontanhängern und Volksfrontgegnern hineingeraten: Für die einen war sie Symbol einer selbständigen, von den moskauhörigen Kommunisten unabhängigen Opposition gegen Hitler, für die anderen war sie verabscheuungswürdige Zerstörerin der Volksfrontidee. Mitte April 1937, zur gleichen Zeit, als die Gründung der DFP bekannt wurde, fand in Paris die erste Konferenz der Deutschen Volksfront, „die auch die einzige bleiben sollte“, statt. Nur mühselig wurde die Kluft zwischen den Fronten verkleistert. Babette Gross berichtet als Augenzeugin, wie Münzenberg die Konferenz eröffnete und später „über die Aufgaben der Volksfront, die er zu einer politisch aktiven Körperschaft ausgebaut wissen wollte“, sprach ${ }^{280}$. Laut Kurt Kersten, einen anderen Augenzeugen, verlangte Münzenberg die „Vereinigung aller antihitlerischen Kräfte“ und „besonders von kommunistischer Seite eine offene Sprache“. Er wandte sich „gegen eine kleinliche Politik von Winkelzügen, die nur das Vertrauen zerstören müßte. Heinrich Mann dankte Münzenberg besonders auffällig für die offenen Worte.“ Der Appell Münzenbergs, der im Grunde ,in tief deprimierter Stimmung [war], die er [allerdings] zu verbergen wußte“281, war nicht unberechtigt, denn „hinter den Kulissen hatte Ulbricht nachdrücklich gegen Münzenbergs weitere Beteiligung an den Volksfrontarbeiten intrigiert. Ihm wurde vorgeworfen, daß er sich zu stark mit den Sozialdemokraten Breitscheid und Max Braun eingelassen [...] und die Politik Ulbrichts in der Volksfront als die des Wolfs im Schafspelz bezeichnet habe, die er nicht mitmachen wolle. "282 In der PTZ erschien ein großer Bericht über den Volksfrontkongreß und gleichzeitig auch einer über ein in Berlin aufgetauchtes Flugblatt der Deutschen Freiheitspartei zum Spanischen Bürgerkrieg $^{283}$.

Die Kommunisten lehnten die DFP natürlich ab und sahen in ihr eine Zersetzungserscheinung der Volksfront ${ }^{284}$. In ihrem Organ Runa behaupteten sie, daß sich der Volksfrontausschuß ausdrücklich von der DFP distanziert habe ${ }^{285}$. Dieser ließ sich aber nicht beirren und lehnte es ab, jemals eine solche Erklärung abgegeben zu haben. In einer von Max Braun unterzeichneten Erklärung hieß es: „Die DFP hat allerdings keinerlei Verbindungen mit der deutschen Volksfront, andererseits sieht der deutsche Volksfrontaus-

\footnotetext{
279 Gross, S. 310.

${ }^{280}$ Gross, S. 304: „Etwa dreihundert westeuropäische Delegierte verschiedenster politischer Richtungen nahmen daran teil. Heinrich Mann referierte über die Widerstandsbewegung, Rudolf Breitscheid über Außenpolitik." Die Tagung dauerte vom 10. bis 12.4. 1937. Vgl. den im Vergleich mit Gross sehr positiven Bericht über die Volksfronttagung bei: Pech, Exil, S. $108 \mathrm{f}$.

281 Kersten, Münzenberg, S. 490 f.

282 Gross, S. 304/314. Vgl. auch Anklageschrift, Bl. 25 ff., Rundschreiben des ZK der KP vom 26. 10. 1937: Die kommunistische Fraktion des Volksfrontausschusses wurde von dem gegen Münzenberg und Emonts eröffneten Untersuchungsverfahren unterrichtet, mit der Begründung, sie hätten „Kontakt zu ,rechtsbürgerlichen Kreisen“" und unterstützten die DFP.

283 PTZ, 11. 4. 1937: Bericht in großer Aufmachung und ein Leitartikel von Georg Bernhard sowie eine Grußadresse von Thomas Mann. Einen Tag später erschien die Rede von Heinrich Mann im Wortlaut.
}

${ }^{284} \mathrm{R}$ 58/678, Bl. $21 \mathrm{ff} .:$ Gestapobericht mit Zitaten aus dem KP-Organ Runa.

285 Anklageschrift, Bl. 22 ff., Zitate aus Runa, Nr. 241. 
schuß auch keine Ursache, die DFP zu bekämpfen."286 Ähnlich reagierte die PTZ auf entsprechende Angriffe von der KP287. Sich auf ihre publizistische Pflicht berufend, schrieb sie, sie habe Aufrufe der DFP veröffentlicht, obwohl sie, das heißt ihr Chefredakteur Georg Bernhard, zur Volksfront gehöre. Sie wisse auch, daß wichtige Katholiken und auch andere der DFP zugehörige Oppositonsbewegungen außerhalb der Volksfront oder sogar ihr nicht freundlich gesinnt gegenüberstünden, das könne sie aber „nie davon abhalten, über sie zu berichten“. Im Gegenteil, die Polemik der Runa unterstütze die NS-Propaganda - wie aus der letzten Hitlerrede ersichtlich -, die die deutsche Oppositionsbewegung als Phantasieprodukte ausländischer Emigrantenkreise bezeichne ${ }^{288}$.

Im Dezember kam es schließlich zu einem Schiedsspruch zwischen Anhängern und Gegnern der DFP, der im Grunde die Erklärung von Max Braun wiederholte, es könne „den Zielen der Volksfront nur förderlich sein, wenn von möglichst vielen Seiten innerhalb Deutschlands Opposition gegen Hitler geschürt" werde ${ }^{289}$. Die Nationalsozialisten hatten von den Auseinandersetzungen in der Tat nur profitiert. Sie wußten die verschiedenartigen Informationen geschickt für ihre Propagandafeldzüge zu nutzen ${ }^{290}$. Diese waren die notwendige Begleitmusik zu den just zu dieser Zeit verhängten Ausbürgerungen ${ }^{291}$, die in der PTZ unter der Überschrift „Ehrenliste des deutschen Freiheitskampfes" veröffentlicht wurden ${ }^{292}$. Verbunden waren die Ausbürgerungen mit der Anweisung des Auswärtigen Amtes an die deutschen diplomatischen und berufskonsularischen Vertretungen, „bei sich bietender Gelegenheit [...] den Betroffenen die in ihren Händen befindlichen Pässe abzunehmen, die Gewährung deutschen Schutzes komme selbstverständlich nicht mehr in Frage " 293 .

Nachdem nun das Konzept und die Entstehung der DFP sowie ihre Stellung zu Münzenberg und zur Volksfront geklärt worden ist, muß noch kurz auf die Arbeit von Beatrix Bouvier eingegangen werden, da sie bisher als die einzige Grundlage für Informationen über die DFP betrachtet wurde. Vom Standpunkt der Arbeit der Freiheitspartei aus gesehen wäre die Frage ohne Belang, wer der oder die führenden Köpfe waren, da sie anonym

${ }^{286}$ Ebenda und Gross, S. 309.

287 U. a. PTZ, 9. 10. 1937, Nr. 483.

288 PTZ, 28. 9. 1937, Nr. 472.

${ }^{289}$ Ebenda, 3. 12. 1937, Bl. 26f., vgl. auch Gross, S. 309 f.

290 Die Berichte kommunistischer Zeitungen gaben der Gestapo wertvolle Hinweise über die Organisation der DFP und ihren Vertriebsapparat. Laut Gross berichtete das Organ der KPD Deutsche Volkszeitung in ihrer Pariser Ausgabe vom 17. 10. 1937 über die DFP (S. 310). Vgl. auch Hinweis in Gestapobericht vom 27. 11. 1937 über die kommunistische Propagandatätigkeit gegen die DFP (R 58/645, Bl. 157 ff.).

291 12. 4. 1937 Bekanntmachung von Kleppers Ausbürgerung sowie 40 weiterer Personen und der Aberkennung der deutschen Staatsangehörigkeit sowie der rückwirkenden Vermögensverfallserklärung, veröffentlicht als Nr. 84 der 10. Liste des Deutschen Reichsanzeigers vom 15. 4. 1937 (PA-AA, Ref. Inland II A/B, Ausbürgerungen 19. Liste A-Z und Preußischer Staatsanzeiger, Nr. 84 vom 14. 4. 1937). Groteskerweise werden die Guthaben bei der Stadtsparkasse Zehlendorf, sogar die der Kinder, genauestens angegeben, sie betragen zwischen 131,16 RM und 12,89 RM. In einem Schreiben des Reichs- und Pr.IM vom 5. 5. 1937 an den stellvertretenden Chef der Gestapo geht es um die Erstreckung der Ausbürgerung des O.K. auf die Familienangehörigen (PA-AA, Ref. Inland II A/B 83-76), erfolgt am 17.1. 1938 (Staatsanzeiger Nr. 13, Liste 28, Nr. 17-20).

292 PTZ, 5. 5. 1937.

293 23. 7.1937 (PA-AA, Ref. Inland II A/B 83-76). 
arbeiten wollte, aber zum Verständnis von Kleppers politischer Arbeit, die er als Auftrag verstand und in einem neuen Deutschland nach Hitler fortzusetzen gedachte, ist es wichtig, seinen Anteil am Kampf gegen Hitler angemessen darzustellen, statt ihn zu leugnen, wie Bouvier es tut. Da sie sich lediglich auf die sich stark widersprechenden Berichte der Gestapo stützen konnte und nur die Sichtweise Spieckers zur DFP aus dem Nachlaß Kluthe kannte, kam sie zu dem Schluß, daß es „unwahrscheinlich [sei], daß Klepper „der Hauptinitiator der Deutschen Freiheitspartei war, wie Babette Gross behauptete“294. Für diese Annahme gibt sie zwei Begründungen: einmal habe Spiecker in einem Brief an Hans Albert Kluthe im November 1938 eine Beteiligung Kleppers an der DFP geleugnet und geschrieben, „daß, wenn irgendein Gremium der Deutschen Freiheitspartei existiere, es nur aus einer, seiner Person bestehe" 295 . Zum anderen habe sich die DFP in einem angeblich im Mai 1937 im Reich verbreiteten Flugblatt ausdrücklich von Klepper distanziert, weil dieser sich „,aus Eitelkeit oder aus Dummheit in einer französischen Linkszeitung, wie ein Wissender" über die Deutsche Freiheitspartei geäußert" habe ${ }^{296}$.

Beide Begründungen bedürfen einer genauen Untersuchung, nicht nur um der Richtigstellung der Sache willen, sondern auch, weil die Erläuterung der Hintergründe ein bezeichnendes Licht auf den verzweifelten Kampf der Emigranten gegen Hitler wirft. Es war ein Kampf, in dem Mißtrauen, Mißverständnisse, Eitelkeiten und Kränkungen nicht ausbleiben konnten, obwohl doch jeder gern von sich behauptete und von anderen forderte, menschliche Schwächen um der Sache willen aus dem Spiel zu lassen.

Der von Bouvier zitierte Satz befindet sich tatsächlich in der Korrespondenz Spieckers mit Kluthe, er muß allerdings im Kontext der Korrespondenz gesehen werden: Kluthe gab seit Anfang 1938 in London die Zeitung Das wabre Deutschland heraus und wollte nun intensiver für die Freiheitspartei arbeiten, allerdings vorher einige Dinge geklärt wissen. Aus diesem Impuls heraus schrieb er im November 1938, also zweieinhalb Jahre nach Gründung der DFP, zwei Briefe aus London an Spiecker ${ }^{297}$. Der aktuelle Anlaß dieser Briefe war, daß Kluthe in der neuesten Nummer der Zukunft einen Freiheitsbrief abgedruckt gefunden hatte und nun anfragte, ob es wohl mehrere Freiheitsbriefe in gleicher Aufmachung gebe, denn er habe den Freiheitsbrief Nr. 49 gelesen und dieser gleiche dem in der Zukunft abgedruckten. Er äußerte sein Mißtrauen gegen die Zusammenarbeit mit der Zukunft, vor allem mit den Interessenvertretern der jüdischen Emigration ${ }^{298}$. Der zweite Anlaß war ein Gerücht, das er gehört habe, daß nämlich Joseph Wirth, der ehemalige Reichskanzler, zu einer Propagandaaktion nach England kommen "und die Eingliederung der DFP in die Einheitsfront feierlich verkünden "

\footnotetext{
294 Bouvier, S. 7.

295 Ebenda, der zitierte Brief stammt aus dem damals noch unzugänglichen Privatarchiv H. A. Kluthes und ist vom 16.11. 1938, heute: BAK, NL-Kluthe, 162/27, 2. Teil, Bl. 49.

296 Bouvier, S. 7. B. zitiert ein Schreiben eines Buchhändlers Engelmann aus Leipzig, der das Flugblatt am 22. 5. 1937 aus Aachen erhalten und am 25. 5. 1937 an die Reichskanzlei geschickt haben soll, wie aus den Gestapo-Akten hervorgeht (BAK, R 43 II/1264, Bl. 9 ff.).

297 NL-Kluthe, Kluthe an Spiecker, 11. und 14.11. 1938 (Bl. 47 f.).

${ }^{298}$ Ebenda. Kluthe nennt namentlich: Henri de Kerillis und Goldmann-Finkler. C.A.R.A.N., F/7, 1526 und 1527: Im „Services d'information der Redaktion der Zukunft“ vom Juni 1939 wird über verschiedene Oppositionsgruppen berichtet, u. a. über die „Lettres des Neuf“ und die DFP, sie bestehe seit ca. 2 Jahren und unterhalte einen Sender. Unter den Publikationen der Zukunft wird das „Manifest der Deutschen Freiheit“ von Ulrich v. Hutten, „Es lebe die Freiheit! Ich hab's gewagt“, genannt.
} 
solle, man mache sich bereits über Wirths Hang zum Whisky lustig ${ }^{299}$. „Wenn die Bewegung weiter nichts ist als der Tummelplatz für emigrierte politische Routiniers, die in diesem Rahmen das alt gewohnte Spiel der Intrigen und Kabalen fortsetzen wollen, dann" ohne ihn. Er wolle „nur ohne jeden persönlichen Ehrgeiz der Sache dienen "300.

Als er von Spiecker nichts hörte, schrieb er einen zweiten Brief, in dem er nach der personellen Zusammensetzung der DFP fragte und leicht provokant hinzufügte: „Ich sehe nicht ein, warum Sie mich über die bestehenden Gegensätze nicht offen aufklären können. Um aus dem Wirrwarr herauszukommen und zum Beispiel zu vermeiden, daß Herr Klepper sagt, er sei die DFP, halte ich es für notwendig, den Helferkreis zu organisieren, ihm eine straffere Disziplin aufzuerlegen und ihn durch Leute unserer couleur zu erweitern. Jedenfalls will ich hier einen Kreis brauchbarer Christenmenschen schaffen, der eingesetzt werden kann. "301 Er berichtet von seinen Verbindungen zu Professor Julius Bonn und Fritz Demuth, die er wegen ihres hohen Ansehens in England als seine Mittelsmänner zu englischen jüdischen Kreisen, die ein „arisches Unternehmen mit einer gewissen Rechtstendenz sehr gern unterstützen würden“, ansieht. Auf diese Kreise habe „die scheinbare liaison mit der Zukunft und die Ankündigung der Wirthschen Aktion einen sehr ungünstigen Eindruck gemacht" ${ }^{302}$. Hier zeigt sich einerseits das große Mißtrauen gegen Münzenberg und alles, was irgendwie mit Kommunismus zu tun hatte, sowie auch ein unterschwelliger Antisemitismus, und es zeigt sich andererseits, daß der praktische Anteil Münzenbergs an der Verbreitung der Freiheitsbriefe offenbar nicht bekannt war oder gern verschwiegen wurde. Kluthe forderte also: „Die Aufklärung dieser Sache ist eine unerläßliche Voraussetzung aller weiteren Schritte."

Auf diese Briefe, die für Spiecker eine höchst bedenkliche Situation signalisierten, war er doch auf die Mitarbeit Kluthes bei der DFP angewiesen, antwortete er mit dem von Bouvier zitierten Brief ${ }^{303}$. Spiecker äußerte sich über "Ton und Inhalt" der Briefe von Kluthe "gleichermaßen überrascht", versuchte ihn dann aber in allen angesprochenen Punkten zu beruhigen und fand es sogar erfreulich, daß nicht nur Die Zukunft, sondern „schon viele Zeitungen der verschiedensten Couleur“ über die DFP geschrieben hätten. Das zeige, daß „die DFP im Lande einen sehr viel größeren Umfang angenommen hat, als ich es bislang gewußt habe“. Allerdings habe sie „leider auch schon sehr viel mehr Opfer gefordert“, als er „befürchtet habe“. Es werden, so prophezeite er, „immer mehr Nachrichten und Falschmeldungen auftauchen, weil der Ursprung der DFP erfreulicherweise immer noch unbekannt ist und weil drinnen sich heute schon ungezählte Zentren gebildet haben, die weder voneinander etwas wissen, noch von einer geistigen Zentrale. Hätten Sie sich darüber einmal in Ruhe Gedanken gemacht“, belehrte er Kluthe, dann „hätten Sie diese Entwicklung als durchaus logisch und erwünscht erkannt." Diese Ausführungen geben ein anschauliches Bild von dem Mit-, Gegen- und Durcheinander, in dessen Netz die

299 Joseph Wirth (Zentrum), 1879-1956, 1920/21 RFinanzM, 1921/22 RK, 1930/31 ReichsIM, 1933 emigriert, erst nach Frankreich, dann in die Schweiz. Sein Hang zum Alkohol wird von Treviranus als „Heimwehbetäubung“ bestätigt (Exil, S. 73).

300 NL-Kluthe, Kluthe an Spiecker, 11.11. 1938 (Bl. 47).

301 Ebenda, Kluthe an Spiecker, 14. 11. 1938 (Bl. 48).

${ }^{302}$ Ebenda: Demuth glaube, daß die "Veröffentlichung in der Zukunft ein häßlicher Trick war und eine Autorisierung nicht vorlag“. Zu Demuth vgl. Sassin, S. 87. Auch Klepper schätzte Demuth sehr und ist ihm in der Schweiz 1935 begegnet.

${ }^{303}$ Ebenda, Spiecker an Kluthe, 16.11. 1938 (Bl. 49). 
DFP neben vielen anderen Widerstandsorganisationen agierte. „Niemand wird auch von vornherein verhindern können, “ so fährt Spiecker fort, „daß sich Leute wie Klepper oder Wirth als Führer der DFP aufspielen - wir wissen, daß sie es nicht sind, und ich kann auch nur nochmals wiederholen, daß bisher das ,Gremium', von dem Sie schreiben, nur aus meiner Person bestanden hat. Meine Taktik habe ich nie nach Lust und Laune geändert ${ }^{304}$, und ich habe auch nur Freunde und Mitarbeiter gesucht, nie Handlanger ${ }^{305}$. Die DFP wird sich weder mit irgendwem vermanschen, noch wird sie je zu einer Emigrationsangelegenheit werden. Das heißt, solange ich die Möglichkeit habe und nur die Sache im Auge habe, laß ich mich auch durch Eitelkeitsregungen anderer, die sich überall als Führer sehen, nicht beirren und noch weniger durch das Bestreben der Emigration, sich überall wichtig zu machen. “ Kluthe möge sich daran halten, daß ,jedenfalls immer falsch [ist], was meinen Mitteilungen und Aufklärungen [...] widerspricht" ${ }^{306}$.

Wenn man diese Texte und Sachverhalte vor dem Hintergrund der historischen Situation, dem chronischen Geldmangel ${ }^{307}$ und der Sorge, mit einer jeweils als falsch angesehenen Ideologie identifiziert zu werden ${ }^{308}$, betrachtet, dann relativieren sich nicht nur die gegen Klepper erhobenen Vorwürfe - sie ließen sich genausogut umdrehen -, sondern Spieckers Ausführungen widersprechen auch seiner eigenen These von der ,EinMann-Gründung' der DFP309. Ganz davon abgesehen, daß er sich in seinem Brief selbst genau so darstellt, wie er es anderen zum Vorwurf macht. Tatsache scheint jedenfalls zu sein, daß Klepper und Spiecker sich voneinander entfernt haben, worunter ihre ursprünglich gute Zusammenarbeit stark gelitten hat. Dennoch ist es unverständlich, warum Spiecker, der über anderthalb Jahre mit Klepper die DFP vorbereitet und manchmal einen fast herzlichen Briefwechsel mit ihm geführt und ihn als Gast in seinem Hause bewirtet hat, plötzlich so tun konnte, als habe er nichts mit Klepper zu tun ${ }^{310}$.

Möglich, daß Klepper sich zunehmend aus der Arbeit der Freiheitspartei zurückgezogen und stärker in den Organisationen Münzenbergs mitgearbeitet hat. Es entspräche seinem Naturell, Dinge in Gang zu setzen und dann die Ausführung anderen zu überlassen. Ehe nun auch die Freiheitspartei, wie die Volksfront, an menschlichen Unzuläng-

304 Vielleicht eine Anspielung auf Klepper, der ausdrücklich im ersten Freiheitsbrief betont hatte, „nach einigen Monaten wird sich diese Taktik ändern“, um die Nationalsozialisten irrezuführen (Spiecker-NL, Bl. 102).

${ }^{305}$ Wohl eine Anspielung auf die Einschaltung Münzenbergs und seiner Organisation durch Klepper.

306 NL-Kluthe, Spiecker an Kluthe, 16. 11. und 21. 11. 1938, Bl. 52.

${ }^{307}$ Ebenda, Spiecker an Kluthe, 12. 5. 1939 (Bl. 145): „Unser Kreuz ist die Finanzfrage, - es geht mir heute schlechter denn je -, und wenn nicht bald etwas geschieht, muß ich meinen Apparat noch mehr verkleinern. Und wir sind schon bedenklich klein geworden."

308 Kluthe argwöhnte in seinem Brief vom 2. 12. 1938, daß „jemand in Paris an unserer Pleite interessiert ist, um unsere Firma fusionsreif zu machen?". Auffallend sei, daß Gerüchte die DFP mit der Zukunft in Verbindung bringen, was Kluthe offensichtlich nicht behagte (ebenda, Bl. 58).

$309 \mathrm{Vgl}$. Gross, S. 310, Kerstens und Münzenbergs Aussagen.

310 Die Nachkriegskorrespondenz zwischen Klepper und Spiecker beschränkt sich auf den Austausch von Grüßen und Wünschen, doch wirft ein Beileidsschreiben Kleppers an den damaligen nordrhein-westfälischen MPräs. Arnold vom 19.11. 1953 zum Tode Spieckers ein interessantes Licht auf die Beziehung zwischen beiden aus Kleppers Sicht: „Ich kannte Spiecker schon aus den Jahren vor 1933 und war später mit ihm zusammen in der Emigration in Paris. Zuletzt, vor wenigen Wochen, traf ich ihn wieder in dem Sanatorium von Dr. Amelung in Königstein. Auf- 
lichkeiten zu scheitern drohte, lag es für Klepper näher, sich zurückzuziehen, als den anderen den eigenen Willen aufzuzwingen. Spiecker scheint sich allerdings auch zunehmend von Kluthe distanziert zu haben. Dies geht aus den Briefen Kluthes an Hermann Rauschning im Herbst 1939 hervor, wobei Kluthe allerdings betonte, daß er Wert auf die Verbindung sowohl mit Spiecker wie mit August Weber - auch ein Mitarbeiter der DFP - lege ${ }^{311}$. Zudem beklagte er, daß es zum Bruch zwischen Rauschning und Spiecker gekommen sei ${ }^{312}$. Rauschning vermutete Hemmungen bei Spiecker und fügte hinzu, daß es eigentlich nicht die Zeit für persönliche Differenzen sei ${ }^{313}$.

So zweifelhaft die erste Begründung Bouviers für die Ausgrenzung Kleppers aus der Arbeit der DFP bei näherer Betrachtung erscheinen muß, so wenig stichhaltig scheint auch die zweite sich auf Gestapo-Unterlagen stützende Begründung zu sein. Es sei „denkbar", so Bouvier, daß die Deutsche Freiheitspartei von Klepper abgerückt sei, weil er das von der DFP „vertretene Prinzip der Anonymität“ durch sein Interview im Le Soir durchbrochen habe ${ }^{314}$. Zunächst ist zu sagen, daß es keine französische, nur eine belgische Zeitung Le Soir gibt; die französische heißt Ce Soir. Sie wurde schon in den 20er Jahren offenbar auf die Initiative von Münzenberg hin in Paris herausgegeben ${ }^{315}$. Das Interview ist nirgends zitiert und offenbar unbekannt geblieben bis auf die ersten in der Anklageschrift der Gestapo gegen Walter zitierten Sätze, so daß niemand wirklich beurteilen kann, was Klepper tatsächlich gesagt hat. Von dem dort ebenfalls zitierten Flugblatt „Freunde“ 316 , in dem die DFP sich von Klepper distanziert haben soll, kann nicht nachgewiesen werden, ob es tatsächlich von der DFP stammte. Es kann genausogut von einer kleinen Splittergruppe der DFP im Reich, die Klepper gerne eins auswi-

grund unserer langjährigen persönlichen Beziehungen kann ich den Verlust, den das Land Nordrhein-Westfalen erlitten hat, ermessen." Ebenda befindet sich auch ein Nachruf für Karl Spiecker von Kurt Kersten in: Aufbau, 20. 11. 1953, dort heißt es u. a.: „Schon seit einigen Jahren erfreute sich Spiecker keiner guten Gesundheit mehr, denn die oft bitteren Enttäuschungen der Emigrationsjahre, zerstörte politische Illusionen, auch Erfahrungen in den Nachkriegsjahren und persönlicher Kummer haben das Herz dieses aufrechten, unerschütterlichen Demokraten [...] geschwächt." (K/Kor.)

311 NL-Kluthe, Kluthes Korrespondenz mit Rauschning, Kluthe an Rauschning: 13./14.10.39 (Bl. 75 f.) Vgl. auch Weißbecker, S. 651.

312 Ebenda und 7. 3. 1940 (Bl. 98): Offenbar seinerseits auf Andeutungen Rauschnings anspielend: „Mein Verhältnis zu Herrn Spiecker war niemals das eines Angestellten zu seinem Chef. Bei unserer Zusammenarbeit ist meine Unabhängigkeit niemals infrage gestellt worden."

${ }^{313}$ Ebenda, Rauschning an Kluthe, Paris 23.10. 1939 (Bl. 79).

${ }^{314}$ Bouvier, S. $7 \mathrm{f}$.

315 Koestler, Vorwort, S. VI.

316 BAK, R 58/645, Bericht Müller vom 22. 9. 1937, S. 3: „In einem Flugblatt, überschrieben: ,Freunde!' wird auf eine ,von seiten der Geheimen Staatspolizei geäußerte Vermutung', es handele sich bei der Deutschen Freiheitspartei um eine kommunistische Angelegenheit, eingegangen und hierbei behauptet, daß zu den Anhängern der Freiheitspartei nur nationalgesinnte Menschen, aber keine Kommunisten und Wichtigtuer vom Schlage des früheren Finanzministers Klepper gehören. - Klepper hatte dem französischen Volksfrontorgan ,Le Soir ' Andeutungen über die Ziele der Freiheitspartei gemacht.“ Diese Version wurde auch im Prozeß gegen G. Walter verwendet. Der Vorspann des Interviews (s.o.) wird zitiert (Bl. 21). In einem etwas früheren Gestapobericht heißt es dagegen: „Eine Organisation oder eine Leitung der ,Deutschen Freiheitspartei' konnte noch nicht festgestellt werden. Nach einem Zeitungsinterview wollte der emigrierte ehemalige preußische Finanzminister Klepper über die ,Deutsche Freiheitspartei‘ Bescheid wissen. Er wurde wegen dieses Interviews heftig in einem kurzen Artikel einer ausländischen Zeitung - wieder ohne Namensnennung der Schreiber - angegriffen“ (Bl. 122). 
schen wollte, herausgegeben worden sein, wie es auch von den Nationalsozialisten oder dem sich angenehm machen wollenden Buchhändler Engelmann, jenes Mannes, der das Flugblatt bei der Gestapo abgab, fingiert worden sein kann.

Was nun das Interview selbst anbelangt ${ }^{317}$, so verstößt es keineswegs, wie immer behauptet wird, gegen die Anonymität der Partei, sondern bestätigt im Gegenteil, daß die DFP innerhalb Deutschlands entstanden sei. Wörtlich antwortete Klepper dem Korrespondenten von Ce Soir, Charles Reber ${ }^{318}$, der ihn in der Schweiz, nahe Basel, interviewt und über die Situation in Deutschland befragt hatte: „La situation est bonne pour les amis de la paix! Il y a trois mois environ, j'ai publié dans une revue allemande, un article $^{319}$ dans lequel je disais que la liberté deviendrait le mot d'ordre de la lutte contre le national-socialisme. Quelques semaines plus tard, les premiers appels du parti allemand de la liberté apparaissaient à Berlin. Pure coïncidence évidamment! mais coïncidence significative!" 320 Befragt, um was für eine Partei es sich handle, sagte Klepper, es sei keine Partei, sondern „un mouvement qui a une tête à Berlin, mais qui n'a pas encore de corps “ 321 . Die Deutschen, nämlich „die kleinen Händler, die Arbeiter und selbst die Bürgerlichen“, hätten, so erklärte er, einen „enormen Bedarf an Freiheit“, nachdem Hitler sie „an den Rand des Abgrundes“ gebracht habe. Sie hätten „noch niemals einen solchen Durst nach Freiheit" gehabt, sie „wollten die Freiheit, die der totalitäre Staat ihnen nicht geben könne“, und so zeige sich die „Erschütterung an der Basis“. Die Bewegung habe sich unabhängig von anderen politischen Organisationen und auch unabhängig von der Volksfront entwickelt, aber "das eine schließe das andere nicht aus“. Noch sei sie nur „ein Geisteszustand des Volkes“, der aber zur "Lebensgrundlage“ werden müsse. Ihr ganzes Programm bestehe in dem Wort „la liberté, toute la liberté", und auf die Frage, wer die Leiter der Bewegung seien, antwortete Klepper: „Tout ce que je peux vous dire, c'est qu'à l'origine de ce mouvement de la liberté se trouvent, avec l'opposition réligieuse et les jeunes officiers de la Reichswehr, l'état d'esprit actuel des grands intellectuels allemands, les milieux universitaires, qui se sentent amoindris sous un régime qui a porté au pouvoir les bas-fonds de l'Allemagne." 322

Aus dieser Erklärung geht hervor, daß Klepper das Entstehen der Freiheitsbewegung als eine logische Folge der Unterdrückung darstellt, die im Reich entstehen mußte, weil der Druck zu groß wurde, und nicht als eine von Emigranten initiierte Partei. Befragt, ob er an ein mögliches Ende des Dritten Reiches glaube, antwortete Klepper, er „glaube an gar nichts, er urteile nur auf der Basis von Fakten“. Zu diesen Fakten gehöre allerdings,

\footnotetext{
317 BN, D 106, Ce Soir, 22. 4. 1937.

$318 \mathrm{Zu}$ Ch. Reber, vor 1933 Korrespondent in Berlin, dann in Paris, vgl. Scheer, S. $92 \mathrm{ff}$.

${ }^{319}$ Gemeint ist der bereits zitierte Artikel „Europäische Freiheit“ im NTB, 26. 12. 1936.

${ }^{320} \mathrm{Ce}$ Soir, 22. 4. 1937. Übersetzung: Die Situation ist für die Freunde des Friedens gut! Vor etwa drei Monaten habe ich in einer deutschen Zeitschrift einen Artikel veröffentlicht, in dem ich sagte, daß die Freiheit ein Schlüsselwort für den Kampf gegen den Nationalsozialismus werden würde. Einige Wochen später erschienen die ersten Aufrufe der Deutschen Freiheitspartei in Berlin. Offensichtlich ein reiner Zufall, aber ein bedeutsamer Zufall.

321 Übersetzung: Eine Bewegung, die einen Kopf in Berlin, aber noch keinen Körper hat.

322 Übersetzung: Alles, was ich Ihnen sagen kann, ist, daß sich am Ursprung dieser Freiheitsbewegung neben der religiösen Opposition und jungen Reichswehroffizieren der aktuelle Geisteszustand der großen deutschen Intellektuellen und des Universitätsmilieus befindet, dic sich unter einem Regime beeinträchtigt fühlen, das den Abschaum Deutschlands an die Macht gebracht hat.
} 
daß das deutsche Volk der Hitler-Diktatur müde zu werden beginne und daß noch vor einem Jahr eine solche „Freiheitsbewegung im Reich unmöglich gewesen wäre“. Klepper führte diese neue Situation vor allem auf zwei Faktoren zurück, einmal empöre man sich inzwischen über die Aktionen der vor Madrid besiegten deutschen Truppen im Spanischen Bürgerkrieg, die man bisher ignoriert habe, und zum anderen sei die wirtschaftliche Situation „beunruhigend“. Der Ausblick, den Klepper in diesem Interview gab, klingt sehr optimistisch und wird durch die folgende von Reber beschriebene Situation symbolisiert: Klepper sei aufgestanden, habe das Fenster geöffnet und gesagt: „Le printemps vient, il faut en respirer l'air! Le monde va sortir d'un cauchemar épouvantable. “ ${ }^{323}$ Den Anlaß für seinen Optimismus bezog Klepper damals, im Frühjahr 1937, aus den Erfolgen der Volksfront in Frankreich und Spanien, und der, wie er glaubte, aufbrechenden Situation im Reich. Wieweit dieser Optimismus ein Zweckoptimismus war und der jungen Freiheitsbewegung Wind unter die Flügel blasen sollte, ist schwer zu beurteilen, jedenfalls steht dahinter der dringende Appell an die ausländischen Mächte, Hitler zu besiegen, solange noch Zeit dazu war, und Deutschland schleunigst „in Europa zu integrieren“, wofür die deutsch-französische Aussöhnung eine erste Voraussetzung sei.

Diese kurzen Hinweise auf eine derart verworrene und von politischen Intrigen durchsetzte Situation illustrieren das, was oben bereits allgemein über die Quellenlage festgestellt wurde. Es ist schwierig, für die Tätigkeit der Deutschen Freiheitspartei verläßliche Anhaltspunkte zu finden. Fest steht jedoch, daß das geistige Konzept für die Deutsche Freiheitspartei weitgehend von Klepper stammte und daß er die Partei entscheidend mitbegründet und aufgebaut hat ${ }^{324}$. Das wohl überzeugendste Argument ist die Tatsache, daß die oben dargelegten Konzepte Kleppers sowohl inhaltlich wie organisatorisch genau mit der späteren Arbeit der Freiheitspartei übereinstimmen und sich sein Gedankengut teilweise fast wörtlich in den Freiheitsbriefen wiederfindet. Diese Identität von Planung und Durchführung wird voll bestätigt durch einen „Die Freiheitspartei“ überschriebenen Artikel vom April 1937 im Neuen Tagebuch ${ }^{325}$. Dort heißt es: „Zum ersten Mal hat dieser Tage die Weltöffentlichkeit von der Tätigkeit einer unterirdischen Organisation erfahren, die in Deutschland selber die Opposition gegen das Hitler-Regime zu sammeln versucht." Es wird berichtet, daß die internationale Presse den 2. Freiheitsbrief, mit dessen „Verbreitung [...] bereits vor mehreren Wochen begonnen“ worden war, in Auszügen nachgedruckt habe, und damit hätten „die Berichte der Auslandsjournalisten nur bestätigt, daß die Organisation funktioniert“, genau das, was Klepper geplant hatte ${ }^{326}$. Weiter heißt es, daß Anfragen ausländischer Journalisten beim Propagandaministerium ergeben hätten, daß die Nationalsozialisten vorgäben, „die Sache

323 Übersetzung: Der Frühling kommt! Man muß Luft holen! Die Welt wird aus einem schrecklichen Alptraum herausschreiten.

324 „Klepper, der längere Zeit im Volksfrontausschuß mitgearbeitet hatte, gründete mit anderen Gleichgesinnten eine „Deutsche Freiheitspartei', die sich ais Sammlungsbewegung unter Ausschluß der Kommunisten entwickelte, wenngleich seine Motive nicht jener aggressiven antikommunistischen Grundhaltung entsprangen wie die von Schwarzschild“ (Pech, Exil, S. 111). Dabei spielte auch das Geld, das Klepper aus Amerika erhielt, eine Rolle. Auf eine Finanzierung durch amerikanische Gelder wird auch in den zitierten Gestapo-Unterlagen mehrfach verwiesen.

${ }^{325}$ NT'B, 4. 4. 1937 , S. 369.

$326 \mathrm{Vgl}$. Klepper an Aron, 18. 7. 1936 (BAP, 90 Sp2, Bl. 101). 
nicht ernst“ zu nehmen und darin "nur ein $[e n]$ neuen Beweis für die Propagandatätigkeit der Emigranten“ zu erblicken. Genau das aber sei „unwahr“, erklärt das NTB, denn abgesehen von dem Auftauchen der Freiheitsbriefe, habe man sogar aus der reichsdeutschen Presse entnehmen können, „daß eine Freiheitspartei sich im Reich bemerkbar macht", eine Partei freilich ohne Mitgliedsbücher und ohne Organisation, aber „leibhaftig, und zwar mitten im nationalsozialistischen Berlin“ existent. Als Beispiel wird der in der Frankfurter Zeitung beschriebene „stürmische Beifall“ im "Deutschen Theater" in Berlin bei dem Satz aus Schillers „Don Carlos": „Sire, geben Sie Gedankenfreiheit!“ zitiert. Der Artikel endet mit den Sätzen: „Von solchen Theaterkundgebungen zum aktiven Kampf für den Sturz des Regimes kann der Weg noch sehr weit sein. Aber sie zeigen immerhin, wie reif bereits der Boden ist, in dem die unterirdischen Vorkämpfer der ,Deutschen Freiheitspartei" säen“. Dieser Artikel ist anonym erschienen, er diente dem gleichen Ziel wie das viel zitierte Interview Kleppers.

\section{„Die Zukunft" und „Die Deutsch-Französische Union“}

„Europäische Freiheit“ nannte Klepper seinen gleich nach der Flucht aus Spanien im Dezember 1936 im Neuen Tagebuch veröffentlichten Aufsatz und dies war zugleich sein Programm, ohne ein freies Deutschland kein freies Europa. In dem Kampf der „Knechtschaft“ mit der „Freiheit" siegt schließlich immer die Freiheit. „Das wird auch das Ergebnis dieser Epoche sein, die 1789 begonnen hat und vor deren Abschluß wir stehen. " ${ }^{327}$ Wo suchte Klepper seine Ansatzpunkte, um für Europa zu arbeiten? Einer war die Deutsche Freiheitspartei, aber da diese anonym und nur auf Deutschland bezogen arbeitete, war das nicht genug. Die Zukunft mußte entworfen werden, damit ein freies Europa zur Realität werden konnte, wenn der Nationalsozialismus und der Faschismus besiegt sein würden. So hat Klepper im Frühjahr und Sommer 1937 neben seiner Tätigkeit für die Freiheitspartei nach neuen Möglichkeiten gesucht. Davon zeugt zum Beispiel, wenn auch in dürren Worten, die Tagebucheintragung Thomas Manns unter dem 13. März 1937: „Zum Tee der ehemalige Minister K. aus Paris. Gespräch über die notwendige Nachfolge des Nazi-Regimes und ihre Vorbereitung." Außerdem war von dem „vermutliche[n] Eingehen der Pariser Tageszeitung und ihr[em] Ersatz durch eine Wochenzeitung" die Rede ${ }^{328}$. Nach dem Gespräch galt es für Klepper, heimzureisen oder bei Freunden Unterschlupf zu finden, für Thomas Mann galt: „Smoking-Toilette und Abendessen" ${ }^{329}$, feine Unterschiede!

${ }^{327}$ NTB, 26. 12. 1936, S. 1238. Auch in dem letzten Satz des Interviews im Ce Soir klingt bereits der zweite große Schwerpunkt von Kleppers Arbeit in den Jahren 1937 bis 1940 an, die Arbeit für ein geeintes Europa.

328 Th. Mann, Tagebücher Bd. II, S. 39.

${ }^{329}$ Ebenda, unter dem 13. 7.1937 (S. 76), notierte Th. Mann: „Studium einer polit. Schrift v. K., Paris“, und am 16. 7. 1937 heißt es: „Nachmittags Brief-Diktate (Dr. Klepper, Paris)“ (S. 76 f.). Der Brief gilt als verschollen. 
$\mathrm{Zu}$ den wichtigsten Gesprächspartnern Kleppers gehörten Babette Gross ${ }^{330}$ und Willi Münzenberg, zumal auch Münzenberg auf der Suche nach einem „neuen Betätigungsfeld für seine unerschöpfliche Energie " war ${ }^{331}$, nachdem die Volksfront im Scheitern begriffen und seine Trennung von den Kommunisten abzusehen war ${ }^{332}$. Klepper verfolgte ein dreifaches Ziel, er suchte ein Organ, das immer wieder über die Tätigkeit der Freiheitspartei in Deutschland berichtete, er suchte eine Zeitschrift, in der er seine Gedanken zur aktuellen politischen Lage und vor allem zur zukünftigen Entwicklung äußern konnte, und er suchte eine Möglichkeit, aktiv etwas für die europäische Vereinigung zu tun. Alle drei Ziele konnte er schließlich mit Münzenberg zusammen durch die neugegründete Wochenzeitschrift Die Zukunft verwirklichen ${ }^{333}$.

Wer nun in welchem Maße an ihrer Gründung beteiligt war, läßt sich schwer ausmachen, jedenfalls ist Die Zukunft ein Gemeinschaftsunternehmen, dessen Hauptinitiator und verantwortlicher Herausgeber allerdings Willi Münzenberg hieß. Neben ihm gab es einen zweiten Herausgeber und vor allem Geldgeber, den Franzosen Guy Menant, ein ehemaliger französischer Abgeordneter ${ }^{334}$. Auch Pierre Comert stand wohl in Verbindung zur Zukunft, aber offiziell nur als Privatmann und Journalist, was nicht ausschließt, daß er sich in seiner Eigenschaft als Pressechef des französischen Außenministeriums für die Unterstützung der Zukunft unter der Hand eingesetzt hat ${ }^{335}$. Comert

${ }^{330}$ Charles Sternberg erinnert sich, beide viel zusammen gesehen zu haben (Brief an Verf.). Sicher wurde hier die Freundschaft begründet, die beide im Exil in Mexiko und später nach dem Kriege in Frankfurt/M. zusammenhielt.

${ }^{331}$ Koestler, Zeuge, S. 386.

332 Gross, S. 304 ff. Münzenberg erklärte seinen Austritt aus der KP im Januar 1939 (C.A.R.A.N., F/7, 15129 [3]). Sein Erklärungsschreiben hat er in der Zukunft vom 10.3. 1939 veröffentlicht, teilweise bei Gross abgedruckt, S. $317 \mathrm{f}$.

333 Ihre erste Nummer erschien am 12. 10. 1938. Gross nennt die Gründung der Zukunft „das ambitiöse Unternehmen seiner [Münzenbergs] letzten Lebensjahre“ (S. 319). Auch Kersten, der nirgends, außer bei Wessel, S. 228, genannt wird, stand Pate bei der Gründung. Laut Tania Schlie, deren Vortrag Harald Wessel zitiert, soll die erste Ausgabe für Anfang Oktober geplant gewesen sein, hätte aber wegen der Münchner Konferenz umgeschrieben und verändert werden müssen (S. 351, Anm. 52).

334 C.A.R.A.N., F/7, 15129 [3], F.: Thormann an Paul Frischauer (London), 14. 1. 1939. In Gestapoberichten und andernorts tauchen Vermutungen über amerikanische Geldgeber auf, was auf Kleppers Verbindungen verweisen könnte (Vladeck und Prinz Löwenstein). Ein Brief Thormanns vom 27. 10. 1939 (F/7 15127/1/a, Dossier sur l'ex-chancelier Wirth + Cor.) legt eine Unterstützung durch das französische Außenministerium nahe; demnach habe es eine monatliche Subvention von 50000 Francs, die später gekürzt wurde, gegeben. Diese Verbindung verweist wiederum auf Pierre Comert, s.u. Vgl. auch Wessel, S. 208 ff., Maas, Handbuch, Bd. 4, S. 245 ff. Laut Gross soll auch O. Aschberg zu den Geldgebern gehört haben. Bezahlt wurden übrigens 100 Francs pro Spalte. Dies erwähnt Münzenberg in einem Brief an den Chef du Cabinet du Ministre des Finances, M. Palewski, vom 21. 9. 1939; in diesem Brief beschreibt Münzenberg die Arbeit der Zukunft genauer, möglich, daß der Brief Grundlage für eine Bitte um Unterstützung war (ebenda, 15123, P).

${ }^{335}$ Nach der Zerstörung der Archive des französischen Außenministeriums durch die Behörde selbst vor dessen Überführung nach Bordeaux, im Juni 1940, sind nur etwa 20 Kartons des „service de Presse" übriggeblieben, in ihnen ist kein Dossier über die Zukunft gefunden worden, ebensowenig in den noch verbliebenen 74 folios „sur la Presse en général“ (Schreiben des Archivs des französischen Außenministeriums vom 15. 10. 1992 und der Archivarin, Madame Pouillon, vom 5. 10. 1992). Auch in den Privat-Papieren Comerts findet sich keinerlei Hinweis auf die Zukunft. Vgl. auch Walter, Bd. 4: Exilpresse, S. 131. 
hatte immer schon eine enge Verbindung zu Deutschland. Er hat in Göttingen studiert, war später lange Korrespondent von Le Temps in Berlin und kannte Münzenberg aus dieser Zeit ${ }^{336}$. Bis 1933 war er Leiter der Presse- und Informationsabteilung des Völkerbundes und ab 1933 Pressechef des Quai d'Orsay und Chef der Propagandaabteilung ${ }^{337}$. Es ist anzunehmen, daß Comert, der häufiger nach Deutschland reiste und eng mit dem französischen Botschafter in Berlin, François-Poncet, befreundet war ${ }^{338}$, wichtige Informationen an Münzenberg weitergab und eventuell auch Material im Botschaftsgepäck nach Deutschland transportierte. Comerts Einschätzungen der Situation in Deutschland sind sehr interessant. So berichtet er zum Beispiel streng vertraulich über seine Eindrücke von einer Berlin-Reise im November 1937. Unter anderem beschreibt er die Demoralisierung und Resignation hoher Staatsbeamter und kommt zu dem Fazit, daß in der deutschen Politik viel weniger Methode und Logik sei, als man glaube, daß sie wie eine Maschine stur ihre Bahn ziehe, und diejenigen, die sie zu bedienen haben, hätten keine Ahnung, während diejenigen, die Ahnung hätten, ohne Einfluß seien ${ }^{339}$.

Es ist wichtig, Die Zukunft als ein Gemeinschaftswerk zu sehen, denn sonst ist die vielgestaltige Linie der Zukunft, die sich aus der Vielfalt der Meinungen ergab, nicht zu verstehen, beziehungsweise mißzuverstehen. So wie Hans-Albert Walter das tut, indem er die Linie der Zukunft, die er als „taktisch kurzatmig, ebenso fintenreich wie letzten Endes opportunistisch “ charakterisiert, mit dem Hinweis erklärt, daß Münzenberg alleiniger Initiator und Gestalter der Zukunft war und damit „an die Grenze seiner Fähigkeiten" als Theoretiker gestoßen sei und „Verrat an sozialistisch-marxistischen Prinzipien" verübt habe ${ }^{340}$. Schon an der Zusammensetzung des Redaktionsstabes läßt sich able$\operatorname{sen}^{341}$, daß es Münzenberg auf eine Vielfalt der Meinungen ankam, so wie Klepper es in einem seiner Zukunfts-Artikel mit dem Titel „Wo stehen wir?" ausdrückte: „Die Mitarbeiter und Leser dieser Zeitschrift sind weder in einer Organisation verbunden, noch entstammt ihr Denken einem gemeinsamen grundanschaulichen Ausgangspunkt. Gleichwohl ist unter ihnen und durch sie eine bestimmte Konzeption künftiger deutscher Politik in der Entwicklung begriffen. " ${ }^{342}$ Aus diesem gemeinsamen Ziel, das am klarsten in dem Untertitel der Zeitschrift „Ein neues Deutschland: Ein neues Europa!“ zum Ausdruck kam, ergibt sich folgerichtig ein zweites Merkmal dieser Zeitschrift,

336 Gross, S. $278 \mathrm{f}$.

337 AD, Comert, Vol.3.

338 Ebenda, Vol.1, Bl. 36: Comert lehnte eine Einladung des deutschen AA mit der Begründung ab, er wohne in der französischen Botschaft, da er mit François-Poncet schon seit 26 Jahren eng befreundet sei.

339 Ebenda, ab Bl. 50.

340 Walter, Exilpresse, S. $180 \mathrm{ff}$. Vgl. dazu: Wessel, S. $205 \mathrm{ff}$.

341 Inhaber und Hrsg.: Guy Menant (französischer Kammerabgeordneter); Hrsg.: Münzenberg; Chefredakteur: Werner Thormann (früher Mitarbeiter von Wirth), anfangs Koestler; Redakteure und Mitarbeiterstab: Koestler, Ludwig Markuse, Herbert Weichmann (Wirtschaft), Max Beer (Außenpolitik); Die Zukunft hat ein besonders enges Verhältnis zu oppositionellen, protestantischen Kreisen, deutschen und österreichischen Schriftstellern, jüdischen Kreisen aller politischen Richtungen (Thormann an Paul Frischauer [London], 14. 1. 1939, C.A.R.A.N., F/7, 15129 [3], F).

342 Klepper in: Die Zukunft, 5. 1. 1940. 
nämlich daß sie eine Propagandaschrift im ursprünglichen Sinne des Wortes ${ }^{343}$ sein wollte und sein mußte ${ }^{344}$. In diesen Zeiten und unter den oben bereits erläuterten Umständen blieb den Emigranten gar nichts anderes übrig, als propagandistische Mittel einzusetzen, um ihre Ziele deutlich zu machen, was nicht heißt, daß es sich um eine „optimistische Phraseologie" handelte, wie Walter es der Zeitung vorwirft und damit begründet, daß Die Zukunft keine detaillierten Verfassungsentwürfe geliefert und nicht den „sozialistischen Anspruch planend und übend zu konkretisieren" versucht habe ${ }^{345}$. Die Zukunft wollte weder eine wissenschaftliche Fachzeitschrift noch eine allein an den Interessen der Arbeiterklasse orientierte Zeitung sein. Sie wollte vielmehr Informationen weitergeben und auf Mißstände aufmerksam machen. So erschien zum Beispiel auf der Titelseite der Zukunft am 27.1. 1939 eine Karte von Deutschland, in der die meisten Konzentrationslager eingezeichnet waren. Außerdem sind in der Zeitschrift sehr wohl Konzepte für die Zukunft entworfen und der soziale Aspekt vorrangig beachtet worden, wie sich unter anderem am Beispiel von Kleppers Artikelserie nachweisen läßt.

Klepper fand in der Zukunft, deren Bild er nach außen mitverantwortete, das, was er gesucht hatte: ein Forum für die Freiheitspartei ${ }^{346}$ und ein Forum für seine eigenen Gedanken. Schließlich gelang es auch, sein drittes Ziel: Europa, auf der Plattform der Zukunft anzusteuern.

Der Schwerpunkt von Kleppers zwölf Artikeln, die er in der Zukunft veröffentlichte, lag in dem Entwurf eines Konzepts für ein Deutschland nach Hitler ${ }^{347}$. Seine historische Ausgangsbasis entsprach der bereits im Zusammenhang mit den Mallorca-Schriften erläuterten, und auch seine Grundgedanken, die alle auf dem Prinzip der Freiheit basieren, sind ähnlich, aber präziser und zielgerichteter gefaßt. „Aufgabe der Politik“, die er als eine „rationalistische Disziplin“ beschreibt, sei es, Bedingungen zu schaffen, die dem einzelnen einen Anreiz bieten, den an ihn gestellten Anspruch, mündiger Staatsbürger zu sein, auch erfüllen zu können, und dadurch dazu beizutragen, die Gesellschaft in ein größeres Gleichgewicht zu bringen. Dafür müßten die Funktionen im Wirtschaftsprozeß, das „Verfügen“ über die Produktionsmittel, das „Planen“ der ökonomischen Prozesse und das „Ausführen“ der Arbeit, näher zusammenrücken, wozu es auf nationaler Ebene eines „scharfen ökonomischen Eingriffs" bedürfe, nämlich der „Lösung der

343 „Propaganda [lat.]: systematische Verbreitung politischer, weltanschaulicher o. ä. Ideen und Meinungen [mit massiven (publizistischen) Mitteln] mit dem Ziel, das allgemeine [politische] Bewußtsein in bestimmter Weise zu beeinflussen" (Fremdwörterlexikon, Mannheim 1982, S. 628).

${ }^{344}$ Vgl. Koestler, Die Geheimschrift, S. 433 und Gross, S. 323.

345 Walter, Exilpresse, S. $181 \mathrm{f}$.

346 „Ohne mit der DFP organisatorisch verbunden zu sein, hat sich Die Zukunft die Aufgabe gestellt, in dem Teil des Blattes, der der bürgerlichen Opposition zur Verfügung gestellt wird, speziell diese Bewegung zu Worte kommen zu lassen. Sie druckte den Artikel des ehemaligen Danziger Senatspräsidenten Rauschning ab, in dem dieser sich zur DFP bekannte und druckte aus Flugblättern dieser Partei nach, soweit sie ihr zugänglich wurden" (Thormann an Frischauer, 14. 1. 1939, F/7, 15129 [3] F).

${ }^{347} \mathrm{Vgl}$. dazu die teilweise parallelen, teilweise abweichenden Pläne linkssozialistischer Emigranten bei Grebing und allgemeiner: Jasper, Entwürfe. 
Großindustrie aus dem privatwirtschaftlichen Sektor und einer radikalen Agrarreform" ${ }^{348}$.

Vor allem die Deutschen müßten alte Denkstrukturen über Bord werfen und durch eine genaue Fehleranalyse zu verstehen suchen, was Deutschland in diese zerstörerische Politik hineingetrieben habe ${ }^{349}$. Das deutsche Volk müsse allmählich an eine Demokratisierung herangeführt werden, indem es lerne, Verantwortung zu übernehmen und sich nicht einfach einem ,Führer' zu überlassen, und indem es eine konkrete Vorstellung davon gewinne, wie der sozialökonomische Organismus umgebaut werden müsse, damit eine freie Marktwirtschaft entstehen könne ${ }^{350}$.

Auf internationaler Ebene bedürfe es einer Überwindung des Autarkiedenkens und einer stärkeren Einsicht in die Tatsache, daß die Welt sich aufgrund der modernen Technik verkleinert habe und wir einer „fortschreitenden Verfeinerung der internationalen Arbeitsteilung" entgegengingen ${ }^{351}$. Gewännen wir diese Einsichten nicht, das hieße konkret gesprochen, bauten wir die Zoll- und Handelsschranken nicht ab, und schafften keinen „einheitlichen europäischen Wirtschaftsraum“, dann verkümmerten wir nicht nur „zu notleidenden Weltwirtschaften in Taschenformat", sondern gefährdeten den Frieden, und zwar die rohstoffärmsten und bevölkerungsreichsten Länder an erster Stelle, weil „schließlich aus Hilflosigkeit jener Expansionsdrang [entstebe], der ,Führer“ benötigt, um den Raub fremden Landes zum Zwecke der Ausbeutung zu organisieren“. Vorbedingung für Europa sei „die Versöhnung Frankreichs und Deutschlands“, sie würde „die Erlösung Europas bedeuten“ ${ }^{352}$. Wie wenig Walter Kleppers Artikel beachtet hat, zeigt die Tatsache, daß er schreibt, Klepper habe den Gedanken der Westorientierung in seinen beiden Artikeln „Abendländischer Rationalismus" vom 16. Februar und vom 5. April 1940 von Hans Schwann übernommen und „im Interesse des wirtschaftlichen Aufbaus [...] für die Westorientierung und die finanzielle Hilfe der Westmächte“ plädiert. Abgesehen von formalen Fehlern - Klepper hat seine Ideen zu Europa schon 1939 entwickelt, der von Walter falsch zitierte Artikel ist „Abendländischer Reformismus" überschrieben und erschien schon vor Schwanns Artikel, der vom 29. März 1940 stammt - handelt es sich hier um eine völlige Fehlinterpretation von Kleppers politischen Zielen und um eine Verkennung seines Einsatzes für Europa und die deutschfranzösische Zusammenarbeit von Beginn an ${ }^{353}$.

Diesem in groben Zügen skizzierten Entwurf für eine zukünftige Politik stellte Klepper eine Analyse der Friedens- beziehungsweise Kriegspolitik der Alliierten Nazideutschland gegenüber an die Seite. Diese Analyse spitzt sich auf den Satz zu: „Realpolitisch lautet die Alternative: Sturz Hitlers oder Krieg." Warnend führte Klepper Anfang Juni 1939 aus: „In dieser Lage muß die aus der Einladung zum Verhandlungstisch klingende Bereitschaft zu weiteren Konzessionen friedensgefährdend wirken; denn der Gegenspieler weiß aus Erfahrung, daß die vollendete Tatsache nicht nur schnelleren, son-

${ }^{348}$ Klepper in: Die Zukunft, 3. 3. 1939. Vgl. zu dem wirtschaftlichen Komplex die alten Denkmustern verhaftete Kritik Walters, die im übrigen Kleppers Artikel völlig außer acht läßt (Exilpresse, S. $170 \mathrm{ff}$.).

${ }^{349}$ Klepper in: Die Zukunft, 14. 7. 1939.

350 Klepper in: Die Zukunft, 13. 10. 1939.

${ }^{351}$ Klepper in: Die Zukunft, 3. 3. 1939.

${ }^{352}$ Klepper in: Die Zukunft, 28. 4. 1939.

${ }^{353}$ Walter, Exilpresse, S. 173. 
dern auch größeren Erfolg verspricht als das diplomatische Gespräch." Nur die entschiedene Front der Alliierten gegen die Ansprüche Hitlers kann sein Ansehen im Inneren schmälern und mit dem ausgebliebenen Erfolg „die bisher fehlenden Voraussetzungen für die erfolgreiche Aktivierung der oppositionellen Kräfte in Deutschland" schaffen $^{354}$. Die Sorge, daß es wahrscheinlich auch dazu schon zu spät war, verpackte Klepper in einen Konjunktiv. Die Tatsache, daß er nur fünf Wochen später ,einer Verbindung der britischen Politik mit dem deutschen Volk gegen den Nationalsozialismus eine reale Chance“ meint geben zu können ${ }^{355}$, zeigt, wie groß die Verzweiflung gewesen sein muß, $\mathrm{daß}$ die realistische Einschätzung immer stärker hinter Wunschdenken und Beschwörung der Verantwortlichen zurücktrat. Ganz deutlich wird dieser taktisch bedingte Selbstbetrug erst, als der Krieg ausgebrochen war und Klepper in der ersten Kriegsnummer der Zukunft schrieb: „Wir haben gehofft, Deutschland werde sich seiner verhängnisvollen Staatsführung selbst entledigen, bevor sie das Verbrechen der Kriegsentfachung begehen konnte. Dafür haben wir in diesen Jahren gekämpft. "356

Nachdem der Krieg ausgebrochen war, wurde Kleppers Beurteilung der Lage trotz vielfacher Meldungen von Blitzsiegen wieder ganz klar, und man könnte sagen, sogar hellsichtig, denn er stellte fest, daß „der Bestand der abendländischen Gesellschaft [...] unabhängig davon [ist], ob Deutschland ihr angehört oder nicht“, wie es „die Erfahrung der letzten sieben Jahre" bereits bewiesen habe, und daß, wenn Deutschland es nicht aus eigener Kraft schaffe, „die sozial-ökonomische Form“ zu finden, die es „dazu befähigt, sich ihr wieder einzugliedern, [...] so wird die abendländische Gesellschaft versuchen, sich vor weiteren Störungen zu sichern. Deutschland würde unter diesen Umständen zerfallen und wahrscheinlich teilweise dem russischen politischen System unterworfen werden.“ ${ }^{357}$ In dieser Zeit größter Bedrohung und der Gefahr zu resignieren, wurde Finnland nicht nur für Klepper zum Symbol der „abendländischen Freiheit“ im Widerstand gegen den Totalitarismus ${ }^{358}$.

Mögen die Zukunftsentwürfe und die Appelle an die Vernunft vielen als Utopie erschienen sein oder heute erscheinen, so galt doch für die Mitarbeiter der Zukunft, die "gewiß nicht in allem das Gleiche" dachten, was Klepper in einer Grußadresse zum einjährigen Geburtstag der Zukunft geschrieben hatte: „Wir wollen aber in die künftige deutsche Politik einen Zug tragen, der unser Volk zur europäischen Freiheit führt. Schwache Seelen glauben nicht an das Gelingen, sondern bezeichnen uns als Utopisten. Verweisen wir sie auf die [...] realistische Devise des Rabbi Tirfon: ,Dir ist es nicht aufgegeben, das Werk zu vollenden. Aber Dir ist nicht die Freiheit gegeben, Dich Deiner Aufgabe zu entziehen." “359

\footnotetext{
${ }^{354}$ Klepper in: Die Zukunft, 9. 6. 1939.

${ }^{355}$ Klepper in: Die Zukunft, 14.7. 1939.

${ }^{356}$ Klepper in: Die Zukunft, 6. 9. 1939.

357 Klepper in: Die Zukunft, 13. 10. 1939.

358 Klepper in: Die Zukunft, 23. 2. 1940. Finnland, sein erstes Zufluchtsland; der Artikel klingt wie eine Dankadresse. In der gleichen Nummer schrieb Thomas Mann ähnlich wie Klepper: „Wenn die Finnen ihre Mannheim-Linie den gegenwärtigen Wall der westlichen Zivilisation nennen und ich glaube, daß sie dies mit Recht tun - so möchte ich dieser Feststellung hinzufügen, daß die Arbeiter und Bauern dieser kleinen Nation, ob sie nun Sozialisten sind oder nicht, augenblicklich die wahren Ideale und Hoffnungen verteidigen."

${ }^{359}$ Klepper, eine der Leserzuschriften: „Ein Jahr Zukunft“, 13. 10. 1939.
} 
Genau darum ging es auch bei der Gründung der Deutsch-Französischen Union wenige Wochen vor Kriegsausbruch, im Frühjahr 1939. Die Gründer, an deren erster Stelle Klepper neben Rauschning, Münzenberg und Thormann stand ${ }^{360}$, waren sich der Verwegenheit ihres Tuns bewußt, in einer Zeit höchster Kriegsgefahr „an die Möglichkeiten einer Zukunft zu denken [und mit] der deutsch-französischen Zusammenarbeit die Grundsteine der Organisation Europas, eines Europas der Freiheit, des Friedens und der Demokratie“ zu legen ${ }^{361}$. Für sie war es die einzige Hoffnung, in dem Sinne, in dem es die französischen Vertreter der Union am 19. Mai 1939 auf der ersten deutsch-französisch gestalteten Seite der Zukunft ausdrückten: „Auch wenn der Krieg unvermeidlich sein sollte, wird die Deutsch-Französische Union fortfahren, all ihre Anstrengungen auf die Gründung eines politisch geeinten und föderativ gegliederten Europa zu richten und auf die Organisation einer wirklichen übernationalen, mit der Verteidigung der Demokratie beauftragten Macht." 362

Was ist der Maßstab, um den Sinn einer solchen Gründung kurz vor dem sehr wohl erahnten Kriegsausbruch zu beurteilen? Hans-Albert Walter fragt nach dem tatsächlichen Einfluß, nimmt die „praktische Bewährungsprobe“ zum Maßstab, zum Beispiel ob die Union nach Ausbruch des Krieges „die Exilierten vor den Internierungsmaßnahmen der französischen Behörden“ hat schützen können. Ob sie’s getan hat, läßt er offen, da „über die tatsächliche Aktivität der Vereinigung" wenig bekannt sei. Sein Urteil heißt dennoch „lebensunfähige Spätgeburt“ und „Potemkinsches Dorf“ ${ }^{363}$. Dazu ist zweierlei zu sagen: Die Mitglieder der Deutsch-Französischen Union sind ebenso wie die Mitarbeiter des $N T B$ und der Zukunft, deren letzte Nummer am 10. Mai 1940, am Tag der deutschen Offensive in Belgien, erschien, tatsächlich entweder gar nicht interniert oder nach ein paar Wochen wieder freigelassen worden ${ }^{364}$, gleiches scheint auch für den Mit-

${ }^{360}$ C.A.R.A.N., F/7, 15129, Vol.2, Heft b.

${ }^{361}$ Die Zukunft, 2. Jg., Nr. 17, 28. 4. 1939. Titelseite: Bekanntmachung der Deutsch-Französischen Union und aller Unterschriften französischer und deutscher Journalisten, Schriftsteller und Politiker, vor allem auf französischer Seite, davon viele spätere Mitglieder der Résistance. Den Leitartikel auf der 2. Seite schrieb Hermann Rauschning, er sticht in seiner Schwülstigkeit etwas von den größtenteils sehr viel nüchterneren übrigen Artikeln der Nummer ab.

362 Die Zukunft, 2. Jg. , Nr. 20, 19. 5. 1939. Titelseite: Aufruf „an alle Vertreter des geistigen und politischen Lebens in Frankreich“, nachdem die Gründung der Deutsch-Französischen Union "ein starkes Echo gefunden" habe.

${ }^{363}$ Walter, Exilpresse, Anm. 74, S. 756 und 182.

${ }^{364}$ Im Gestapobericht vom 30. 11. 1939 (BAK, R 58/627, Bl. 83) heißt es, sie seien in Freiheit. Dazu paßt ein Brief von Babette Gross an Prinz Löwenstein (USA), 20.10. 1939, in dem sie Löwenstein um einen Beitrag bittet und berichtet, daß zwar "alles unverändert" sei, aber die Zukunft mit großer Mühe weitergeführt werde, da „unsere Leute immer noch interniert" seien, wobei es nicht nur um die Mitarbeiter, sondern vor allem auch um die Leserschaft ging, die nun fehlte (Der Brief ist in französischer Sprache abgefaßt. Dt.Bibl., NL-Löwenstein). Klepper hat zwischen Mitte Oktober (VI, 13.10. 1939) und Anfang Januar (VII, 5. 1. 1940) keine Artikel geschrieben, und in seinem autorisierten Lebenslaut heißt es, daß er bei Ausbruch des Krieges interniert, dann aber auf Veranlassung französischer Freunde entlassen worden sei (KNL), wobei "Ausbruch des Krieges" keine ganz korrekte Angabe ist, denn die 50-jährigen wurden zunächst nicht interniert, was auch Gross in dem zitierten Brief erwähnt: „[...] jetzt sind auch die älteren Leute zwischen 50 und 65 interniert worden. “ Bei Kleppers sogenannter Internierung kann es sich nur um ein zwei Tage gehandelt haben, denn in der Akte Mexiko heißt es ausdrücklich, daß er nicht interniert gewesen sei, weil er aufgrund seiner Staatenlosigkeit seit dem 7. 2.1938 im Besitz einer französischen Identitätskarte war, die bis zum 9. 8. 1942 Gültigkeit hatte (Dokument: 
arbeiterkreis der PTZ zuzutreffen, denn die PTZ erschien noch bis Februar $1940^{365}$. Selbst wenn die französischen Behörden wenig dazu beigetragen haben, daß die deutschen Antifaschisten auf freiem Fuß blieben, so hat das doch sehr wenig mit der Beurteilung der Deutsch-Französischen Union zu tun, die ja gerade auch von solchen Franzosen unterstützt wurde, die mit dem offiziellen Frankreich keineswegs einig und sich sehr wohl der Krise bewußt waren, in der ihr eigenes Land steckte ${ }^{366}$.

Vor allem aber ist zu fragen, ob dies in jener historischen Situation der angemessene Maßstab ist, um ein Werk wie die Deutsch-Französische Union angemessen zu beurteilen? Ging es nicht viel mehr darum, Zeichen zu setzen, Zeichen im Sinne einer historischen Kontinuität, die mit der deutsch-französischen Verständigungsarbeit eines Stresemann und eines Briand begonnen hatte und später von Adenauer und de Gaulle wieder aufgenommen werden sollte; Zeichen der Erinnerung, die die beiden Länder auch während der Zeiten der „Verblendung" zusammengehalten hat, wie sie Yvon Delbos, ehemaliger französische Außenminister, in der Unions-Ausgabe der Zukunft unter der Überschrift „Die Stunde wird kommen“ beschwört ${ }^{367}$, Zeichen der persönlichen Freundschaft, die auch mitten in der Enttäuschung und Verzweiflung Hoffnung anbieten konnte?368 Alain Poher, bis 1992 Präsident des französischen Senats, der die Gründung der Deutsch-Französischen Union als junger Mann miterlebt hat und die meisten der Mitglieder, vor allem der französischen, auch aus der Nachkriegszeit, soweit sie den Krieg überlebt hatten, kannte, hat in einem persönlichen Gespräch bestätigt ${ }^{369}$, daß jeder Versuch und besonders der der Deutsch-Französischen Union dazu beigetragen habe, nicht nur während der Zeit der größten Barbarei, nicht den Glauben an ein besseres Deutschland und an die Möglichkeit einer deutsch-französischen Verständigung in der Zukunft zu verlieren, sondern auch nach dem Kriege Anknüpfungspunkte für die deutsch-französische Aussöhnung zu finden. Er erinnerte sich genau an Klepper und beschrieb ihn als einen dynamischen, zielbewußten Demokraten und überzeugten Europäer.

Neben der Deutsch-Französischen Union entstanden in diesen letzten Monaten vor dem Krieg noch zwei weitere Vereinigungen. Das eine war das im Februar 1939 gegründete „Büro zum Sturze des Naziregimes“, das aus dem „Baldwin-Fonds“ gespeist wurde und den Schwerpunkt seiner Tätigkeit in London hatte, obwohl auch Beziehungen zu namhaften Franzosen wie dem Kammerabgeordneten und Vizepräsidenten des auswärtigen Ausschusses, Ernest Pezet, ebenfalls Mitglied der Deutsch-Französischen Union, und dem Kardinalerzbischof Jean Verdier bestanden ${ }^{370}$. Die andere war das ganz auf die Praxis gerichtete, im Juni 1939 von Münzenberg ins Leben gerufene Komitee „Menschen in Not", dem unter anderem auch Klepper angehörte und dessen einziger Zweck

American Foreign Service à Marseille, Application for Nonimmigrant Visa vom 2. 1. 1941). Walter selbst zählt in seinem Buch Internierung, eine Reihe von Namen - darunter auch Klepper auf, die erst im Mai 1940 einberufen worden seien (S. 112). Auch Münzenberg sei auf freiem Fuß geblieben (S. 93).

${ }^{365} \mathrm{BN}, \mathrm{D} 141$.

${ }^{366} \mathrm{Vgl}$. Bloch, Die seltsame Niederlage.

367 Die Zukunft, 28. 4. 1939.

${ }^{368}$ Z. B.: die Freundschaft zwischen Romain Rolland und Stefan Zweig.

${ }^{369}$ Gespräch im Arbeitszimmer des Senatspräsidenten im Palais de Luxembourg am 1. 4. 1992.

370 BDC, W 49, BI. 35 und Berichte über den von Neill Malcom geleiteten Baldwin-Fonds in der PTZ vom 4. und 12.1. 1939. 
die Sammlung von Spenden für Flüchtlinge und Insassen des Lagers Gurs am Rande der Pyrenäen war. ${ }^{371}$. Die Hilfe wurde nach Kriegsausbruch auf andere Internierungslager ausgedehnt ${ }^{372}$. Klepper hat diese Hilfe später, nach der Besetzung Frankreichs, als er bei Degon versteckt war, fortgesetzt. Degon berichtete humorvoll von den Hilfsaktionen und Einkäufen für die Lagerinsassen, bei denen Klepper auch eine übergroße Damenunterhose zu erwerben hatte ${ }^{373}$. In den Akten der Zukunft findet sich eine reiche Korrespondenz mit vielen Dankesschreiben von den Insassen des Lagers Gurs, die teilweise auch Die Zukunft abonniert hatten. In dem Buch von Claude Laharie über das Lager Gurs heißt es, daß sich der Großteil der Kommunisten im Lager als „explicitement partisans de la tendance Münzenberg" bezeichnet hätten ${ }^{374}$.

\section{Internierung und Flucht}

Mit Ausbruch des Zweiten Weltkrieges am 3. September 1939 veränderte sich für die meisten Emigranten die Lage schlagartig. Hans-Albert Walter gibt davon ein anschauliches Bild, indem er sowohl die allgemeinen Bedingungen wie einzelne Schicksale schil$\operatorname{dert}^{375}$. Die nun einsetzende Internierungswelle muß im allgemeinen politischen Zusammenhang gesehen werden ${ }^{376}$. Sie widersprach eigentlich jeglichem Sinn für Pragmatismus, denn durch die Mobilisierung der Franzosen wurden dringend Arbeitskräfte gebraucht. Offensichtlich war das Land in keiner Weise auf den Krieg vorbereitet, weder waren die asylberechtigten Emigranten auf ihre Zuverlässigkeit hin überprüft worden, noch gab es Lager und das entsprechende Personal, sie zu organisieren ${ }^{377}$. Bei der Internierung spielten viele Faktoren eine Rolle, sie reichten vom Antisemitismus über den seit dem Hitler-Stalin-Pakt verschärften Antikommunismus und den mit der Angst vor Spionage verbundenen Deutschenhaß ${ }^{378}$ bis zu jener tief sitzenden Krise, die nach Marc Bloch, dem Augenzeugen und Historiker, die ganze französische Gesellschaft erfaßt hatte $^{379}$. Diese Krise manifestierte sich zunächst in einer fast apathischen Lethargie wäh-

${ }^{371}$ Bittbrief Thormanns an Kroacher (Hotel Bellevue, Genf), C.A.R.A.N., F/7, 15123, K, vgl. auch $\mathrm{F} / 7,15125,4$.

$372 \mathrm{Vgl}$. auch Walter, Internierung, S. $93 \mathrm{f}$. Walter berichtet von einer Zusammenarbeit Münzenbergs mit den Quäkern und von den Verteilungsschwierigkeiten in den Lagern. Bericht über erste Erfolge der Aktion in: Die Zukunft, 22. 12. 1939.

${ }^{373}$ Gespräch mit Degon.

${ }^{374}$ Laharie, S. 109 und Gespräch mit dem Autor, der sagte, daß er wegen seines Buches starken Anfeindungen ausgesetzt sei. Vom Lager ist nichts übrig, allerdings ist das durch eine Hinweistafel gekennzeichnete Areal trotz des wild wuchernden Waldes noch genau erkennbar. Es gibt einen Friedhof und ein Archiv in der Stadt.

375 Walter, Internierung. Im Kapitel „Die erste Internierungswelle in Frankreich“ werden die juristischen und politischen Voraussetzungen der Internierung und die Sammlung im Stade de Colombe in Paris behandelt, außerdem ist eine fast vollständige Liste der Lager abgedruckt, die Walter aus verschiedenen Listen zusammengestellt hat.

376 Badia u. a., Les barbelés, S. 171, Walter, Internierung, S. 34 ff. und Ders., Europäisches Appeasement, S. $101 \mathrm{ff}$.

377 Walter, Internierung, S. $153 \mathrm{ff}$.

378 Ebenda, S. $121 \mathrm{ff}$. Die Angst vor der sog. 5. Kolonne, unter der besonders die Emigranten zu leiden hatten. Walter zitiert Auszüge aus dem Buch des Holländers Louis de Jong, S. 10.

${ }^{379}$ Bloch, S. $180 \mathrm{ff}$. 
rend des sogenannten „Drôle de Guerre“, eine von André Billy geprägte Bezeichnung für die ersten sieben Kriegsmonate, in denen die Franzosen „suspendiert zwischen Krieg und Frieden lebten "380. Diese Zeit hat auch Bloch als Soldat erlebt und als äußerst deprimierend beschrieben. „Die unmittelbare Ursache“ für die katastrophale Niederlage Frankreichs sei in der „Unfähigkeit der militärischen Führung" zu suchen, die als Sieger von 1918 glaubten, noch einmal den Krieg von 1914 führen zu können, und deshalb der modernisierten, verjüngten und alle technischen Möglichkeiten nutzenden deutschen Armee hoffnungslos unterlegen war ${ }^{381}$. Doch, so fährt Bloch fort, die wahren Ursachen liegen tiefer, und zwar „in einem psychologischen Klima, das sie selbst [die militärischen Stäbe] nur teilweise erzeugt hatten. Sie selbst waren das, was die Bevölkerungsschichten, denen sie entstammten, aus ihnen gemacht hatten, und das, was die Gesamtheit der französischen Nation ihnen erlaubt hatte zu sein. " Das heißt, nach Bloch war die Niederlage eine Folge einer durch alle Schichten reichenden intellektuellen und psychologischen Krise, die Bloch unter der Überschrift: „Gewissensprüfung eines Franzosen“ genau diagnostiziert ${ }^{382}$. Die führende Schicht habe versäumt, die Massen wirklich in die Gesellschaft zu integrieren und an dem Aufbau der Demokratie zu beteiligen; so habe "der Volksstaat", in Abwandlung eines Wortes von Montesquieu, seine "Antriebskraft [...,] die Tugend" verloren. In dieser angeschlagenen Verfassung hätten dann die überalterten Generäle ihr Land der fremden deutschen Besatzungsmacht, die zumindest durch ihre Führer Böses beabsichtigte, ausgeliefert. Diese Diagnose gibt nicht nur Hinweise zur Erklärung der raschen Niederlage, sondern macht auch verständlich, warum die Kollaboration zunächst so ausgezeichnet geklappt, der Widerstand, die Résistance, sich dagegen erst sehr allmählich entwickelt hat und die ganze Problematik bis heute nicht verarbeitet ist ${ }^{383}$.

Auch von deutscher Seite wurde die Kollaboration von Leuten unterstützt, die auf subtile Weise genau an diese angeschlagene, bürgerliche Mentalität' die Bloch beschreibt, anknüpften. Es waren Leute wie Otto Abetz, der spätere deutsche Botschafter in Paris, und Friedrich Sieburg, der Frankreichkorrespondent der Frankfurter Zeitung. Für beide war die deutsch-französische Verständigung ein Anliegen von Jugend an ${ }^{384}$, und sie setzten sich schon lange vor Kriegsausbruch für sie ein, aber in einer Weise, die nicht der demokratischen Tradition beider Länder entsprach. Scheer faßt die Art dieser deutschen Einflußnahme in ein Bild, das er auf Abetz bezieht. Er war ,just der Mann, der wie eine Spinne über das Parkett der Pariser Salons glitt und das dichteste der Netze spannte, in denen Frankreich jahrelang seinen nationalen Zusammenhalt, Mut und Stolz

380 „La France vécut suspendue entre la guerre et la paix“, in: Journaux de Guerre. Numéro Spécial: La Drôle de Guerre septembre 1939 - avril 1940. Vgl. auch das soeben erschienene Tagebuch des mehrfachen Ministers Henri Queuille.

${ }^{381}$ Bloch, S. 70. Bloch ist sich als Historiker der Gefährlichkeit einer solchen Verallgemeinerung sehr wohl bewußt und differenziert und belegt sein Urteil im folgenden genau.

382 Ebenda, S. 180-232.

383 In dem Zusammenhang sind einige neuere französischen Filme über das Vichy-Regime und das Internierungslager „Les Milles“ sehr interessant.

${ }^{384}$ Scheer, S. $155 \mathrm{ff}$. und $202 \mathrm{ff}$. Manfred Flügge beschreibt noch so eine widersprüchliche Gestalt der deutsch-französischen Beziehung, Gerhard Heller, der als Leutnant der Propagandaabteilung der deutschen Besatzungsmacht, und als solcher Vollstreckungsgehilfe von Otto Abetz, in Paris war, S. $175 \mathrm{ff}$. 
verlor" ${ }^{385}$. Er stellte seine Frankreichliebe in den Dienst des Dritten Reiches. In der Formulierung von Abetz, der eine Denkschrift: „Richtlinien für die politische Arbeit in Frankreich“, verfaßt hat, hört sich das so an: „Die Härtegrade unserer Haltung müssen je nach Partner und dem ihm zugedachten Zweck variieren. Ein Teil der politischen Persönlichkeiten und Bewegungen muß in der Hoffnung beziehungsweise Illusion einer späteren Verständigungsmöglichkeit belassen werden. "386 Für diese Politik ließ auch Sieburg, „das Chamäleon“, sich benutzen; er pries auf der Titelseite der Tageszeitung L'Intransigeant den deutschen Pavillon auf der Pariser Weltausstellung 1937 als einen „von unserem Volk und seinem Führer als Symbol der Arbeit in Frieden und Freiheit und Ehre entworfen“, und fügte stolz hinzu, „wir wollten zeigen, was wir wirklich sind“ 387 . Diese kurzen Anmerkungen zeigen, wie schwierig es für die Demokraten auf beiden Seiten war - die französischen wie die deutschen emigrierten -, sich für die deutsch-französische Freundschaft unter demokratischem Vorzeichen und für ein friedliches Europa einzusetzen, und wieviel Mut und Weitsicht zur Gründung der Deutsch-Französischen Union gehört hatte 388 .

Der 10. Mai 1940 war der Stichtag, an dem auch Klepper mit Decke oder ohne, jedenfalls wohl mit Köfferchen, in das Stade de Colombe zog, um sich internieren zu lassen ${ }^{389}$. Aus einem letzten Brief an Engelmann geht hervor, daß er sich nicht um sein Schicksal sorgte, sondern um das des zukünftigen Deutschland, dessen Niederlage er klar voraussah: „Stellen Sie sich nur die Stellung vor, die Deutschland in der Welt einnehmen wird, wenn Hitler den Krieg verloren hat. Es ist nicht auszudenken. Was wäre vermieden worden, wenn man damals 1932 mir gefolgt wäre und Hindenburg und Hitler und seine Spießgesellen verhaftet hätte." 390

Die erste Station seiner Internierung war das französischen Lager von Chambaran ${ }^{391 .}$ Das bedeutet, daß Klepper zunächst mit Münzenberg, Leopold Schwarzschild, Paul Westheim, Kurt Wolff und Clément Korth zusammen im Lager war. Doch muß er sehr bald von dort nach Catus geschickt worden sein, denn sein Name taucht bei Babette Gross nicht auf, als sie von einem Gespräch berichtet, das zwischen den oben Genannten über die Fluchtmöglichkeiten geführt worden sei, nachdem das Lager am 20. Juni 1940

${ }^{385}$ Scheer, S. 202, vgl. die Memoiren von Otto Abetz, in denen er seine Rolle als Mittler zwischen Deutschland und Frankreich darzustellen versucht.

386 Flügge, S. 185.

387 Scheer, S. 155 und 160.

${ }^{388}$ Es gibt eine sehr gute Erzählung von Jean Buller (Pseudonym Vercors), „Le silence de la mer“ (Paris 1951, Neuauflage), die genau dieses Problem der echten und der falschen deutsch-französischen Beziehungen literarisch umsetzt.

${ }^{389}$ Joseph Rovan, franz. Journalist, bestätigte in einem Gespräch am 22. 11. 1990, daß auch er als junger Mann in jenen Maitagen im Stade de Colombe war und Klepper begegnet sei. Rovan meldete sich als Freiwilliger zur französischen Armee. Nach dem Kriege hielt er als französischer Journalist Vorträge bei der von Klepper mitbegründeten Wipog in Frankfurt/M. Zur Beschreibung, wie die Internierung vor sich ging, auch die der Frauen im „Vélodrome d'Hiver“, vgl. Fittko, S. $19 \mathrm{ff}$.

390 Engelmann, S. $41 \mathrm{f}$.

${ }^{391}$ Beileidsschreiben, L. Manners (New York), eines ehemaligen „Bett'-Nachbarn“ aus dem Lager Chambaran, 27. 5. 1957. Interessant ist das Urteil über Klepper in der Lagersituation: „Ich hatte Gelegenheit, ihn als einen aufrechten, hilfsbereiten und geistig hochstehenden Kameraden kennenzulernen" (KNL). 
geöffnet worden war ${ }^{392}$. Engelmann, dessen Informationen meist stimmen, berichtet, Klepper sei „der Reihe nach in fünf verschiedenen Lagern interniert“ gewesen ${ }^{393}$. Demnach wäre Klepper also bei der Masse der Internierten geblieben, um schließlich als Prestataire $^{394}$ in dem eigens für diese eingerichteten Lager Catus zu landen ${ }^{395}$.

Wie aus einem ausführlichen Bericht über das Lager hervorgeht, wurde es zu Beginn der ersten Mobilisierung im Herbst 1939 eingerichtet, um dort in erster Linie deutsche, österreichische, ungarische und tschechoslowakische Prestataires zu sammeln ${ }^{396}$. Dieses Lager war verhältnismäßig klein und nur für Prestataires, die aus dem Reservoir der „réfugiés bénéficiaires du droit d'asile“ rekrutiert wurden, im Gegensatz zu den „camps d'internés“, in denen die Flüchtlinge sozusagen unsortiert, also auch „nazis“, gesammelt wurden ${ }^{397}$. Von 1939 bis September 1940, als die deutschen sowie die ungarischen und die aus dem Saarland stammenden Prestataires nach Montauban und Agen evakuiert wurden, waren 290 bis 400 Leute im Lager, wobei einige der dort registrierten Prestataires gar nicht im Lager, sondern bei umliegenden Bauern oder als Kleinpächter versteckt in den Wäldern lebten ${ }^{398}$. Die Erstankömmlinge hatten nichts außer einer Scheune neben dem Schloß von Villary bei Catus vorgefunden, sie hatten die gesamte Einrichtung selber schaffen müssen. Doch auch als Klepper ein Jahr später im Lager ankam, waren die Lebensbedingungen primitiv. Wasser mußte aus dem Fluß geholt werden, wo man auch sich selbst und die Wäsche wusch, bis die nahegelegene Mühle ihren Brunnen wenigstens für das Trinkwasser zur Verfügung stellte. Die Bewachung war korrekt, die Lagerdisziplin gut, es gab keinen Streit und keine Probleme, die Lagerbewohner trugen keine Lagerkleidung, sie konnten sonntags Besuch empfangen, und wenn ihnen das Essen nicht schmeckte und sie genug Geld hatten, konnten sie sich Essen aus den Restaurants von Catus kommen lassen. Sogar für Unterhaltung wurde gesorgt, man spielte Dame

392 Gross, S. $13 \mathrm{f}$.

393 Engelmann, S. 42.

394 Vgl. zu Vorgeschichte, Begriff, Status und gesetzlicher Regelung: Walter, Internierung, S. 110 f. Prestataires waren eine Art unbewaffneter Arbeitssoldaten, die in Lagern zusammengefaßt, aber auch auf Höfe oder in Fabriken etc. zur Arbeit verschickt werden konnten und bezahlt wurden.

395 Akte Mexiko und vgl. Brief von Walter Habicht, Oberinspektor und Chef des Saarbataillons in Völklingen, an Klepper, 14. 3. 1950: „Sie werden sich sicher noch an die Zeit erinnern, als wir vor nunmehr 10 Jahren in den Wäldern von Catus (Lot) vegetierten und den diversen Waffenstillstandskommissionen aus dem Wege gehen mußten" (K/Kor). Der Aufenthalt Habichts in Catus wird bestätigt durch das „Bureau de Recrutement sowie in einem Gespräch am 10.6. 1992 bei Fumel (Lot-Garonne) durch seine Frau und seinen Sohn, die mir Dokumente und Angaben zum Leben Walter Habichts übergaben. Außerdem wurde mir im Bureau de Résistance bestätigt, daß es eine Akte Habicht gibt, das heißt Walter Habicht in Frankreich als Widerstandskämpfer anerkannt wurde und eine entsprechende Rente bezog. Habicht hatte sich 1944 freiwillig als Soldat bei der Résistance gemeldet.

396 Das „Comité d'Histoire de la 2e Guerre Mondiale“ hat in den 60er Jahren eine „enquête sur les camps et prisons“ veranlaßt und M. Lafargue gebeten, einen Bericht für die Kommission zu schreiben. Der $71 / 2$ Seiten lange Bericht ist mit der Hand geschrieben und enthält genaue Angaben über die Einrichtung des Lagers und das Lagerleben (C.A.R.A.N., 72 AJ 282/13.I).

397 Ebenda, Commission im allgemeinen: genaue Anweisungen zur Abfassung der Berichte, erlassen vom Generalsekretär der Commission, M. Michel, eine lange Liste aller (?) Lager, Briefe wegen Befreiung, Regeln zur Behandlung der Internierten, Briefe aus den Lagern und Briefe des American Rescue Committee.

${ }^{398}$ Lagerbericht, einige „travailleurs étrangers“ lebten „comme métayers (Pächter) ou fermiers dans un domaine abondonné“. 
und Schach, bastelte Schiffe in Flaschen, offenbar eine Lieblingsbeschäftigung der Franzosen im Ersten Weltkrieg, und hatte sogar ein von einer Dame des Ortes zur Verfügung gestelltes Klavier; als Entgelt wurde ihr Holz gehackt. Die Kranken kamen nach Catus oder ins Krankenhaus nach Cahors. Monsieur Lafargue faßt seinen Bericht so zusammen: „En somme l'existence dans le camp s'est revelée tranquille, à une époque troublée, dans un monde divisé, inquiet, soupçonneux et prompt aux représailles. “399

Klepper hatte also Glück gehabt, nicht nur mit dem Lager und seinen Mitinsassen, zu denen auch Leute zählten, die er schon aus Berlin kannte, zum Beispiel Hans Pink, ehemaliges Mitglied des Landesrates des Saargebietes, der ihn wiederum mit dem ehemaligen kommunistischen Reichstagsabgeordneten Gustav Flohr zusammenbrachte ${ }^{400}$, sondern auch mit seinem Lagerkommandanten René Schlosser, einem elsässischen Juden, der, wie viele elsässische Zivilbeamte, zu Beginn des Krieges aus dem Elsaß abgezogen worden war ${ }^{401}$ und der sich offensichtlich sehr fair und vernünftig verhalten und Klepper vor dem Zugriff der Nazis geschützt hat. Dieser Schutz wurde notwendig, als der Waffenstillstand in Compiègne am 22. Juni 1940 unterzeichnet worden und damit der Artikel 19, der die Auslieferung von Emigranten und Antifaschisten an die Nationalsozialisten forderte, wirksam geworden war. Um die Durchführung dieses Artikels zu überwachen, wurde von der Waffenstillstandskommission in Wiesbaden eine Kontrollkommission unter der Leitung von Ernst Kundt eingerichtet, die sogenannte KundtKommission, die Frankreich im August und September bereiste, im ganzen etwa $700 \mathrm{~km}$ zurücklegte und 40 Zivilinternierungslager sowie 30 Gefängnisse und Lazarette besuchte ${ }^{402}$.

Als die Kommission am 24. August 1940 zwischen 16 und 17 Uhr in Catus eintraf, waren laut dem französischen Bericht von den 104 im Lager registrierten Ausländern 81 anwesend, 4 waren im Krankenhaus und 19 beurlaubt. Bei einer Besprechung der Kommission mit dem Lagerpersonal im Büro des Kommandanten habe der Lagerkommandant Schlosser Schwierigkeiten gehabt, zu erklären, wo Klepper, der von der Kommission dringend gesucht wurde ${ }^{403}$, sich aufhalte ${ }^{404}$. Schlosser hatte Klepper den Decknamen Hans Norbert Stahn sowie die entsprechenden Papiere gegeben und ihn versteckt ${ }^{405}$. Die Kommission übernachtete im Hotel „Des Ambassadeurs“ in Cahors und

399 Ebenda. Übsetzung: Im ganzen erwies sich das Leben im Lager als ruhig in einer verwirrten Zeit, in einer entzweiten, unruhigen, mißtrauischen, jederzeit zur Erpressung bereiten Welt. Dem Bericht liegen ein genauer Lageplan und eine Zeichnung der Gebäude bei.

${ }^{400}$ Brief Gustav Flohr an Klepper, 17. und 26. 7. 1953 (KKor.). Vgl. außerdem den Artikel über Gustav Flohr in: Schumacher (Hrsg.), M.d.R., Nr. 385.

${ }^{401}$ Diese erste Generation von Lagerkommandanten wurde dann mehr oder weniger bald nach dem Waffenstillstand durch Vichy-treue Leute ersetzt.

${ }^{402}$ Bericht nach Abschluß der Reise (18. 9. 1940) von v. Studnitz in: PA-AA, R XII zv, 67/68. Dem Bericht liegen eine Liste der besuchten Lager, Hotel- und Restaurantrechnungen bei.

${ }^{403}$ Karteikarte mit dem Vermerk: K. im Geheimerlaß der Gestapo vom 15. 5. 1939, Landes-Archiv Speyer, H 91. Im Studnitz-Bericht heißt es zum „Fall des ehemaligen preußischen Finanzministers Klepper“, er gehöre zu den meistgesuchten „Personen, die wegen politischer oder krimineller Straftaten von Deutschland gesucht" werden.

${ }^{404}$ C.A.R.A.N., A J 41, 507, IV, Divers, Einzelberichte über die Lagerbesichtigungen; aus Catus wollte keiner zurückkehren, außer einem nach Lyon und drei Luxemburger in ihr Land, den Prestataires schien es im Lager zu gefallen. Auch in den deutschen Berichten wird die vergebliche Suche nach Klepper erwähnt.

${ }^{405}$ Akte Mexiko. 
speiste luxuriös, natürlich mit Champagner, Heidsieck brut 1919 für 600 Francs - zum Vergleich: das Dîner kostete für 7 Personen 455 und die 7 Übernachtungen 463 Francs! Ernst Kundt selbst hat sich in einem nach dem Kriege geschriebenen Bericht als ausgesprochen frankophil, kompromißbereit und als Gegner der Gestapo dargestellt ${ }^{406}$.

Während die Herren speisten, saß Klepper in einer dem Lager nahegelegenen Grotte auf Stroh und ließ sich das Essen aus dem Lager bringen. So fand ihn auch Degon vor, nachdem er ihn auf einen Hinweis Rawitschers hin gesucht hatte. Inzwischen hatte Klepper sich offenbar dort eingerichtet, denn Degon fand ihn mit Büchern aus der Leihbibliothek von Catus lesend vor. Klepper sei ausgesprochen guter Dinge und wie stets voller Pläne gewesen. Seit ihrem letzten Wiedersehen hatte Degon auch einige Abenteuer hinter sich gebracht. Ende Mai 1940 war er mit den Engländern zusammen von Dünkirchen nach England geflohen und war dann von da aus nach Frankreich zurückgekehrt. Seit Beginn des Krieges gehörte er zum 2e Bureau und ging dann direkt zur résistance. Nachdem sein Freund und Vorgesetzter François Verdier von den Deutschen auf viehische Weise - man ließ eine Handgranate in seinem Mund platzen - im Wald von Bauconne ermordet worden war, nahm er als sein Nachfolger den Decknamen Colonel Bauconne an ${ }^{407}$.

Als Degon Klepper nun von einer kleinen Farm erzählt habe, die er durch Zufall von heimkehrenden Mexikanern habe übernehmen können, die aber völlig verrottet sei und die er unmöglich allein bewirtschaften könne, sei Klepper Feuer und Flamme gewesen, habe ihm vorgeschlagen, er werde zwölf Prestataires aus dem Lager mitbringen und die Farm auf Vordermann bringen.

In der Zwischenzeit wurde das Lager Catus Mitte September evakuiert, doch konnte Klepper mit Degons Hilfe und Duldung der französischen Behörden durchsetzen, daß er und zwölf weitere Gefangene, statt in das Lager von Montauban eingewiesen zu werden, nach En-Bec, der Farm Degons, als Prestataires abkommandiert wurden ${ }^{408}$. Sie waren als Prestataires „sous la responsabilité de l'armée d'armistice“, hatten also einen soldatenähnlichen Status, bekamen einen kleinen Sold, wurden eingekleidet und von der Armee kontrolliert ${ }^{409}$. Einige der Männer scheinen in dem kurzen Zeitraum zwischen September und Dezember 1940 noch in Montauban gewesen oder sonstwo untergeschlüpft zu sein. Klepper konnte sich bei Hans Pink in Agen verstecken ${ }^{410}$, von wo aus er sofort Kontakt mit En-Bec aufnahm, um dann Anfang November endgültig dorthin zu übersiedeln ${ }^{411}$. Die übrige Mannschaft folgte unter Pink als Chef d'equipe ${ }^{412}$ Mitte Dezember nach. Zu ihr gehörte neben Gustav Flohr, mit Frau und Tochter, auch Pinks Frau. Weihnachten 1940 wurde bereits in En-Bec gefeiert, ein bewegendes Fest, so wie Madeleine Landy-Degon es schildert, und für Klepper eines der vier schönsten Weihnachtsfeste zwischen 1933 und 1947413. Madeleine, eine junge Frau von 28 Jahren, war

\footnotetext{
406 PA-AA, R XII zv, 67. Kundts Bericht stammt vom 31. 7. 1952.

407 Akte als Widerstandskämpfer: im Bureau de Résistance, im Schloß Vincennes.

408 Mexiko Akte.

409 Bericht Landy-Degon.

410 Klepper an Tochter Ingrid aus Mexiko, 30. 10. 1943.

411 Bericht Landy-Degon.

412 Klepper an Tochter Ingrid (ebenda).

${ }^{413}$ Klepper an Schwiegertochter Mary-Beth aus Frankfurt, 26. 12. 1947.
} 
neben all der Sorge um ihre Schützlinge mit der Angst um ihren Mann belastet, der nach Paris zurückkehren mußte, um seinen kranken Vater in das unbesetzte Frankreich zu holen ${ }^{414}$.

Das Leben in En-Bec läßt sich aus den Erzählungen von Degon sowie seiner früheren Frau Madeleine Landy-Degon, die noch heute mit 80 Jahren in En-Bec lebt und alles erklärt und gezeigt hat, rekonstruieren. Diese Rekonstruktion des Geschehens erscheint sinnvoll, da sie über das persönliche Schicksal Kleppers hinaus einen Einblick in das Schicksal deutscher Emigranten bietet, Emigranten, die nicht in Lagern, sondern als sozusagen freie Prestataires unter Franzosen gelebt und gearbeitet haben, angewiesen auf deren Hilfe und ständig in der Furcht, denunziert oder von Deutschen entdeckt und gefangen zu werden, eine Gefahr, die im Verlaufe des Krieges immer stärker anwuchs ${ }^{415}$. Wie stark die Gefahr war und welchen abenteuerlichen Erfahrungen die sich frei bewegenden Emigranten ständig ausgesetzt waren, schildert Lisa Fittko auf anschauliche Weise. Sie hat zusammen mit ihrem Mann von Oktober 1940 bis März 1941, bis zum Erlaß der Pétain-Regierung, der die Räumung aller Grenzgebiete anordnete, von Banyulssur Mer an der französisch/spanischen Grenze aus die Flucht vieler Emigranten, unter anderem die Walter Benjamins, über die Pyrenäen organisiert ${ }^{416}$.

Die Lebensbedingungen auf der Farm in den Bergen oberhalb von Quillan, einem kleinen Provinzstädtchen im Departement Aude gelegen, muß man sich beschwerlich, zugleich aber auch reizvoll vorstellen. Die Farm bestand aus Degons kleinem steinernen Wohnhaus, in dem auch gekocht ${ }^{417}$ und gegessen wurde, einer Scheune, in der die Prestataires schliefen, einem Stall für die Schafe, die nach und nach angeschafft wurden, und einem etwas abseits gelegenen Steinhaus, in dessen oberem Stock Klepper ein Zimmer für sich allein hatte. Aus seinem Fenster hat man auch heute noch einen weiten Blick in das sehr schöne Bergtal, das sich nach Westen in leicht ansteigenden Wiesen öffnet und nach Norden durch einen bewaldeten Bergrücken begrenzt wird. Das Tal war und ist immer noch sehr abgelegen, dennoch gab es in ein paar Kilometer Entfernung bäuerliche Nachbarn, die teils für, teils gegen das Vichy-Regime waren, so daß Madeleine Degon stets auf der Hut sein mußte, ihre Schützlinge abzuschirmen. Immer wieder kamen Kontrollen, die mit viel Geschick getäuscht oder abgelenkt werden konnten. Trotz aller Gefährdung wurde in En-Bec hart gearbeitet. Es galt die völlig heruntergekommene und seit sechs Jahren nicht mehr bearbeitete Farm zu bewirtschaften und wenigstens so viel damit zu verdienen oder an Naturalien zu erzeugen, $d a ß$ die vielen dort lebenden Menschen ernährt werden konnten. Klepper war laut Aussage des Ehepaars Degon der „chef spiri-

\footnotetext{
${ }^{414}$ Bericht Landy-Degon.

415 Klepper schreibt in dem bereits erwähnten Brief an seine Tochter Ingrid im Oktober 1943: „Für die Leute - es sind viele, die noch in Frankreich geblieben sind - ist es nach den neuesten Nachrichten entsetzlich. Soweit sie Juden sind, werden sie einfach, wie das Vieh, eingefangen und nach Deutschland oder Polen transportiert. Was dort aus ihnen wird, kann man sich denken.“ ${ }_{416}$ Fittko, Mein Weg, S. 154-207.

417 Von den beiden Ehefrauen Flohr und Pink.
} 


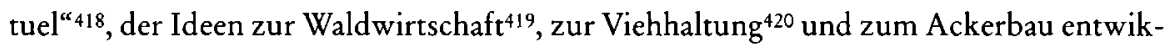
kelte. Angeblich soll er die in der Gegend unbekannte Egge eingeführt haben. Als die umliegenden Bauern sich zu dieser nicht bekehren lassen wollten, habe er sie durch einen Priester segnen lassen; da hätten auch die Bauern der Gascogne den Segen der Egge erkann ${ }^{421}$. So kam der Agrarpolitiker noch dazu, praktische Landwirtschaft zu betreiben, und gleichzeitig mit Madeleine Degon, die Deutsch und Englisch sprach, über den Agrarkredit zu sprechen, da sie beim Crédit Agricole gearbeitet hatte und dabei war, ein Buch über den französischen und europäischen Agrarkredit zu schreiben, bei dem Klepper ihr wertvolle Hilfe leisten konnte ${ }^{422}$.

Man könnte fragen, warum Klepper nicht in En-Bec geblieben ist, so wie Pink, der die Befreiung Frankreichs in En-Bec erlebt und sogar selbst ein "Comité de la liberation" gegründet hat? Pink war Saarländer und hatte dadurch in Frankreich einen anderen Status. Klepper war einer der prominentesten und von den Nationalsozialisten am stärksten gesuchten Personen ${ }^{423}$, er sprach kaum Französisch und sah sehr deutsch aus, zumal mit seinem Schmiß. Einerseits wurde es für die französischen lokalen Behörden, die ihn ja als Prestataire registriert hatten und bezahlten, immer schwieriger, solche Leute wie Klepper zu schützen, da sie ihrerseits immer stärker unter den politischen Druck des Vichy-Regimes gerieten, andererseits entwickelte sich der französische Widerstand erst 1942/43, als Klepper schon längst das Land verlassen hatte, so daß er nicht die Möglichkeit hatte, mit seinen Freunden zusammen beim Widerstand mitzumachen und unterzutauchen ${ }^{424}$. Die Gefahr war groß, und die Versuche, Klepper zu retten, liefen seit September 1940 über die von Prinz Löwenstein in New York gegründete Hilfsorganisation „American Guild for German Cultural Freedom“. Klepper war über alle „konventionelle $[n]$ Hemmungen", die er sehr wohl empfand, hinaus fest entschlossen, sich zu retten. Er begründet diesen Wunsch in einem Brief aus Quillan an den Schatzmeister des „American Guild“, Oswald Garrison Villard, im November 1940 auf folgende Weise: „Betrachtet man meinen Fall [...], der ja als Schulfall gelten könnte, [so müßte er sich] auch regeln lassen, ohne daß dies den Charakter einer Bevorzugung aufgrund persönlicher Beziehungen erhielte. [...] Diese Entschlossenheit, [...] unter allen Umständen zum Ziel zu gelangen [...], entstammt nicht nur dem Wunsch, mich individuell zu ret-

418 Degon: Er war überall in der Gegend bekannt als Mann mit dem Schmiß. Bericht Landy-Degon: „Son ascendant moral et intellectuel ainsi que la simplicité de son comportement vis à vis de tous le faisait très bien admettre par toutes les classes sociales présentes."

${ }^{419}$ Degon: Für den am Nordhang ansteigenden Wald erfand Klepper eine Art Kabelbahn mit Flaschenzug, um die gefällten Bäume runterzuholen.

420 Bericht Landy-Degon: Es wurde eine Herde von 100 Mutterschafen und zwei Paar Ochsen angeschafft, Klepper habe oft die Schafe gehütet.

${ }^{421}$ Bericht Degon.

${ }^{422}$ Landy-Degon, Le Crédit Agricole.

${ }^{423}$ "Chacun savait que Klepper était le plus exposé" (Landy-Degon). Vgl. Kleppers Briefe an O. G. Villard (Dt. Bibl., Eb 70/112) vom 27.11. und 19. 12. 1940, die alle den Absender der kleinen Wohnung Degons in Quillan, Grand rue 22, tragen, und die Klepper betreffende Korrespondenz in der Akte Klepper, American Guild, sowie die Kleppers Gefährdung und Ausreise betreffende Korrespondenz Arnold Brechts mit Karl Brandt, Mrs. Fritz Epstein (New England Christian Committee for Refugees) und Jakob Goldschmidt in: BAK, NL-Brecht.

${ }^{424}$ Degons gehörten zu der Gruppe Franc Tireur, eine der ersten Widerstandsgruppen, die ihre Arbeit erst richtig ab 1943 entfalteten. 
ten, sondern ich bin fest davon überzeugt, daß es darüber hinaus zweckmäßig ist, mir die Chance zu geben, an den Platz zu gelangen, den ich suche." 425

$\mathrm{Da}$ auch Madeleine Degon von der Notwendigkeit von Kleppers Ausreise überzeugt war ${ }^{426}$, bedeutete er doch auch eine Gefährdung für die ganze Gruppe in En-Bec, fuhr sie im November und Dezember 1940 zweimal unter äußerst schwierigen Bedingungen mit ihm nach Marseille, um „mit den dort tätigen amerikanischen Stellen Kontakt zu gewinnen" ${ }^{427}$. Schreckliche Fahrten mit Bussen und Zügen, die entweder gar nicht fuhren oder ewig brauchten, weil sie umgeleitet wurden. Es war eisig kalt, es gab nichts zu essen, und man schwebte ständig in Lebensgefahr und der Sorge, kontrolliert oder gar identifiziert zu werden ${ }^{428}$. Die Zustände in Marseille waren nicht besser: Miese kleine Hotels, ständig Razzien, vergebliches Schlangestehen vor den Konsulaten, kein Geld für ein anständiges warmes Essen, Gerüchte, Verhaftungen, Erpressungen, man kann sich diese Welt nicht abenteuerlich genug vorstellen. Der Roman „Transit“ von Anna Seghers ${ }^{429}$ und auch die unter dem Eindruck der Erlebnisse mit Klepper geschriebene kleine Novelle von Madame Landy ${ }^{430}$ vermitteln ein anschauliches Bild von den Verhältnissen in Marseille. Einer der kleinen Lichtpunkte in dieser Hoffnungslosigkeit war das „American Rescue Committee“ von Varian Frey. Er und sein Mitarbeiter Daniel Bénédite $^{431}$ haben sehr anschaulich über die Arbeit und die ungeheuer sich auftürmenden Probleme berichtet ${ }^{432}$. Auch Klepper haben sie geholfen ${ }^{433}$. Er bekam am 2. Januar 1941 ein sechs Monate gültiges Einreisevisum für die USA, ein sogenanntes Nonimmigrant Visa, aber es nützte ihm nicht viel, weil es auf den Namen Klepper ausgestellt war, er aber unter diesem Namen das Land nicht verlassen konnte. So bemühte Klepper sich um ein Transit-Visum für Mexiko, das auf sein Pseudonym ausgestellt werden mußte. Dies dauerte ein Jahr.

Schließlich gelang es durch die Vermittlung des Prinzen Löwenstein, der 500 BlancoVisen von der mexikanischen Regierung bewilligt bekommen hatte, und durch die Inter-

${ }_{425}$ Brief vom 27. 11. 1940 aus Quillan/Aude (Dt.Bibl., Eb 70/117).

${ }^{426}$ M. Landy-Degon nennt als Motiv für ihre Hilfe, um „un des plus éminents combattants antihitlèriens" zur Flucht zu verhelfen.

427 Brief vom 27.11. 1940.

${ }^{428}$ Bericht Landy-Degon. Lisa Fittko schildert mehrere solcher Zugreisen ohne gültige Papiere; man brauchte nicht nur eine Reiseerlaubnis, sondern auch eine Aufenthaltserlaubnis von dem Ort, zu dem man fuhr.

${ }^{429}$ Seghers, Transit, Konstanz 1948. Vgl. auch Fittko und Freyermuth.

430 „Marseille 1941“ (Privatbesitz).

431 Frey, Surrender on Demand und Bénédite, La Filière.

432 In einem Bericht der Vichy-Regierung über deutsche Flüchtlinge wird ein Brief Freys an die Vichy-Regierung erwähnt, in dem er darum bittet, die Situation der deutschen Flüchtlinge, die teilweise hochangesehene Emigranten seien und viel für Frankreich getan hätten, zu ändern, zumal das Ansehen Frankreichs durch die schlechte Behandlung in den USA stark geschädigt werde. Eine Liste derjenigen Flüchtlinge, deren Flucht nach USA wünschenswert sei, werde nachgereicht (AD, Guerre 1939-1945, Vichy Europe, Serie C, No. 146, p. 93).

${ }^{433}$ Bénédite, p. 279 f., 291 f. und Bericht Landy-Degon. Brief von Charles Sternberg (International Rescue Committee, New York) vom 8.7. 1992 bestätigt, daß Klepper häufiger im American Rescue Committee war. 
vention von Babette Gross von Mexiko aus ${ }^{434}$, daß der mexikanische Konsul in Marseille ein Transit-Visum für den 13. Januar 1942 auf den Namen Hans N. Stahn ausstellte, obwohl er von offizieller Stelle unterrichtet worden war, daß der wahre Name Klepper lautete ${ }^{435}$. Blieb noch das Problem: wie aus der Mausefalle Frankreich herauskommen, da ihm der Weg über Spanien wegen Haftbefehls verwehrt war? Auch dieses Problem konnte mit Hilfe des American Rescue Committee gelöst werden ${ }^{436}$, er bekam ein Ausreisevisum ebenfalls auf den Namen Hans N. Stahn. Nun fehlte noch ein Schiffsplatz. Diese letzten Wochen vor seiner Abreise im Januar 1942 in Marseille waren aufregende Wochen, jeden Tag konnte man Gestapo-Leuten in die Hände laufen. Klepper hatte Unterschlupf in einem Dominikaner-Kloster und Unterstützung durch eine befreundete Familie Fleischmann gefunden ${ }^{437}$. Schließlich gelang es, einen Schiffsplatz zu organisieren und mit Hilfe des American Rescue Committee die Schiffskontrollen dadurch zu täuschen, daß Klepper ein Bart und eine Brille verpaßt wurden ${ }^{438}$. Tatsächlich gelangte er unerkannt auf das Schiff mit Kurs auf Oran in Algier und von dort weiter nach Mexiko ${ }^{439}$. Im Herbst 1941 war die Flucht seiner Familie aus Mallorca mit amerikanischer Hilfe in die USA gelungen ${ }^{40}$. Was die Frauen damals zustande gebracht haben, ist enorm ${ }^{44}$.

Fünf Monate war Klepper unterwegs. Sosehr ihm sein Pseudonym geholfen hatte, Frankreich zu verlassen, so schwierig wurde es nun für ihn, seine wahre Identität zurückzuerlangen, denn die Papiere, die seine wahre Identität nachwiesen, mußte er aus

${ }^{434}$ Briefe in: Dt.Bibl., Eb 70/112 von W. Sauerländer und Brief Kleppers vom 19. 12. 1940, in dem er den Empfang eines Einreisevisums für die USA bestätigt und nach den Möglichkeiten eines mexikanischen Visums fragt, um via Mexiko nach USA zu gelangen. Das Visum für ihn zu bekommen, hatte Babette Gross erreicht (Klepper an seinen Sohn, Frankfurt/M. 30. 5. 1948). Sie war, nachdem sie vor dem Waffenstillstand aus Gurs herausgekommen war, bereits 1940 über Portugal nach Mexiko entkommen (Gross, S. 331, vgl. auch Wessel, S. 221).

${ }^{435}$ Akte Mexiko, KNL.

436 Bénédite, p. $279 \mathrm{f}$.

437 Dankbar erwähnt Klepper die Hilfe des Ehepaares Fleischmann, die redlich mit ihm geteilt hätten, als er in "den letzten Wochen in Marseille kaum noch Geld“ gehabt habe, in einem Brief an die Tochter Renate vom 30. 10. 1943 aus Mexiko.

${ }^{438}$ Bénédite, p. $279 \mathrm{f}$.

${ }^{439}$ Autorisierter Lebenslauf. Laut Pohle, S. 35, soll Klepper zunächst nach Casablanca und dann mit dem portugiesischen Schiff "Nyssa“ nach Mexiko gefahren sein, und zwar in Begleitung des KPD-Funktionärs Erich Jungmann, des SAP-Funktionärs Max Diamant und „weiterer Kommunisten und Linkssozialisten", was nicht zutrifft. Vielleicht verwechselt Pohle diese Information mit der über Familie Klepper, die tatsächlich im Herbst 1941 auf der „Nyssa“ von Lissabon nach den USA gefahren ist.

${ }_{440}$ Brief von Frau Klepper aus Plainfield/New Jersey vom 3. 11. 1941 an Elsbeth Weichmann in New York: „Seit einem Monat bin ich mit meinen Kindern hier in der Neuen Welt. Vielleicht kommt mein Mann auch bald herüber" (StAH, 622-1, 74, Bd. 1). Brief der Tochter Renate vom 8. 2. 1993. Die Fahrt bis Lissabon und auch Zuschüsse zum Leben der Familie auf Mallorca wurden von Dina Bowden, die eine große selbstlose Arbeit für das „American Friends Service Committee" geleistet hat, finanziert (Kopie des Briefes von der Tochter von Dina Bowden an Renate Taylor-Klepper).

${ }^{441}$ Wenn das Schicksal von Frau Klepper und den Kindern auch nicht Thema dieser Arbeit ist, so sollte es doch mitreflektiert werden, gerade im Hinblick auf die in der Exilliteratur vernachlässigte Rolle der Frauen. Zur Anregung ein Buch von Kreis, Frauen im Exil. Vgl. auch die bereits zitierte E. Weichmann und Fittko. 
Sicherheitsgründen einer anderen Person, die später nachkam, überlassen. Das Schiff legte auf den Bermudas an, und die britischen Behörden verweigerten die Anerkennung von Kleppers Papieren. Es mußte erst Auskunft in London eingeholt werden. Als die Aufklärung des Falles Klepper eintraf, war das Schiff abgefahren. Aber Klepper scheint das nicht gestört zu haben, im Gegenteil, er genoß und nutzte seinen unfreiwilligen Aufenthalt auf den Bermudas in dem Appartement eines erstklassigen Hotels, das ihm die Briten zur Verfügung gestellt hatten, und begann ein Buch zu schreiben ${ }^{442}$. Das schien mehr nach Kleppers Geschmack als in En-Bec Schafe zu hüten.

\section{Mexiko: letzte Station - „mit dem Gesicht nach Deutschland“}

Am 15. Mai 1942 setzte Klepper seine Reise nach Mexiko fort und traf wenig später in Veracruz ein ${ }^{43}$. Aufatmen konnte er allerdings immer noch nicht, denn die Schwierigkeiten mit seinem falschen Namen setzten sich fort. Die von Erna Riess aus Marseille mitgebrachten Originalpapiere gingen mitsamt einem ihr in Havanna gestohlenen Koffer verloren ${ }^{444}$, und es dauerte abermals fast zwei Monate, bis es gelang, Klepper aufgrund des zwar schon abgelaufenen, aber wiederaufgetauchten Nonimmigrant Visa für die USA mit Fingerabdrücken und einem Foto zu identifizieren ${ }^{445}$. Am 29. Juli 1942 erhielt er von den mexikanischen Behörden eine einjährige Aufenthalts- und Arbeitserlaubnis, die ein Jahr später auf unbegrenzte Zeit verlängert wurde ${ }^{446}$. Begründet hatte er seine Bitte um Verlängerung mit der Notwendigkeit, sein Buch fertig schreiben und Informationen über die landwirtschaftlichen Probleme Mexikos, insbesondere seines Agrarkreditsystems, sammeln zu müssen. In der kurzen Zeit, die er in Mexiko sei, schrieb er, habe er viele Analogien zu Deutschland, Italien, Spanien und China in Bezug auf die nicht durchgeführte Liquidation des Feudalismus gefunden, und es interessiere ihn sehr, seine Beobachtungen, die er in anderen Ländern gemacht habe, mit den Realitäten in Mexiko zu vergleichen ${ }^{447}$.

Damit ist bereits der eine Schwerpunkt seiner Betätigung genannt: forschen und schreiben. Der zweite Schwerpunkt, schließlich mußte er ja auch Geld verdienen, war seine Tätigkeit als Anwalt. Als seine Arbeitserlaubnis auf unbegrenzte Zeit verlängert worden war, trat er im November 1943 der Anwaltskanzlei Fernández, Ballvé und Murad bei. Sein Arbeitsgebiet waren internationale Rechtssachen, dazu die Verteidigung

\footnotetext{
442 Akte Mexiko.

${ }^{443}$ Akte Mexiko. Er traf also nicht am 4. 3. 1942 ein, wie Pohle, S. 35, behauptet.

${ }^{444}$ Briefe des amerikanischen Botschafters in Mexiko an Klepper vom 11.6.8. und 21. 7. 1942 (Akte Mexiko). Erna Riess war mit dem portugiesischen Schiff San Tomé Ende Juni in Havanna gelandet.

${ }^{445}$ Brief des amerikanischen Botschafters vom 21. 7. 1942. Im August tauchten auch drei Pässe und ein Waffenschein von Klepper auf (Brief vom 22. 8. 1942).

446 Akte Mexiko, Schreiben der Einwanderungsbehörde vom 20. 7. 1943.

${ }^{447}$ Ebenda, Klepper an die Einwanderungsbehörde (freie Übertragung aus dem Spanischen).
} 
von Interessen im Zusammenhang mit der Liquidation des Krieges ${ }^{448}$, eine Arbeit, die nie so recht in Gang kam, weil die Zeit für die Frage nach der Liquidation der Kriegsschäden noch nicht reif war. Klepper war, wie er verschiedentlich an Weichmann schrieb, nicht sonderlich zufrieden mit seiner Anwaltstätigkeit ${ }^{449}$. Um so zufriedener war er mit seinem bald erfolgten Rückzug aufs Land, ein wenig außerhalb von Mexiko-City. Er lebte gern auf dem Lande, hielt sich Hühner und pflanzte Salat ${ }^{450}$. Er liebte die Landschaft, das Klima und mochte die Menschen, und er fand die nötige Ruhe für seine gründlichen geschichtlichen und philosophischen Studien ${ }^{451}$. „Wenn nicht chronische Kümmernisse es beeinträchtigten, wäre ich wie ein Fisch im schönen Wasser [...] so bin ich [...] von einer Milde erfüllt, die mir weise vorkommt. "452 Er gewann neue und fand alte Freunde, vor allem Babette Gross, die schon seit Ende 1940 in Mexiko lebte. So wohl er sich einerseits fühlte, so sehr trieb ihn andererseits das Schicksal Deutschlands um, ständig befaßte er sich in Gedanken damit, was aus Deutschland werden sollte. Im Sommer 1944 hatte er offensichtlich fest vor, nach Europa zurückzukehren, aber der Wunsch scheiterte an behördlichen Bestimmungen ${ }^{453}$.

Im gleichen Zeitraum wurde von dem ehemaligen Reichsminister Erich Koch-Weser von Brasilien aus ein Versuch unternommen, aus allen „repräsentativen deutschen Nazigegnern im Ausland eine Exilregierung zu bilden“, daran war auch Klepper maßgeblich beteiligt. Getragen wurde diese Initiative, die allerdings bald im Sande verlief, von der Zeitschrift Deutsche Blätter, die im Jahre 1942 von Albert Theile und Udo Rusker in Santiago de Chile, dem „einzigen Land Amerikas, das neutral geblieben“, gegründet worden war. Ihre Gründer wollten die Zeitschrift als eine Antwort auf die sich ändernde Kriegspolitik der Alliierten verstanden wissen, denn diese machten den Kampf gegen

448 BAK, NL-Rüstow, Nr. 44 und 45: Lic. Mariano Fernández war früher Mitglied der Deputiertenkammer, Distriktrichter und Chef der Rechtsabteilung des Wirtschaftsministeriums, Prof. Faustino Ballvé, Dr. jur. der Universität Madrid, langjähriger Anwalt des Deutschen Konsulats sowie der deutschen Handelskammer in Barcelona, und Lic. Antonio Murad, Anwalt der Banco Mexicano. Klepper versuchte auch über die amerikanische Botschaft Hilfe für noch in Europa weilende gefährdete Personen zu erlangen (Brief des amerikanischen Botschafters vom 8.7. 1942 an Klepper).

${ }^{449}$ Klepper an Weichmann, 8. 2. 1944 und 3. 5. 1945 (StAH, 622-1, 74, Bd. 1; alle folgenden Briefe Kleppers an Weichmann stammen aus diesem Bestand).

450 Als er später in Frankfurt lebte, wo er sich übrigens auch ein paar Hühner hielt, schrieb er am 30. 6. 1951 an seine Freunde Baerensprung: „Um Ihre forstwirtschaftliche Idylle beneide ich Sie ein wenig. Ich bin gar nicht gewohnt und liebe es gar nicht, als reiner Stadtmensch zu leben. Überhaupt, was privates Leben angeht, wäre es in Mexiko viel schöner. Aber wir müssen ja hier etwas leisten" (K/Kor.), bestätigt durch einen Brief von Peter Gross, dem Sohn Babette Gross', der 1946/47 auch in Mexiko lebte, an die Verf. (25. 1. 1991).

${ }^{451}$ Engelmann, S. 43.

${ }^{452}$ StAH, 622-1, 74, Bd. 1, Klepper an Weichmann, 6. 5. 1945, mit den chronischen Kümmernissen ist die Trennung von seiner Familie gemeint. In einem anderen Brief (undatiert) schreibt er, „ich habe mir übrigens überlegt, ob ich nicht Mexikaner werden solle“. Vgl. auch Briefe an die Kinder und Kersten, Klepper.

${ }^{453}$ Er wandte sich sowohl an den amerikanischen Botschafter in Mexiko (Akte Mexiko, Brief des Botschafters an Klepper vom 28. 8. 1944, in dem er auf Kleppers Anfrage vom 26.8. Bezug nimmt) als auch an seinen alten Bekannten Henri de Hoppenot, den er zur Befreiung von Paris beglückwünschte. Hoppenot saß als Ministre Plénipotentiaire, Délégué du Gouvernement Provisoire de la République Française aux Etats Unis in Washington (Hoppenot an Klepper, 18. 9. 1944). 
Hitler mehr und mehr zu einem Kampf gegen das deutsche Volk. Dagegen sollte, ohne die Verbrechen des Hitler-Regimes verharmlosen zu wollen, „die Existenz eines , anderen Deutschland“" gestellt werden, das wert war, nach dem Kriege Europa mitaufbauen zu helfen. Der Untertitel der Zeitschrift zeigt die Tendenz: „Für ein europäisches Deutschland, gegen ein deutsches Europa“454. Entsprechend „standen Fragen der Zukunftsgestaltung mit großem Abstand an der Spitze der redaktionellen Interessen “ 455 .

Klepper wurde zu einem ihrer Mitarbeiter und aktiven Förderer. „None fought harder than Otto Klepper“, schreibt Ralph Vander Heide, und zwar weil er davon durchdrungen war, daß „die Grundlagen einer zukünftigen deutschen Politik schon jetzt gedanklich entwickelt werden“ müßten. Das sei „in Deutschland selbst“ und überhaupt „in Europa zur Zeit unmöglich. Gegenstand der künftigen deutschen Politik muß die Rückgewinnung der Freiheit sein; das heißt die Frage, wie das zu geschehen hat. Schon wegen der Besatzung kann man in Deutschland darüber kaum sprechen, und andere Länder wie zum Beispiel die Schweiz, würden die Unbequemlichkeit scheuen, die das Erscheinen eines unabhängigen deutschen Organs naturnotwendig mit sich bringt. Davon abgesehen“ seien, so meint Klepper, „die Deutschen Blätter die einzige Publikation, die qualitativ den Anforderungen entspricht, die Ernst und Schwere der Situation stellen. “ An Thomas Mann, den er um Unterstützung bat, schrieb Klepper, daß „die Leute bestrebt [sind], eine neue Orientierung zu gewinnen, und die Frage ist, ob sie in die richtigen oder wiederum in die falschen Hände fallen“. Mann hat übrigens, wie Klepper an

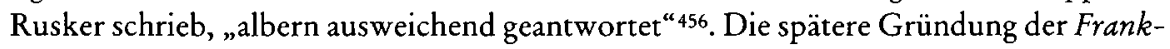
furter Allgemeinen Zeitung ist durchaus im Zusammenhang mit Kleppers zähem Engagement für die $D B$ zu sehen. Die enge Verbindung zu Rusker, den er schon aus der Weimarer Zeit kannte, und Theile hielt bis zu seinem Tode ${ }^{457}$.

Im Herbst 1946 veröffentlichte Klepper zwei Artikel, „Vorfragen des Friedens“ und die „Kunst des Möglichen“, in den Deutschen Blättern ${ }^{458}$. Die Gedanken, die er in den beiden Aufsätzen entwickelte, basieren auf seinem bereits skizzierten gesellschaftspolitischen Konzept und griffen Überlegungen aus seinen Artikeln in Münzenbergs Zeitung Die Zukunft auf. Es ging Klepper um den Versuch, zu erklären, wie es zum Nationalsozialismus kommen konnte und welche dessen wesentliche Merkmale waren, es ging ihm nicht darum, eine umfassende Faschismustheorie zu entwickeln. Er sah im Nationalsozialismus eine "gesellschafts-politische Bewegung", die, im nachhinein betrachtet, vergeblich versucht habe, „den Klassenkampf als einen destruktiven Faktor zu unterdrükken" und statt dessen die innerhalb der Gesellschaft notwendigen wirtschaftlichen Auseinandersetzungen nach außen, in den „Lebensraum im Osten“, zu verlagern. Dadurch

${ }_{454}$ IfZ, F213/4: Theile: Vorwort zur Reprint-Ausgabe der Deutschen Blätter (DB). Die Zeitschrift war finanziell unabhängig, sie wurde von privaten Geldgebern, vor allem auch von Rusker selber, finanziert. Vgl. die Dissertation von Vander Heide und Walter, Exilpresse, S. 306-373.

455 Walter, Exilpresse, S. 319.

456 Klepper, 15. 8. 1946, der Brief wurde auch an potentielle Spender verschickt. Klepper an Thomas Mann, 22. 8. 1946, zitiert bei Vander Heide, S. $38 \mathrm{ff}$.

457 BAK, NL-Lübke, Nr. 42, Bl. 238, Rusker an Lübke, 8. 1. 1958. Vgl. zwei große Mappen mit der Korrespondenz mit beiden nach dem Kriege. Rusker, der in Chile geblieben war, schrieb etwa dreimal im Monat an Klepper und nahm detailliert Stellung zu allen tagespolitischen Problemen (KNL).

${ }^{458}$ Klepper, Vorfragen und Die Kunst, in: letzte Ausgabe der DB, Nov./Dez. 1946. 
sollten „die Besitzenden von der Furcht vor sozialem Umsturz" und die Besitzlosen von der Angst vor dem endgültigen sozialen Abstieg befreit werden. Das Ganze sei unter dem ideologischen Dach der Volksgemeinschaft mit allen dazugehörigen Erscheinungsformen propagiert worden ${ }^{459}$. Dieses Experiment des Nationalsozialismus sei ebenso gescheitert wie der Versuch des Kommunismus, nur eine Klasse als Sieger aus der gesellschaftlichen Auseinandersetzung hervorgehen zu lassen. Daraus sei nach Klepper nur eine Konsequenz zu ziehen, nämlich endlich den Ausgleich zwischen den unterschiedlichen Interessen innerhalb der Gesellschaft zu erreichen und damit die alte Forderung nach Freiheit zu verwirklichen. Dies war für Klepper vornehmlich eine Aufgabe der Gesellschafts- und nicht der Staatspolitik, die von einer angemessenen Wirtschaftspolitik begleitet werden müsse ${ }^{460}$.

Deshalb hielt Klepper, obwohl er „mit einer langfristigen Okkupation unseres Landes" rechnete, den „Übergang der Initiative im Bereich der Sozialökonomie in deutsche Hände" für eine „Conditio sine qua non". Denn die Wirtschaftspolitik müsse sich durch Abbau von Subventionen und Zöllen, durch „ein freies Spiel der Kräfte“ auszeichnen, und jedes Land müsse die Kräfte einbringen, die ihm besonders entsprächen, so daß, international gesehen, ein freier Markt entstehen könne. In diesem Sinne müßten die Deutschen ihre Kräfte von Anfang an selbst entfalten und aus dem Zusammenwirken privatwirtschaftlicher und staatlicher Initiative Triebkräfte für den Wiederaufbau der Nachkriegswirtschaft entwickeln. Auch hielt Klepper die Kraft der deutschen Arbeiterbewegung für stark genug, um „den allgemeinen Fortschritt für die Arbeiterklasse nutzbar zu machen“, und die deutsche Sozialgesetzgebung für so „entwicklungsfähig“, daß ein gerechter Ausgleich innerhalb der Gesellschaft möglich sein werde. Zu einer gesunden Entwicklung des öffentlichen Lebens in Deutschland gehöre außerdem „die Wiederherstellung der sogenannten Grundrechte der Persönlichkeit" und eine offene Auseinandersetzung über die Ursachen und Folgen des Nationalsozialismus. Diese Auseinandersetzung solle den Deutschen nicht durch ein von den Siegermächten initiiertes ,reeducation-program‘ abgenommen werden, ganz abgesehen davon, daß „kein Volk, das im Kampf unterlegen ist, willens [sez], sich von den Siegern umerziehen zu lassen " ${ }^{461}$.

Für Klepper ging es nun um einen letzten „Ausscheidungskampf“, um die Lösung der Frage, in welchem System, dem östlichen oder dem westlichen, sich die "gesellschaftliche Umgestaltung “ mit dem Ziel der Verwirklichung von soviel Freiheit wie möglich vollziehen werde. In Rußland denke man zwar "gesellschaftspolitisch ungleich geschulter $[\ldots]$ als in der bürgerlichen Welt", aber "doktrinärer Starrsinn $[\ldots]$ und nicht zuletzt der Selbsterhaltungstrieb der politischen und militärischen Maschinerien" führe dennoch nur zur Herrschaft einer Klasse und damit zu Unterdrückung der Freiheit. Demgegenüber stehe die „engstirnige Beschränktheit des Interessentums im Lager des überkommenen Gesellschaftssystems", das durch Protektionismus und reaktionäre Politik die Freiheit der neu entstehenden Arbeiterklasse zu unterdrücken versucht habe. Es gehe also um „die Frage, ob die abendländische bürgerliche Gesellschaft [...] [soweit] regenerationsfähig" sei, daß sie die Freiheit innerhalb ihrer Gesellschaft realisiere, also den

${ }^{459}$ Klepper, Vorfragen, S. $3 \mathrm{f}$.

${ }^{460}$ Klepper, Die Kunst, S. 14.

${ }^{461}$ Ebenda, S. 17 f. Klepper hielt keineswegs nur die privatwirtschaftliche Initiative für die alleinige Triebkraft einer aufstrebenden Volkswirtschaft (S. 16 f.). Wie recht er mit der letzteren Einschätzung hatte, beweisen heutige historische Analysen, vgl. stellvertretend: Kleßmann, S. $92 \mathrm{ff}$. 
Zugang sowohl zu den „immateriellen“ wie den „materiellen“ Lebensgütern für jeden möglich mache und sich damit langfristig allen totalitären Systemen als überlegen erweise $^{462}$. Da Klepper das kommunistische System, so wie es in der Sowjetunion realisiert worden war, für totalitär hielt, war er gegen jede Kooperation mit diesem. Er setzte sich für die Einführung der Demokratie auf der Basis einer sozialen Marktwirtschaft ein. Die Voraussetzungen seien durch den verlorenen Krieg bereits weitgehend geschaffen worden, denn die in der Weimarer Zeit geforderte Agrar- und Industriestruktur-Reform habe sich durch die Maßnahmen der Siegermächte weitgehend von selbst erledigt und der größte Teil des Großgrundbesitzes liege ohnehin in der Sowjetischen Besatzungszone $^{463}$.

Es ist also falsch, wenn Walter schreibt, Klepper habe, im Gegensatz zu Rusker, eine Agrarreform abgelehnt ${ }^{464}$. Beide waren sich, wie aus der langjährigen Korrespondenz hervorgeht, einig in Bezug auf die gesellschafts- und wirtschaftspolitische Konzeption für ein neues Deutschland nach dem Kriege, das gilt auch für das allgemeine Wirtschaftsprogramm, das Walter fälschlich als „neoliberalistisch“ bezeichnet, weil er den Zusammenhang, in dem Gesellschafts- und Wirtschaftspolitik für Klepper standen, nicht erkennt. In Kenntnis des Klepperschen Konzepts und dessen, was er nach dem Kriege geschrieben hat, ist das folgende Urteil Walters unqualifiziert: „Man braucht die weiteren Ausführungen über das, was für Deutschland von Schaden [...] bzw. von Nutzen sein würde [...] gar nicht mehr zu untersuchen, denn bereits jetzt ist eindeutig, daß Klepper an jene Restauration gedacht hat, die in der Bundesrepublik dann tatsächlich vollzogen worden ist." Auf dieser Fehlinterpretation Klepperscher Konzepte aufbauend, fragt Walter sich, ob die Deutschen Blätter vor einer „Änderung ihres Kurses “ gestanden hätten, da doch Kleppers Artikel „eine radikale Abkehr von den bisher vertretenen Auffassungen“ der $D B$ markierten, oder ob die Zeitschrift ,ihr Erscheinen zu einer Zeit [ babe] einstellen müssen, als ihre Politik unter ihren Mitarbeitern nicht mehr unumstritten gewesen sei“? Diese Fragen seien, so fügt er selbst hinzu, „, bei dem heutigen Informationsstand nicht zu klären“; geschrieben 1978, als alle Veröffentlichungen Kleppers in der Frankfurter Allgemeinen Zeitung und den Schriften der Wipog zugänglich waren. Die Zeitschrift mußte ihr Erscheinen einstellen, weil die finanziellen Mittel erschöpft waren $^{465}$.

Die so viele Emigranten quälende Frage, ob sie zurückkehren sollten in ein Land, das sie möglicherweise nicht zur Rückkehr auffordern würde ${ }^{466}$ und in dem sie abermals als unerwünscht erscheinen könnten, war auch für Klepper vorrangig; doch nicht nur für ihn, wie das folgende Zitat von Kurt Pinthus zeigt: „Keine Regierung der Bundesrepublik und, soviel ich weiß, keine Regierung eines Bundesstaates hat bis zur Stunde, da dies geschrieben wird [1963], das getan, was die Vertriebenen, Geflüchteten, Beschimpften und Mißhandelten als das Mindeste hätten erwarten können: mit klaren, offenen, ehrlichen Worten zur Rückkehr ins Vaterland aufzurufen, einzuladen, zu bitten. Auch an mich als Individuum, als Wissenschaftler und Schriftsteller, hat keine deutsche Regie-

${ }^{462}$ Klepper, Vorfragen, S. $11 \mathrm{ff}$.

${ }^{463}$ Klepper, Die Kunst, S. 15. Klepper an Weichmann, 3. 5. 1945 (StAH, 622-1, 74, Bd. 1).

464 Walter, Exilpresse, S. 368.

${ }^{465}$ Theile, Vorwort.

466 Pinthus, S. $137 \mathrm{f}$. 
rung, keine Institution, kein Kulturbeamter und keine Akademie eine solche Aufforderung ergehen lassen. “ Klepper hat dieses Problem mehrfach mit Weichmann diskutiert. Im Februar 1944 schrieb er, es würde „weder eine leichte, noch eine frohe Heimkehr sein, eine andere, als ich früher dachte ${ }^{“ 467}$. Da Weichmann ihn offensichtlich ermutigt hatte, „er habe drüben noch eine Aufgabe“, schreibt er ihm zurück, er "glaube das auch; denn so sonderbare Schicksale haben ja wohl einen positiven Sinn", aber zunächst müsse man erst einmal sehen, „nach drüben zu gelangen und sich wieder mit der Atmosphäre vertraut zu machen", außerdem ziehe er es wohl doch vor, Anwalt zu werden, statt in die Politik zu gehen ${ }^{468}$. Er scheint stark geschwankt zu haben ${ }^{469}$. Heinrich Lübke schien ihm von einer Heimkehr eher abzuraten, ,weil die allgemeinen Lenbensverhältnisse - nichts zu essen, nichts zu trinken, nichts zu rauchen und keine Wohnungen - zu trübselig“ seien. Dagegen setzte Klepper, „wenn überhaupt, dann muß man jetzt gehen, bevor der Wagen aus dem Dreck gezogen ist“ ${ }^{470}$, obgleich er sehr wohl wisse, daß „Leute von prononcierter Konzeption und Eigenwilligkeit [...] nicht sehr willkommen sein“ wür$\operatorname{den}^{471}$.

Ein halbes Jahr später, nachdem er sich durchgerungen hatte zu fahren, schrieb er an Weichmann: „Die Rückkehr ist nicht weniger riskant als der Ausmarsch in das Exil. Für mich gibt es aber keine andere Alternative, und so werfe ich mein Gepäck wieder einmal hinter mich. “ ${ }^{472}$ „Keine Alternative“ bedeutete nicht, daß er nicht hätte in Mexiko bleiben können, aber dann hätte er „das Bewußtsein gehabt, der Logik [s]eines Lebens untreu geworden zu sein" "473. Es galt also, was auch für seinen Entschluß, in die Emigration zu gehen, gegolten hatte, es war „eine politische Entscheidung für die Sache der Freiheit", obwohl, wie er sehr wohl wußte, keiner ihn gerufen und „kein Huhn und kein Hahn [...] danach gekräht" hatte, welche Ideen er in seinen beiden Aufsätzen, von denen er etliche nach Deutschland verschickte, entwickelt hatte. Klepper versuchte, sich das Desinteresse an seinen Aufsätzen damit zu erklären, „daß die so ereignisreiche Zwischenzeit uns von denen, die in Deutschland geblieben sind, wenn nicht gefühls-, so doch vorstellungsmäßig getrennt hat". Anfang 1950 schrieb Klepper - bereits aus Deutschland - an Engelmann in New York, „das gesamte Niveau der Mentalität in den hiesigen ,maßgebenden' Kreisen ist noch viel niedriger, als es früher war. Man wünscht keine Konkurrenz, und sie vor allem nicht von den Leuten, die durch die Unbefangenheit und Erfahrung der Emigration bevorzugt sind. " ${ }^{474}$

Viele Emigranten mögen so empfunden haben, es gab Mißtrauen auf beiden Seiten. Es war gewiß sehr schwierig, sich jeweils in die Lage des anderen hineinzuversetzen. Die Zuhausegebliebenen hatten auch kein leichtes Leben gehabt, sie waren unter Umständen Repressionen ausgesetzt gewesen, hatten Kompromisse gemacht, für die sie sich nun

\footnotetext{
${ }^{467}$ StAH, 622-1, 74, Bd. 1, Klepper an Weichmann, 8. 2. 1944.

${ }^{468}$ Ebenda, Klepper an Weichmann, 6. 5. 1945.

$469 \mathrm{Vgl}$. Engelmann, S. $43 \mathrm{ff}$.

470 Klepper erwähnt den Brief von Lübke in seinem Brief an Mary Beth, 12.6. 1946.

${ }^{471} \mathrm{StAH}, 622-1$, 74, Bd. 1, Klepper an Weichmann, 3. 5. 1945.

472 Ebenda, Klepper an Weichmann, 12. 12. 1946. Letzter Brief an W. aus Mexiko.

${ }^{473}$ Ebenda, Klepper an Weichmann, 14. 3. 1948, Frankfurt/M.

${ }^{474}$ Klepper an Engelmann, 20. 2. 1950. Sein pessimistisches Urteil scheint sich wohl vorwiegend auf Deutschland bezogen zu haben, denn aus der Schweiz schrieb er am 12. 5. 1947: „Meine Artikel sind viel gelesen. In einer französischen Zeitschrift [...] sind sie ausführlich besprochen und große Passagen nachgedruckt" worden.
} 
insgeheim schämten, hatten den Krieg mitmachen oder zumindest erfahren müssen und waren zwölf Jahre eingeschlossen gewesen. Die Emigranten waren zwar ständig neuen Gefahrensituationen ausgesetzt gewesen, hatten alles verloren, aber sie konnten sich frei von Schuld fühlen, sie hatten eine klare Position, und sie hatten dazulernen, viele neue Erfahrungen sammeln und den ,Platz in der Welt' gewinnen können, der ihnen nun den neuen Blick ermöglichte. Der Dialog zwischen beiden Gruppen hätte ungeheuer fruchtbar auf die Gestaltung der Anfangsjahre im Nachkriegsdeutschland wirken können; daß das nur sehr partiell gelungen ist, zeigen unter anderem die im nächsten Kapitel dargestellten Schwierigkeiten, denen Klepper begegnete.

Mag Klepper im Frühjahr 1947 auch pessimistisch aus Mexiko abgereist sein, seine Reise muß ihn beflügelt haben. Zunächst besuchte er seine Familie in New Orleans, wo sein inzwischen verheirateter Sohn mit Tochter lebte. Welch ein Wiedersehen nach über zehn Jahren der Trennung! Es hat ihn, der Familienglück neben dem Beruf als höchstes schätzte ${ }^{475}$, unbeschreiblich erfreut ${ }^{476}$. Engelmann schreibt, man müsse „Kleppers Scheu, seine Gefühle Fernerstehenden gegenüber zu äußern, und seine Abneigung gegen große Worte" bedenken, wolle man die folgende Briefstelle in ihrem ganzen Ausmaß verstehen: „Das Zusammensein mit meiner Frau, den Kindern und der Enkeltochter war nicht nur wunderbar schön, sondern auch eine große notwendige Erleichterung. Ich bin unendlich dankbar dafür. [...] Wir haben allem zum Trotz viel mehr Substanz gerettet, als ich zu hoffen wagte. [...] Was die Zukunft anlangt, so ist während dieser vierzehn Jahre so viel gefügt und geholfen worden, daß ich so unverzagt bin wie seit vielen, vielen Jahren nicht mehr. “477 Aus dieser Briefstelle spricht gewiß ein großes Glück, aber sie zeigt auch versteckt, unter welchem Gewissensdruck Klepper wohl zu Recht die ganzen Jahre über gestanden hat, da er seine Familie im Grunde sich selbst überlassen hatte. Gewiß hatte die Verfolgung Kleppers durch die Nationalsozialisten sie immer wieder voneinander getrennt, und jegliche finanziellen Möglichkeiten hatten gefehlt, um eine Zusammenführung zu erleichtern. In Paris hätte Klepper seine Familie nicht ernähren können, für die Vereinigten Staaten hatte er kein Einreisevisum erhalten. Die Kinder, die amerikanische Colleges besuchten, übrigens unter schwierigsten finanziellen Bedingungen, konnten nicht nach Mexiko auswandern. Es war eine äußerst konfliktreiche Situation, die alle sehr belastet hat. Hinzu kam, daß die Eheleute sich natürlicherweise in all den Jahren auseinandergelebt hatten und beide gewiß Angst vor dem Wiedersehen gehabt haben. So ist die große Erleichterung zu verstehen und die vielleicht etwas zu euphorische Hoffnung auf eine bessere Zukunft.

Seine anschließende Schiffsreise auf der "Thompson Lykes" nach Le Havre scheint ihn ebenfalls belebt und erfreut zu haben. Ganz der Gegenwart hingegeben, beschreibt er in seinen Briefen das Leben auf dem Schiff, die Arbeitsbedingungen der Schiffsmannschaft und seinen eigenen Tagesablauf. Auf dem Meere zwischen zwei Kontinenten und ,zwischen den Zeiten' hatte er Muße nachzudenken. Dabei haben ihn auch drei Bücher besonders angeregt, von denen er ausführlich in seinen Briefen berichtet. Sie umreißen das Feld, in dem seine Gedanken sich bewegten. Da war einmal eine Broschüre über „Natur und Geist“ von Büchenbacher, der „Grundzüge einer neuen christlichen Philo-

\footnotetext{
${ }^{475}$ Klepper an seinen Sohn, 25. 7. 1946.

${ }^{476}$ Vgl. Klepper Dankesbrief an den Sohn und seine Frau, 10.3. 1947 vom Schiff.

477 Engelmann, S. 48. Außer seiner Tochter Ingrid waren alle versammelt.
} 
sophie" entwickelt habe, die helfen solle, eine "Synthese" zwischen dem einseitigen idealistischen Denken des 19. und dem materialistischen, nur das Sichtbare und Greifbare beachtenden Denken des 20. Jahrhunderts zu finden. Klepper sah da eine Parallele zu seinen eigenen Gedanken, die er selbst am Schluß seines Artikels „Vorfragen des Friedens“ angedeutet hatte. Dort hatte er geschrieben: „Sollen die ausgefahrenen Gleise, auf denen unser politisches Denken planlos rangiert, ohne das Signal zur Abfahrt wahrzunehmen, tatsächlich abgebrochen und zum alten Eisen geworfen werden, und soll sodann der große Wurf gelingen, so bedarf es des Antriebes aus einer dem Raisonnement übergeordneten Sphäre“, wobei er an „eine Heiligung des Geistes zur Verwirklichung der menschlichen Solidarität", aus der dann die Freiheit erwachse, dachte ${ }^{478}$. Das zweite Buch war „Die Kultur der Renaissance“ von Jacob Burckhardt, ein für ihn ausgesprochen lehrreiches Buch ${ }^{49}$, und als drittes erwähnte er Pearl S. Bucks „Pavillon of Women“, ein Roman, der „eine wunderbare Konzeption dessen entwickelt, was Liebe ist“, was ihn "tief berührt" habe ${ }^{480}$. Auf dieser Schiffsreise, die wegen heftiger Stürme noch länger dauerte als geplant ${ }^{481}$, hatte er noch einmal die Gelegenheit, sich zu sammeln, Gewesenes und Kommendes zu überdenken; den Briefen nach zu urteilen, war er guten Mutes, auch die Stürme machten ihm nichts, weil er, wie er seiner Schwiegertochter schrieb, „die Wildheit des Meeres von einer realistischen Schönheit“ finde und außerdem "Seebeine" habe, die ihn auch auf schaukelnden Schiffen tragen.

In Paris wurde er von seinen alten Freunden am Bahnhof abgeholt, darunter auch von Degons ${ }^{482}$, die von ihrem Wiedersehen mit Klepper berichtet haben. Es muß bewegend gewesen sein. Ein Höhepunkt des Pariser Aufenthalts war für Klepper ein Dîner im Quai d'Orsay, das der damalige französische Außenminister Robert Schuman, dessen Kabinettschef Alain Poher zu jener Zeit war, zu Ehren Kleppers gegeben hat ${ }^{483}$. Ein guter Auftakt! Klepper schreibt in die USA: „Ich habe das Gefühl, daß die eigentliche Probe meines Lebens nunmehr vor mir liegt, und ich will alles daransetzen, sie zu bestehen." 484

Es war gar nicht so einfach, nach Deutschland zurückzukehren. Von Frankreich aus über die Grenze zu gehen, riet man ihm ab, weil die amerikanische oder englische Besatzungsmacht argwöhnen könnte, er „habe den Franzosen gegenüber Verpflichtungen übernommen“485. So reiste er in der ersten Aprilwoche 1947 in die Schweiz, nach Zürich, von wo er seine Einreise nach Deutschland beantragte. Die britische Zone sei angeblich ganz gesperrt, in die russische wollte er nicht, obwohl dort sein Geburtsort lag, und in die amerikanische Zone konnte er nur, wenn er von einer amtlichen deutschen Stelle angefordert wurde. Notgedrungen verbrachte Klepper noch fast zwei Monate in der Schweiz. „Krankheit, Schwierigkeiten, die die Besatzungsbehörden zuerst machten, offenbar auch Mißverständnisse aller Art hatten ihm diese neue Nervenprobe auferlegt.“ Der Aufbruchselan von Paris war angesichts der sich türmenden Schwierigkeiten etwas

\footnotetext{
${ }^{478}$ Klepper, Vorfragen, S. 16.

479 Klepper an die Familie, 10. 3. 1947.

480 Klepper an den Sohn, 16. 3. 1947.

${ }^{481}$ Klepper an Mary-Beth aus Paris, 31. 3. 1947.

482 Ebenda.

${ }^{483}$ Bestätigt durch Alain Poher und Degon, der ebenfalls anwesend war.

${ }^{484}$ Klepper an Mary-Beth aus Paris, 31. 3. 1947.

485 Ebenda.
} 
abgeflaut und „der Glaube an das Gelingen der Rückkehr stark erschüttert", aber Klepper verstand auch aus dieser Wartesituation etwas zu machen, er las Bücher aus der Leihbibliothek, informierte sich über die Situation in Deutschland, traf Menschen und lernte unter anderen den Schriftsteller Werner Bergengruen kennen, mit dem er sich sehr gut verstand, oder er saß allein mit Pfeife beim Apfelwein in einer kleinen Kneipe ${ }^{486}$. Schließlich gelang es Lübke, der inzwischen Landwirtschaftsminister in NordrheinWestfalen geworden war, Klepper für Wiederaufbauarbeiten auf dem Genossenschaftsund Agrarsektor anzufordern. Ende Mai 1947 traf er in Frankfurt/Main ein und wurde von seinen Freunden herzlich empfangen. Damit begann das letzte Kapitel seines ereignisreichen Lebens. 